\title{
Direct Kinetic Formation of Nonanomeric [6.5]-Spiroketals in Aqueous Media
}

Daniele Castagnolo, Irene Breuer and Petri M. Pihko*

\section{Supporting Information}

Laboratory of Organic Chemistry, Helsinki University of Technology, P.O.B. 6100, FI-02015 TKK, Finland.E-mail: Petri.Pihko@tkk.fi

Table of Contents

General methods.

S2

Experimental Procedures and Characterization of New

Compounds. $\mathrm{S} 3-\mathrm{S} 24$

Copies of ${ }^{1} \mathrm{H}$ and ${ }^{13} \mathrm{C}$ NMR spectra. S25-S51

Additional Spiroketalization Experiments in the Presence of Inorganic Salts. S52 
General Methods. All reactions were carried out under argon atmosphere in flame-dried glassware, unless otherwise noted. Nonaqueous reagents were transferred under argon via syringe or cannula and dried prior to use. THF and $\mathrm{Et}_{2} \mathrm{O}$ were distilled from $\mathrm{Na}$ /benzophenone. $\mathrm{CH}_{2} \mathrm{Cl}_{2}$ and $\mathrm{BF}_{3} \cdot \mathrm{Et}_{2} \mathrm{O}$ were distilled from $\mathrm{CaH}_{2}$. Benzyl alcohol $(\mathrm{BnOH})$ and $p$-methoxybenzyl alcohol (PMBOH) were fractionally distilled. Other solvents and reagents were used as obtained from supplier, unless otherwise noted. Analytical TLC was performed using Merck silica gel F254 (230-400 mesh) plates and analyzed by staining upon heating with vanillin solution ( $6 \mathrm{~g}$ vanillin, $5 \mathrm{~mL}$ conc. $\mathrm{H}_{2} \mathrm{SO}_{4}, 3 \mathrm{~mL}$ glacial acetic acid, $250 \mathrm{~mL}$ EtOH), anisaldehyde solution $\left(2.8 \mathrm{~mL}, 2.0 \mathrm{~mL} \mathrm{H} \mathrm{SO}_{4}, 1.2 \mathrm{~mL} \mathrm{AcOH}\right.$, $100 \mathrm{~mL}$ EtOH) or Cerium PMA solution (2.5 g phosphomolybdic acid, $1.25 \mathrm{~g}$ cerium (IV)-sulfate, $12.5 \mathrm{~mL}$ conc. $\mathrm{H}_{2} \mathrm{SO}_{4}, 112.5 \mathrm{~mL} \mathrm{H} \mathrm{H}_{2} \mathrm{O}$ ). For silica gel chromatography, the flash chromatography technique was used, with Merck silica gel 60 (230-400 mesh) and p.a. grade solvents unless otherwise noted.

The ${ }^{1} \mathrm{H}$ NMR spectra were recorded in $\mathrm{CDCl}_{3}$ or acetonitrile- $\mathrm{d}_{3}$ on a $400-\mathrm{MHz}\left({ }^{1} \mathrm{H} 399.98 \mathrm{MHz}\right)$ spectrometer. The chemical shifts are reported in ppm relative to the residual $\mathrm{CHCl}_{3}\left(\delta_{\mathrm{H}}=7.26\right.$ ppm) or TMS $\left({ }^{1} \mathrm{H} N M R ; \delta_{\mathrm{H}}=0.00 \mathrm{ppm}\right)$. In ${ }^{13} \mathrm{C} \mathrm{NMR}$, the $\mathrm{CDCl}_{3}\left({ }^{13} \mathrm{C} \mathrm{NMR} \delta_{\mathrm{C}}=77.00 \mathrm{ppm}\right)$ or acetonitrilee- $\mathrm{d}_{3}\left({ }^{1} \mathrm{H} \mathrm{NMR} ; \delta_{\mathrm{H}}=1.94 \mathrm{ppm} ;{ }^{13} \mathrm{C}\right.$ NMR $\left.\delta_{\mathrm{C}}=118.26 \mathrm{ppm}\right)$ were used as reference signals. Signal assignments are based on standard APT, DEPT, HSQC, and ${ }^{1} \mathrm{H}-{ }^{1} \mathrm{H}$ COSY experiments. Abbreviations s, d, t, q, m are used to designate singulet, doublet, triplet, quartet, multiplet, respectively. 


\section{Lactone 2, synthesis with TEMPO oxidation}

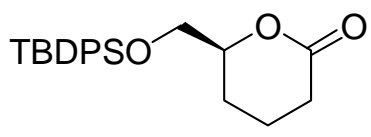

2

This oxidation protocol represents an improvement to the protocol reported by Forsyth and coworkers. ${ }^{1}$

The reaction flask was charged with (2S)-1-tert-Butyldiphenylsilyloxy-2,6-hexanediol ${ }^{1}(0.59 \mathrm{~g}, 1.58$ mmol), TEMPO (3 mg, $0.02 \mathrm{mmol}), \mathrm{KBr}(19 \mathrm{mg}, 0.16 \mathrm{mmol}), \mathrm{CH}_{2} \mathrm{Cl}_{2}(6 \mathrm{~mL})$ and $\mathrm{H}_{2} \mathrm{O}(0.21 \mathrm{~mL})$. The mixture was stirred and cooled to $0{ }^{\circ} \mathrm{C}$ with an ice bath. Within 5-10 min an aqueous $\mathrm{NaOCl}-$ solution $(2.35 \mathrm{~mL}, 3.81 \mathrm{mmol}, 1.65 \mathrm{M})$ at $\mathrm{pH} 9.6$ (buffered with $\mathrm{NaHCO}_{3}$ ) was added dropwise, maintaining the temperature at $0{ }^{\circ} \mathrm{C}$. After 15 min the organic phase was seperated and washed with a $10 \%$ aqueous $\mathrm{HCl}$-solution $(1 \mathrm{~mL})$ containing $\mathrm{KI}(13.2 \mathrm{mg})$, a $10 \%$ aqueous $\mathrm{Na}_{2} \mathrm{~S}_{2} \mathrm{O}_{3}$-solution and $\mathrm{H}_{2} \mathrm{O}(1 \mathrm{~mL})$. The organic layer was dried over $\mathrm{MgSO}_{4}$, filtered and concentrated. Silica gel column chromatography (1:1 Et $2 \mathrm{O} /$ hexanes $)$ yielded the desired lactone $2(0.57 \mathrm{~g}, 98 \%)$ as a tan oil.

$\mathrm{R}_{f}=0.11$ (1:4 EtOAc/hexanes, UV/ cerium PMA stain); ${ }^{1} \mathrm{H} \mathrm{NMR}\left(\mathrm{CDCl}_{3}, 400 \mathrm{MHz}\right) \delta .7 .68-7.65$ (m, 4 H), 7.46-7.37 (m, 6 H), 4.42-4.36 (m, 1 H), 3.77 (ddd, 2 H, J = 15.7, 10.7, 4.3 Hz), 2.63-2.55 (m, 1 H), 2.49-2.41 (m, 1 H), 2.01-1.93 (m, 2 H), 1.87-1.71 (m, 1 H), 1.06 (s, 9 H) ppm.

The other analytical data of this compound are consistent with those reported in the literature. ${ }^{1 \mathrm{a}}$

\section{Keto alcohol $3^{2}$}

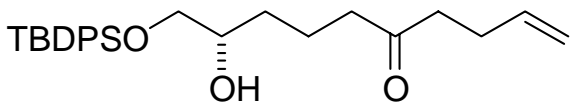

3

To a stirred solution of $\mathrm{Mg}$ powder (48 mg, $2.0 \mathrm{mmol}$ ) in THF (4 mL) was added 4-bromo-1-butene $(0.20 \mathrm{~mL}, 0.27 \mathrm{~g}, 2.0 \mathrm{mmol})$. Heat was evolved and the formation of the Grignard reagent was evident from the darkening of the reaction mixture. After $1 \mathrm{~h}, 3 \mathrm{~mL}$ of the solution of the Grignard reagent prepared above was added dropwise to a $-78{ }^{\circ} \mathrm{C}$ solution of the lactone $2(0.27 \mathrm{~g}, 0.73$ $\mathrm{mmol})$ in THF $(4 \mathrm{~mL})$. The resulting solution was stirred at $-78{ }^{\circ} \mathrm{C}$ for additional $1 \mathrm{~h}$ and $15 \mathrm{~min}$. Then, saturated aqueous $\mathrm{NH}_{4} \mathrm{Cl}(2.0 \mathrm{~mL})$ and $\mathrm{H}_{2} \mathrm{O}(2.0 \mathrm{~mL})$ were added. The mixture was warmed 
to $\mathrm{rt}$ and then extracted with $\mathrm{Et}_{2} \mathrm{O}(3 \mathrm{x} 50 \mathrm{~mL})$. The combined organic phases were dried over $\mathrm{MgSO}_{4}$, filtered and concentrated. The crude product was purified by flash column chromatography $\left(\mathrm{SiO}_{2}\right)$ using EtOAc:hexanes, $1: 2$ as the eluent to yield ketoalcohol $3(0.16 \mathrm{~g}, 51 \%)$ as a pale yellow oil in addition to non converted starting material ( $0.13 \mathrm{~g}, 49 \%)$.

$\mathrm{R}_{f}=0.39$ (1:2 EtOAc/hexanes, compound strongly UV active/ cerium PMA stain), $[\alpha]^{23}{ }_{\mathrm{D}}=-0.2(c=$ 6.25, $\mathrm{CH}_{2} \mathrm{Cl}_{2}$ ); IR (thin film, $\mathrm{cm}^{-1}$ ) 3468, 3072, 2930, 2857, 1713, 1641, 1472, 1428, 1113, 998, 741, $702 \mathrm{~cm}^{-1} ;{ }^{1} \mathrm{H}$ NMR $\left(\mathrm{CDCl}_{3}, 400 \mathrm{MHz}\right) \delta$ 7.68-7.66 (m, $\left.4 \mathrm{H}\right), 7.46-7.41$ (m, $\left.6 \mathrm{H}\right), 5.81$ (ddt, 1 $\mathrm{H}, J=17.1,10.2,6.5 \mathrm{~Hz}), 5.01(\mathrm{dq}, 1 \mathrm{H}, J=17.1,1.7 \mathrm{~Hz}), 4.96(\mathrm{dq}, 1 \mathrm{H}, J=10.2,1.4 \mathrm{~Hz}), 3.73-$ $3.72(\mathrm{~m}, 1 \mathrm{H}), 3.64(\mathrm{dd}, 1 \mathrm{H}, J=10.0,5.2 \mathrm{~Hz}), 3.50(\mathrm{dd}, 1 \mathrm{H}, J=10.0,7.5 \mathrm{~Hz}), 2.52(\mathrm{~d}, 1 \mathrm{H}, J=3.6$ Hz), 2.48 (t, $2 \mathrm{H}, J=7.4 \mathrm{~Hz}), 2.41(\mathrm{t}, 2 \mathrm{H}, J=7.3 \mathrm{~Hz}), 2.34-2.32(\mathrm{~m}, 2 \mathrm{H}), 1.74-1.62(\mathrm{~m}, 2 \mathrm{H})$, 1.43-1.37 (m, $2 \mathrm{H}), 1.06$ (s, $9 \mathrm{H}) \mathrm{ppm} ;{ }^{13} \mathrm{C} \mathrm{NMR}\left(\mathrm{CDCl}_{3}, 100 \mathrm{MHz}\right) \delta .210 .1,137.5,135.9,133.5$, 130.4, 128.1, 115.6, 72.0, 68.3, 43.0, 42.1, 32.5, 28.1, 27.2, 20.1, 19.6 ppm; HRMS (ESI) calcd. for $\mathrm{C}_{26} \mathrm{H}_{36} \mathrm{O}_{3} \mathrm{NaSi}$ 447.2331, found 447.2321, $\Delta 2.2 \mathrm{ppm}$.

\section{Ketal 4}

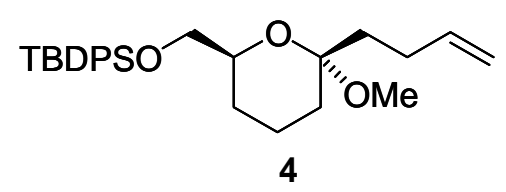

To a stirred solution of ketoalcohol $3(0.13 \mathrm{~g}, 0.30 \mathrm{mmol})$ in methanol $(3.5 \mathrm{~mL})$ at $\mathrm{rt}$ was added pyridinium $p$-toluenesulfonate $(0.02 \mathrm{~g}, 0.061 \mathrm{mmol})$. The resulting solution was stirred for $3 \mathrm{~h}$ and then saturated aqueous $\mathrm{NaHCO}_{3}(1.5 \mathrm{~mL})$ and $\mathrm{H}_{2} \mathrm{O}(4.5 \mathrm{~mL})$ were added. The separated aqueous phase was further extracted with EtOAc $(3 \times 50 \mathrm{~mL})$ and the combined organic phases were dried over $\mathrm{MgSO}_{4}$, filtered and concentrated. The crude product was purified by flash column chromatography $\left(\mathrm{SiO}_{2}\right)$ using 1:3 EtOAc/hexane, as the eluent to yield the ketal $4(0.13 \mathrm{~g}, 100 \%)$ as a tan oil.

$\mathrm{R}_{f}=0.68\left(1: 1 \mathrm{Et}_{2} \mathrm{O} /\right.$ hexanes, $\mathrm{UV} /$ anisaldehyde stain), $[\alpha]^{23}{ }_{\mathrm{D}}=+20.7\left(c=6.25, \mathrm{CH}_{2} \mathrm{Cl}_{2}\right)$; IR (thin film, $\left.\mathrm{cm}^{-1}\right)$ 3072, 2933, 2858, 2828, 1473, 1428, 1115, 1081, 1034, 911, 824, 702; ${ }^{1} \mathrm{H} \mathrm{NMR}\left(\mathrm{CDCl}_{3}\right.$, $400 \mathrm{MHz}) \delta$ 7.78-7.73 (m, $4 \mathrm{H}), 7.47-7.39$ (m, $6 \mathrm{H}), 5.87$ (ddt, $1 \mathrm{H}, J=13.3,10.1,6.5 \mathrm{~Hz}), 5.07$ $(\mathrm{dq}, 1 \mathrm{H}, J=17.0,1.7 \mathrm{~Hz}), 5.03(\mathrm{dq}, 1 \mathrm{H}, J=10.2,1.4 \mathrm{~Hz}), 3.74-3.69$ (m, $2 \mathrm{H}), 3.62(\mathrm{dd}, 1 \mathrm{H}, J=$ 10.1, 4.6 Hz), $3.21(\mathrm{~s}, 3 \mathrm{H}), 2.13-2.08(\mathrm{~m}, 2 \mathrm{H}), 1.87-1.78(\mathrm{~m}, 3 \mathrm{H}), 1.67-1.62(\mathrm{~m}, 3 \mathrm{H}), 1.48$ (dt, 1

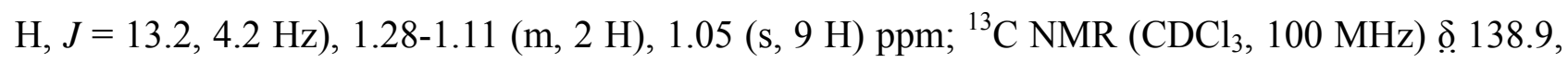
$136.1,135.9,134.2,129.9,128.2,127.9,114.6,99.6,71.5,67.9,47.6,35.8,32.9,28.1,27.6,27.2$, 
19.6, 19.0 ppm; HRMS (ESI) calcd. for $\mathrm{C}_{26} \mathrm{H}_{36} \mathrm{O}_{3} \mathrm{NaSi}[\mathrm{M}-\mathrm{OMe}]^{+}$407.2406, found 407.2428, $\Delta 5.4$ ppm. $^{2}$

\section{Ketal 5}

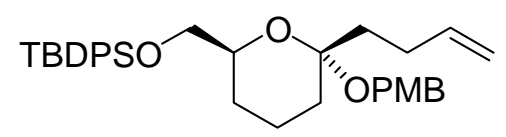

5

To a stirred solution of ketoalcohol $3(0.10 \mathrm{~g}, 0.24 \mathrm{mmol})$ in $\mathrm{CH}_{2} \mathrm{Cl}_{2}(8.0 \mathrm{~mL})$ at $\mathrm{rt}$ was added $p$ methoxybenzyl alcohol $(0.21 \mathrm{~mL}, 0.23 \mathrm{~g}, 1.72 \mathrm{mmol})$ and pyridinium $p$-toluenesulfonate $(0.01 \mathrm{~g}$, $0.049 \mathrm{mmol})$. The resulting solution was stirred for $3 \mathrm{~h}$ and then saturated aqueous $\mathrm{NaHCO}_{3}(1.0$ $\mathrm{mL})$ and $\mathrm{H}_{2} \mathrm{O}(3.0 \mathrm{~mL})$ were added. The separated aqueous phase was further extracted with EtOAc $(3 \times 50 \mathrm{~mL})$ and the combined organic phases were dried over $\mathrm{MgSO}_{4}$, filtered and concentrated. The crude product was purified by flash column chromatography $\left(\mathrm{SiO}_{2}\right)$ using 1:2 EtOAc/hexanes, as the eluent to yield the ketal $5(0.08 \mathrm{~g}, 62 \%)$ as a tan oil.

$\mathrm{R}_{f}=0.68\left(1: 2 \mathrm{Et}_{2} \mathrm{O} /\right.$ hexanes, $\mathrm{UV} /$ vanillin stain), $[\alpha]^{20}{ }_{\mathrm{D}}=+0.8\left(c=0.77, \mathrm{CH}_{2} \mathrm{Cl}_{2}\right)$; IR (thin film, $\mathrm{cm}^{-}$ 1) $3071,2932,2857,1613,1514,1463,1428,1248,1113,1078,1037,1019,1009,823,807,740$, 702; ${ }^{1} \mathrm{H} \mathrm{NMR}\left(\mathrm{CDCl}_{3}, 400 \mathrm{MHz}\right) \delta$ 7.77-7.72 (m, $\left.4 \mathrm{H}\right), 7.45-7.26(\mathrm{~m}, 8 \mathrm{H}), 6.93-6.85(\mathrm{~m}, 2 \mathrm{H})$, 5.86 (ddt, $1 \mathrm{H}, J=17.1,10.2,6.4 \mathrm{~Hz}), 5.09$ (dq, $1 \mathrm{H}, J=17.1,1.8 \mathrm{~Hz}), 5.03$ (m, $1 \mathrm{H}), 4.55$ (d, $1 \mathrm{H}$, $J=11.2 \mathrm{~Hz}), 4.35$ (d, $1 \mathrm{H}, J=11.2 \mathrm{~Hz}), 3.91-3.82(\mathrm{~m}, 1 \mathrm{H}), 3.84$ (s, $3 \mathrm{H}), 3.71(\mathrm{dd}, 1 \mathrm{H}, J=10.3$, $6.2 \mathrm{~Hz}), 3.63$ (dd, $1 \mathrm{H}, J=10.3,4.5 \mathrm{~Hz}), 2.17-2.14$ (m, $2 \mathrm{H}), 1.97-1.84$ (m, 3H), 1.72-1.60 (m, 3H), 1.44-1.25 (m, 2H), 1.07 (s, $9 \mathrm{H}) \mathrm{ppm} ;{ }^{13} \mathrm{C} \mathrm{NMR}\left(\mathrm{CDCl}_{3}, 100 \mathrm{MHz}\right) \delta .159 .2,139.1,136.1,134.2$, $131.7,130.1$, 129.9, 129.6, 127.9, 114.6, 114.1, 100.0, 71.9, 67.9, 61.5, 55.7, 36.7, 33.0, 28.3, 27.5, 27.2, 19.6, 19.1 ppm. HRMS (ESI) calcd. for $\mathrm{C}_{34} \mathrm{H}_{44} \mathrm{O}_{4} \mathrm{NaSi} 567.2907$, found 567.2883, $\Delta 4.2 \mathrm{ppm}$.

\section{Diol S1 via AD}

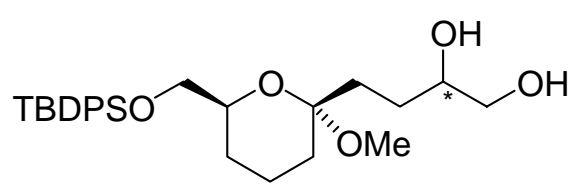

S1

(DHQ) 2 PYR (7.0 mg, $0.007 \mathrm{mmol}), \mathrm{K}_{3} \mathrm{Fe}(\mathrm{CN})_{6}(416 \mathrm{mg}, 1.26 \mathrm{mmol}), \mathrm{K}_{2} \mathrm{CO}_{3}(174 \mathrm{mg}, 1.26$ mmol), $\mathrm{CH}_{3} \mathrm{SO}_{2} \mathrm{NH}_{2}(40 \mathrm{mg}, 0.42 \mathrm{mmol})$ and $\mathrm{OsO}_{4}$ as a $2.5 \%$ solution in $t$-butanol $(4 \mu \mathrm{L}, 0.004$ 
mmol) were dissolved in 1:1 tert-butyl alcohol/water $(7 \mathrm{~mL}$ each). The mixture was stirred for 20 min, then it was cooled to $0{ }^{\circ} \mathrm{C}$ using cryo equipment. A solution of the ketal $4(0.18 \mathrm{~g}, 0.42 \mathrm{mmol})$ in tert-butyl alcohol $(4 \mathrm{~mL})$ was added via cannula. Stirring was continued at $0{ }^{\circ} \mathrm{C}$ for $30 \mathrm{~h}$, then the cooling bath was removed, the solution was allowed to warm to $\mathrm{rt}$ and stirred for another $34 \mathrm{~h}$ before $\mathrm{Na}_{2} \mathrm{SO}_{3}$ was added. The resulting mixture was stirred vigorously for addional $30 \mathrm{~min}$. The mixture was diluted with EtOAc $(20 \mathrm{~mL})$. Separated aqueous phase was extracted with EtOAc $(3 \mathrm{x}$ $50 \mathrm{~mL})$ and the combined organic phases were washed with $\mathrm{H}_{2} \mathrm{O}(10 \mathrm{~mL})$, dried over $\mathrm{MgSO}_{4}$ filtered and concentrated. The crude product was immediately used in the next reaction without further purification.

$\mathrm{R}_{f}=0.15\left(1: 1 \mathrm{Et}_{2} \mathrm{O} /\right.$ hexanes, $\mathrm{UV} /$ vanillin stain), ${ }^{1} \mathrm{H} \mathrm{NMR}\left(\mathrm{CDCl}_{3}, 400 \mathrm{MHz}\right) \delta 7.75-7.48(\mathrm{~m}, 4 \mathrm{H})$, 7.36-7.19 (m, $6 \mathrm{H}), 3.70-3.39$ (m, 5 H), 3.39-3.26 (dd, $1 \mathrm{H}, J=11.0,7.6 \mathrm{~Hz}), 3.26-2.75(\mathrm{~m}, 5 \mathrm{H})$, 1.86-1.02 (m, $10 \mathrm{H}), 0.97$ (s, $9 \mathrm{H}) \mathrm{ppm} ;{ }^{13} \mathrm{C} \mathrm{NMR}\left(\mathrm{CDCl}_{3}, 100 \mathrm{MHz}\right) \delta .135 .7,133.8,129.7,128.4$, 127.7, 99.4, 72.2, 71.4, 67.4, 66.8, 47.3, 32.4, 32.3, 27.2, 26.9, 19.3, 18.6 ppm.

\section{Benzoate 10}

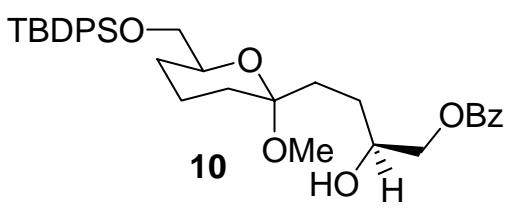

To a stirred $0{ }^{\circ} \mathrm{C}$ solution of dihydroxyketal S1 $(0.19 \mathrm{~g}, 0.34 \mathrm{mmol})$ in pyridine $(2.1 \mathrm{~mL})$ was added benzoyl chloride $(60 \mu \mathrm{L}, 77 \mathrm{mg}, 0.55 \mathrm{mmol})$. The resulting solution was stirred at $0{ }^{\circ} \mathrm{C}$ for additional $10 \mathrm{~h}$. Aqueous saturated $\mathrm{NaHCO}_{3}(3 \mathrm{~mL})$ and $\mathrm{H}_{2} \mathrm{O}(5 \mathrm{~mL})$ were added and the phases were separated. The aqueous phase was extracted with EtOAc $(3 \times 50 \mathrm{~mL})$ and the combined organic phases were washed with $\mathrm{H}_{2} \mathrm{O}(5 \mathrm{~mL})$, dried over $\mathrm{MgSO}_{4}$, filtered and concentrated. The crude product was purified by flash column chromatography $\left(\mathrm{SiO}_{2}\right)$ using 1:3 EtOAc/hexanes as the eluent to yield benzoate $\mathbf{1 0}$ (158 $\mathrm{mg}, 76 \%$ over 2 steps) as a yellow viscous oil.

$\mathrm{R}_{f}=0.15$ (1:3 EtOAc/hexanes, $\mathrm{UV} /$ vanillin stain), $d r 1: 2.5 ;[\alpha]^{20}{ }_{\mathrm{D}}=+18.4\left(c=0.9, \mathrm{CH}_{2} \mathrm{Cl}_{2}\right) ; \mathrm{IR}$ (thin film, $\mathrm{cm}^{-1}$ ) 3460, 3071, 2932, 2857, 1722, 1452, 1428, 1274, 1113, 1028, 824, 740, 709; ${ }^{1} \mathrm{H}$ NMR (acetonitrile-d $\mathrm{d}_{3}, 400 \mathrm{MHz}$, major isomer) $\delta$ 8.09-8.06 (m, $\left.2 \mathrm{H}\right)$, 7.77-7.72 (m, $\left.4 \mathrm{H}\right)$, 7.61-7.59 (m, $1 \mathrm{H}), 7.51-7.40(\mathrm{~m}, 8 \mathrm{H}), 4.32-4.21$ (m, $2 \mathrm{H}), 3.89$ (br s, $1 \mathrm{H}), 3.75-3.71(\mathrm{~m}, 1 \mathrm{H}), 3.65-3.63$ $(\mathrm{m}, 2 \mathrm{H}), 3.33(\mathrm{~m}, 1 \mathrm{H}), 3.17(\mathrm{~s}, 3 \mathrm{H}), 1.76-1.16(\mathrm{~m}, 10 \mathrm{H}), 1.05(\mathrm{~s}, 9 \mathrm{H}) \mathrm{ppm}$; in addition, the following signals due to the minor isomer 10b were observed: $3.71(\mathrm{~m}, 1 \mathrm{H}), 3.63(\mathrm{~m}, 2 \mathrm{H}), 3.16(\mathrm{~s}$, $3 \mathrm{H}) ;{ }^{13} \mathrm{C} \mathrm{NMR}$ (acetonitrile-d $3,100 \mathrm{MHz}$, major isomer) $\delta .166 .5,135.9,134.1,133.4,130.7,130.1$, 
$129.8,128.9,128.1,99.6,71.5,69.5,69.2,69.1,67.9,46.9,32.5,27.7,27.1,26.7,19.2,18.8$ ppm; in addition, the following signals due to the minor isomer 10b were observed: 135.9, 128.1, 99.5, 46.9, 32.5; HRMS (ESI) calcd. for $\mathrm{C}_{34} \mathrm{H}_{44} \mathrm{O}_{6} \mathrm{NaSi} 599.2805$, found 599.2781, $\Delta 4.0 \mathrm{ppm}$.

\section{Diol S2 via AD}

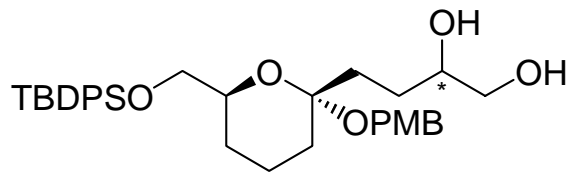

S2

Ketal 5 (100 mg, $0.18 \mathrm{mmol})$ was dissolved in 1:1 tert-butyl alcohol/water $(4: 4 \mathrm{~mL})$ and the solution was cooled at $0{ }^{\circ} \mathrm{C}$. AD-mix $\alpha(250 \mathrm{mg})$ and $\mathrm{CH}_{3} \mathrm{SO}_{2} \mathrm{NH}_{2}(17.5 \mathrm{mg}, 0.18 \mathrm{mmol})$ were slowly added and the mixture was stirred at the same temperature for $2 \mathrm{~h}$. Then the mixture was allowed to warm to $\mathrm{rt}$ and stirring was continued for $15 \mathrm{~h}$ before $\mathrm{Na}_{2} \mathrm{SO}_{3}$ was added. The resulting mixture was stirred vigorously for additional $30 \mathrm{~min}$ and then diluted with EtOAc $(10 \mathrm{~mL})$. Separated aqueous phases were washed with $\mathrm{H}_{2} \mathrm{O}(10 \mathrm{~mL})$, dried over $\mathrm{MgSO}_{4}$, filtered and concentrated. The crude product was immediately used in the next step without further purification. $\mathrm{R}_{f}=0.14$ (1:2 Et $\mathrm{E}_{2} \mathrm{O} /$ hexanes, $\mathrm{UV} /$ vanillin stain); $d r$ 2.5:1 (NMR spectra), ${ }^{1} \mathrm{H}$ NMR (acetonitrile- $\mathrm{d}_{3}$, $400 \mathrm{MHz}$ ) 7.76-7.67 (m, 4 H), 7.47-7.34 (m, 6 H), 7.34-7.24 (m, 2 H), 6.93-6.86 (m, 2 H), 4.50 (d, $1 \mathrm{H}, J=11.0 \mathrm{~Hz}), 4.34(\mathrm{dd}, 1 \mathrm{H}, J=11.0,4.6 \mathrm{~Hz}), 3.90-3.79(\mathrm{~m}, 1 \mathrm{H}), 3.77$ (s, $3 \mathrm{H}), 3.68-3.60$ (m, $2 \mathrm{H}), 3.60-3.50$ (m, $1 \mathrm{H}), 3.46$ (dd, $1 \mathrm{H}, J=11.0,4.0 \mathrm{~Hz}), 3.34$ (dd, $1 \mathrm{H}, J=11.0,6.9 \mathrm{~Hz}), 2.99$ 2.65 (br s, $2 \mathrm{H}), 2.11-1.10$ (m, $10 \mathrm{H}), 1.02$ (s, $9 \mathrm{H})$ ppm; ${ }^{13} \mathrm{C}$ NMR (acetonitrile-d $\mathrm{d}_{3}, 100 \mathrm{MHz}$ ) $159.9,136.5,136.4,134.7,134.7,132.3,132.3,130.7,130.7,130.1,128.7,128.7,114.6,100.7$, $100.6,72.8,75.5,68.5,67.2,67.1,61.8,61.7,55.8,34.1,34.1,33.3,28.2,27.6,27.2,19.8,19.5$ ppm (signals of both isomers).

\section{Benzoate 11}

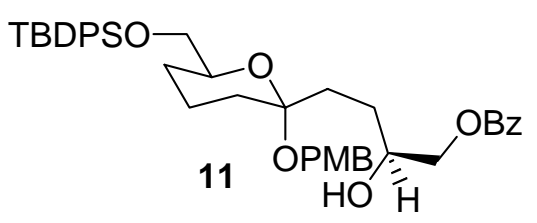

To a stirred solution of dihydroxyketal $\mathbf{S} 2(74 \mathrm{mg}, 0.12 \mathrm{mmol})$ at $0{ }^{\circ} \mathrm{C}$ in pyridine $(3 \mathrm{~mL})$ was added benzoyl chloride $(0.014 \mathrm{~mL}, 0.12 \mathrm{mmol})$. The resulting solution wa stirred at $0{ }^{\circ} \mathrm{C}$ for additional $10 \mathrm{~h}$. Aqueous saturated $\mathrm{NaHCO}_{3}(3 \mathrm{~mL})$ and water $(5 \mathrm{~mL})$ were added and the phases 
were separated. The aqueous phase was extracted with EtOAc $(3 \times 5 \mathrm{~mL})$ and the combined organic phases were washed with $\mathrm{H}_{2} \mathrm{O}(5 \mathrm{~mL})$, dried over $\mathrm{MgSO}_{4}$, filtered and concentrated. The crude product was purified by flash column chromatography (SiO2) using EtOAc:hexane, 1:3 as the eluent to yield benzoate 11 (75 mg, 63\%, over 2 steps) as an yellow viscous oil (2.5:1 diastereomeric ratio).

$[\alpha]^{20}{ }_{\mathrm{D}}=+2.2\left(c=1.34, \mathrm{CH}_{2} \mathrm{Cl}_{2}\right)$; IR (thin film, $\left.\mathrm{cm}^{-1}\right)$ 3443, 3054, 2987, 1732, 1551, 1422, 1264; ${ }^{1} \mathrm{H}$ NMR (acetonitrile- $\mathrm{d}_{3}, 400 \mathrm{MHz}$, major isomer) $\delta 8.09-8.06(\mathrm{~m}, 2 \mathrm{H}), 7.75-7.70(\mathrm{~m}, 4 \mathrm{H}), 7.59(\mathrm{~m}$, 1H), 7.48-7.28 (m, 10H), 6.90-6.87 (m, 2H), $4.55(\mathrm{~d}, 1 \mathrm{H}, J=11.2), 4.43-4.37(\mathrm{~m}, 2 \mathrm{H}), 4.29-4.24$ (m, 1H), $4.01(\mathrm{~m}, 1 \mathrm{H}), 3.89-3.87(\mathrm{~m}, 1 \mathrm{H}), 3.82(\mathrm{~s}, 3 \mathrm{H}), 3.73-3.70(\mathrm{~m}, 1 \mathrm{H}), 3.63(\mathrm{~m}, 1 \mathrm{H}), 2.53(\mathrm{~m}$, $1 \mathrm{H}), 2.17(\mathrm{~m}, 1 \mathrm{H}), 1.94-1.62(\mathrm{~m}, 7 \mathrm{H}), 1.30-1.28(\mathrm{~m}, 2 \mathrm{H}), 1.07(\mathrm{~s}, 9 \mathrm{H}) \mathrm{ppm}$; in addition, the following signals due to the minor isomer $11 \mathrm{~b}$ were observed: $3.82(\mathrm{~s}, 3 \mathrm{H}), 3.59(\mathrm{~m}, 1 \mathrm{H}) ;{ }^{13} \mathrm{C} \mathrm{NMR}$ (acetonitrile- $\mathrm{d}_{3}, 400 \mathrm{MHz}$, major isomer) $\delta 160.3,159.3,135.8,134.1,133.4,131.6,130.7,130.1$, $129.7,129.5,128.9,128.1,114.0,99.9,71.9,69.4,69.1,67.9,61.2,55.2,33.3,32.7,27.8,26.9$, 26.6, 19.2, $18.9 \mathrm{ppm}$; in addition, the following signals due to the minor isomer 11b were observed: 159.9, 135.9, 134.1, 130.1, 129.5, 128.0, 114.0, 100.0, 69.5, 61.3, 33.5; HRMS (ESI) calcd. For $\mathrm{C}_{41} \mathrm{H}_{50} \mathrm{O}_{7} \mathrm{NaSi} 705.3231$, found 705.3224, $\Delta 1.0 \mathrm{ppm}$.

\section{Diol S1}

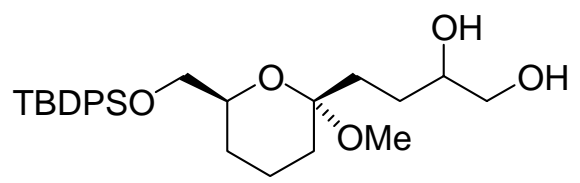

The alkene 4 (153 mg, $0.35 \mathrm{mmol})$ was dissolved in a 10:2:1 mixture of $t$-butanol:THF:water (6.5 $\mathrm{mL}$ ) at room temperature. To this was added $N$-methylmorpholine- $N$-oxide ( $85 \mathrm{mg}, 0.72 \mathrm{mmol}$ ) followed by a $2.5 \%$ solution of osmium tetroxide in $t$-butanol $(10 \mu \mathrm{L}, 0.01 \mathrm{mmol})$. The reaction mixture was allowed to stir vigorously for $84 \mathrm{~h}$ at $\mathrm{rt}$, the mixture was cooled to $0{ }^{\circ} \mathrm{C}$, then $\mathrm{Na}_{2} \mathrm{SO}_{3}$ (1.2 g) was added. The resulting mixture was stirred for an additional hour while allowing it to warm to rt. The mixture was diluted with EtOAc $(20 \mathrm{~mL})$. The separated aqueous phase was extracted with EtOAc $(3 \times 50 \mathrm{~mL})$ and the combined organic phases were washed with $\mathrm{pH} 7 \mathrm{buffer}$ $(10 \mathrm{~mL})$ and brine $(10 \mathrm{~mL})$, dried over $\mathrm{MgSO}_{4}$ filtered and concentrated. The crude product $\mathbf{S 1}$ was immediately used in the next reaction without further purification.

$\mathrm{R}_{f}=0.14$ (1:1 Et ${ }_{2} \mathrm{O} /$ hexanes, $\mathrm{UV} /$ vanillin stain); ${ }^{1} \mathrm{H}$ NMR (acetonitrile-d $\left.\mathrm{d}_{3}, 400 \mathrm{MHz}\right) \delta .7 .84-7.63$ (m, 4 H), 7.50-7.32 (m, 6 H), 3.75-3.64 (m, 1 H), 3.64-3.58 (m, 2 H), 3.58-3.49 (m, 1 H), 3.49-3.41 (m, $1 \mathrm{H}), 3.37-3.27(\mathrm{~m}, 1 \mathrm{H}), 3.13(\mathrm{~s}, 3 \mathrm{H}), 2.92-2.70$ (br s, $2 \mathrm{H}), 1.91-1.24(\mathrm{~m}, 10 \mathrm{H}), 1.03(\mathrm{~s}, 9 \mathrm{H})$ 
ppm; ${ }^{13} \mathrm{C}$ NMR (acetonitrile-d $\left.\mathrm{d}_{3}, 100 \mathrm{MHz}\right) \oint 136.5,134.7,130.7,128.7,100.3,100.2,72.9,72.0$, 67.2 , 67.1, 47.5, 47.4, 33.3, 33.2, 33.2, 33.1, 33.1, 31.5, 28.1, 28.1, 27.7, 27.3, 19.8, 19.4 ppm (signals of both isomers).

\section{Diol S2}

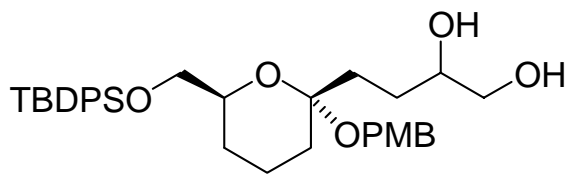

The alkene 5 (82 mg, $0.15 \mathrm{mmol})$ was dissolved in a 5:1:1 mixture of $t$-butanol:THF:water $(7 \mathrm{~mL})$ at room temperature. To this was added $N$-methylmorpholine- $N$-oxide (64 mg, $0.53 \mathrm{mmol}$ ) followed by a $2.5 \%$ solution of osmium tetroxide in $t$-butanol $(7 \mu \mathrm{L}, 0.007 \mathrm{mmol})$. The reaction mixture was allowed to stir vigorously for $84 \mathrm{~h}$ at $\mathrm{rt}$, the mixture was cooled to $0{ }^{\circ} \mathrm{C}$, then $\mathrm{Na}_{2} \mathrm{SO}_{3}(0.8 \mathrm{~g})$ was added. The resulting mixture was stirred for an additional hour while allowing it to warm to rt. The mixture was diluted with EtOAc $(20 \mathrm{~mL})$. The separated aqueous phase was extracted with EtOAc $(3 \mathrm{x} 50 \mathrm{~mL})$ and the combined organic phases were washed with $\mathrm{pH} 7$ buffer $(5 \mathrm{~mL})$ and brine $(5$ $\mathrm{mL}$ ), dried over $\mathrm{MgSO}_{4}$ filtered and concentrated. The crude product was immediately used in the next reaction without further purification.

$\mathrm{R}_{f}=0.14$ (1:2 Et ${ }_{2} \mathrm{O} /$ hexanes, $\mathrm{UV} /$ vanillin stain); $d r$ 1:1 (NMR spectra), ${ }^{1} \mathrm{H}$ NMR (acetonitrile-d $\mathrm{d}_{3}$,

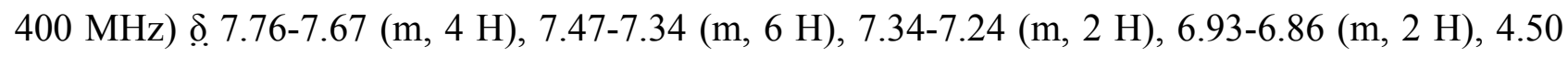
(d, $1 \mathrm{H}, J=11.0 \mathrm{~Hz}), 4.34$ (dd, $1 \mathrm{H}, J=11.0,4.6 \mathrm{~Hz}), 3.90-3.79$ (m, $1 \mathrm{H}), 3.77$ (s, $3 \mathrm{H}), 3.68-3.60$ (m, $2 \mathrm{H}), 3.60-3.50$ (m, $1 \mathrm{H}), 3.46$ (dd, $1 \mathrm{H}, J=11.0,4.0 \mathrm{~Hz}), 3.34$ (dd, $1 \mathrm{H}, J=11.0,6.9 \mathrm{~Hz}), 2.99$ 2.65 (br s, $2 \mathrm{H}), 2.11-1.10(\mathrm{~m}, 10 \mathrm{H}), 1.02$ (s, $9 \mathrm{H}) \mathrm{ppm} ;{ }^{13} \mathrm{C}$ NMR (acetonitrile-d $\left.\mathrm{d}_{3}, 100 \mathrm{MHz}\right) \delta$ $159.9,136.5,136.4,134.7,134.7,132.3,132.3,130.7,130.7,130.1,128.7,128.7,114.6,100.7$, $100.6,72.8,75.5,68.5,67.2,67.1,61.8,61.7,55.8,34.1,34.1,33.3,28.2,27.6,27.2,19.8,19.5$ ppm (signals of both isomers). 


\section{Aldehyde 6}

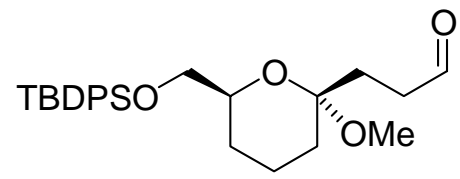

6

The crude diol S1 $(0.35 \mathrm{mmol})$ was dissolved in THF $(15 \mathrm{~mL})$ and the mixture was cooled to $0{ }^{\circ} \mathrm{C}$, then a $\mathrm{pH} 7$ buffered saline solution $(52 \mathrm{~mL})$ was added followed by sodium periodate $(0.3 \mathrm{~g}, 1.44$ mmol). The suspension was stirred vigorously for $4.5 \mathrm{~h}$ at $0{ }^{\circ} \mathrm{C}$. The mixture was allowed to warm to $\mathrm{rt}$ and diluted with EtOAc $(20 \mathrm{~mL})$. The separated aqueous phase was extracted with EtOAc $(3 \mathrm{x}$ $50 \mathrm{~mL})$ and the combined organic phases were washed with $\mathrm{pH} 7$ buffer $(5 \mathrm{~mL})$, dried over $\mathrm{MgSO}_{4}$ filtered and concentrated. The crude product 6 (52\% yield over 2 steps) was immediately used in the next reaction without further purification.

$\mathrm{R}_{f}=0.39$ (1:1 Et $\mathrm{E}_{2} \mathrm{O}$ : hexanes, $\mathrm{UV} /$ vanillin stain); ${ }^{1} \mathrm{H}$ NMR (acetonitrile- $\left.\mathrm{d}_{3}, 400 \mathrm{MHz}\right) \oint \underline{9} 9.71(\mathrm{t}, 1$ $\mathrm{H}, \mathrm{J}=1.5 \mathrm{~Hz}), 7.77-7.72(\mathrm{~m}, 4 \mathrm{H}), 7.48-7.43$ (m, $6 \mathrm{H}), 3.73-3.68(\mathrm{~m}, 1 \mathrm{H}), 3.63$ (d, $2 \mathrm{H}, \mathrm{J}=5.1$ $\mathrm{Hz}), 3.15(\mathrm{~s}, 3 \mathrm{H}), 2.46-2.41(\mathrm{~m}, 2 \mathrm{H}), 1.88-1.39(\mathrm{~m}, 8 \mathrm{H}), 1.03(\mathrm{~s}, 9 \mathrm{H}) \mathrm{ppm} ;{ }^{13} \mathrm{C} \mathrm{NMR}$ (acetonitrile- $\left.\mathrm{d}_{3}, 100 \mathrm{MHz}\right) \oint .202 .6,135.9,134.1,130.1,128.1,99.2,72.7,67.7,47.0,38.5,32.3$, 28.5, 26.8, 26.2, 19.2, 18.7 ppm; HRMS (ESI) calcd. for $\mathrm{C}_{26} \mathrm{H}_{36} \mathrm{O}_{4} \mathrm{NaSi}$ 463.2281, found 463.2295, $\triangle 3.0 \mathrm{ppm}$.

\section{Aldehyde 7}

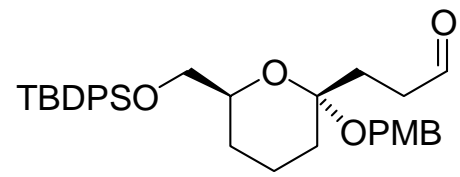

7

The crude diol S2 (theoretically $0.15 \mathrm{mmol}$ ) was dissolved in THF $(15 \mathrm{~mL})$ and the mixture was cooled to $0{ }^{\circ} \mathrm{C}$, then a $\mathrm{pH} 7$ buffered saline solution $(30 \mathrm{~mL})$ was added followed by sodium periodate $(0.13 \mathrm{~g}, 0.58 \mathrm{mmol})$. The suspension was stirred vigorously for $4 \mathrm{~h}$ at +7 to $+12{ }^{\circ} \mathrm{C}$. The mixture was allowed to warm to $\mathrm{rt}$ and diluted with EtOAc $(20 \mathrm{~mL})$. The separated aqueous phase was extracted with EtOAc $(3 \times 50 \mathrm{~mL})$ and the combined organic phases were washed with $\mathrm{pH} 7$ buffer $(5 \mathrm{~mL})$, dried over $\mathrm{MgSO}_{4}$ filtered and concentrated. The crude product 7 (45\% yield over 2 steps) was immediately used in the next reaction without further purification. The product is extremely sensitive to acids. 
$\mathrm{R}_{f}=0.36\left(1: 1 \mathrm{Et}_{2} \mathrm{O} /\right.$ hexanes, $\mathrm{UV} /$ vanillin stain); ${ }^{1} \mathrm{H}$ NMR (acetonitrile- $\left.\mathrm{d}_{3}, 400 \mathrm{MHz}\right) \oint 9.73(\mathrm{t}, 1$ H, J = 1.5 Hz), 7.78-7.70 (m, 4 H), 7.49-7.36 (m, $6 \mathrm{H})$, 7.34-7.28 (m, $2 \mathrm{H}), 6.94-6.88$ (m, $2 \mathrm{H}), 4.54$ (d, $1 \mathrm{H}, J=11.1 \mathrm{~Hz}), 4.35$ (d, $1 \mathrm{H}, J=11.1 \mathrm{~Hz}), 3.93-3.82(\mathrm{~m}, 1 \mathrm{H}), 3.80$ (s, $3 \mathrm{H}), 3.70-3.64$ (m, 2 $\mathrm{H}), 2.57-2.46$ (m, $2 \mathrm{H}), 2.34-1.46(\mathrm{~m}, 8 \mathrm{H}), 1.05$ (s, $9 \mathrm{H}) \mathrm{ppm} ;{ }^{13} \mathrm{C}$ NMR (acetonitrile- $\mathrm{d}_{3}, 100 \mathrm{MHz}$ ) ঠ. 202.6, 159.4, 135.9, 135.8, 134.1, 134.0, 131.5, 130.1, 129.9, 128.8, 128.1, 114.6, 99.6, 72.1, 67.8, 61.3, 55.3, 38.6, 32.5, 30.1, 26.8, 27.6, 19.2, 18.8 ppm; HRMS (ESI) calcd. for $\mathrm{C}_{33} \mathrm{H}_{42} \mathrm{O}_{5} \mathrm{NaSi}$ 569.2699, found 569.2698, $\Delta 0.1 \mathrm{ppm}$.

\section{Primary alcohol 8}

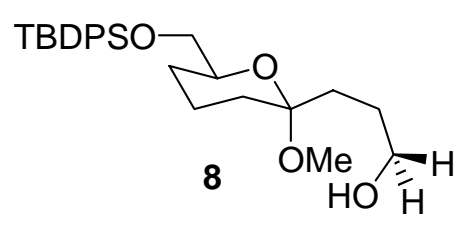

A solution of the crude aldehyde $6(33 \mathrm{mg}, 0.076 \mathrm{mmol})$ in THF $(3.0 \mathrm{~mL})$ was cooled to $-78{ }^{\circ} \mathrm{C}$ and DIBAL-H $(0.15 \mathrm{~mL}$ of a $1 \mathrm{M}$ solution in toluene, $0.153 \mathrm{mmol})$ was added dropwise over a period of $10 \mathrm{~min}$. The resulting solution was stirred at $-78^{\circ} \mathrm{C}$ for additional $20 \mathrm{~min}$ and then warmed to $0{ }^{\circ} \mathrm{C}$. After another $20 \mathrm{~min}$ the reaction was quenched with aqueous saturated Rochelle's salt $(1 \mathrm{~mL})$. The mixture was warmed to $\mathrm{rt}$ and stirred for an additional $20 \mathrm{~min}$ before the solution was extracted with EtOAc ( 3 x $40 \mathrm{~mL})$. The combined organic phases were washed pH 7 buffer, dried over $\mathrm{MgSO}_{4}$, filtered and concentrated. The crude product was purified by flash column chromatography $\left(\mathrm{SiO}_{2}\right)$ using 2:1 $\mathrm{Et}_{2} \mathrm{O} /$ hexanes as the eluent to yield the primary alcohol $8(23 \mathrm{mg}, 67 \%)$ as a viscous, tan oil.

$\mathrm{R}_{f}=0.29\left(2: 1 \mathrm{Et}_{2} \mathrm{O} /\right.$ hexanes, $\mathrm{UV} /$ vanillin stain); $[\alpha]^{20}{ }_{\mathrm{D}}=+19.9\left(c=1.39, \mathrm{CH}_{2} \mathrm{Cl}_{2}\right)$; IR (thin film, $\mathrm{cm}^{-1}$ ) 3401, 3071, 2931, 2858, 1472, 1462, 1113, 1082, 1010, 824, 702; ${ }^{1} \mathrm{H}$ NMR (acetonitrile-d $\mathrm{d}_{3}$, $400 \mathrm{MHz}) \oint$ 7.75-7.69 (m, $4 \mathrm{H}), 7.48-7.38(\mathrm{~m}, 6 \mathrm{H}), 3.71-3.64(\mathrm{~m}, 1 \mathrm{H}), 3.61(\mathrm{dd}, 2 \mathrm{H}, J=5.1,1.2$ Hz), 3.49 (br m, $2 \mathrm{H}), 3.13$ (s, $3 \mathrm{H}), 2.58$ (br s, $1 \mathrm{H}), 1.81-1.41$ (m, $10 \mathrm{H}), 1.03$ (s, $9 \mathrm{H}) \mathrm{ppm} ;{ }^{13} \mathrm{C}$ NMR (acetonitrile-d $\left.\mathrm{d}_{3}, 100 \mathrm{MHz}\right) \oint \underline{1}$ 135.9, 135.9, 134.1, 130.1, 128.1, 128.0, 99.6, 71.4, 67.8, 62.1, 46.8, 33.0, 32.5, 27.0, 26.5, 19.2, 18.8 ppm. HRMS (ESI) calcd. for $\mathrm{C}_{26} \mathrm{H}_{38} \mathrm{O}_{4} \mathrm{NaSi} 465.2437$, found 465.2435, $\Delta 0.4 \mathrm{ppm}$. 


\section{Primary alcohol 9}

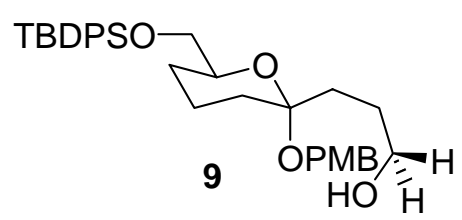

A solution of the crude aldehyde $7(32 \mathrm{mg}, 0.058 \mathrm{mmol})$ in THF $(3.0 \mathrm{~mL})$ was cooled to $-78^{\circ} \mathrm{C}$ and DIBAL-H $(0.12 \mathrm{~mL}$ of a $1 \mathrm{M}$ solution in toluene, $0.117 \mathrm{mmol})$ was added dropwise over a period of $10 \mathrm{~min}$. The resulting solution was stirred at $-78^{\circ} \mathrm{C}$ for additional $20 \mathrm{~min}$ and then warmed to $0{ }^{\circ} \mathrm{C}$. After another 20 min the reaction was quenched with aqueous saturated Rochelle's salt $(1 \mathrm{~mL})$. The mixture was warmed to $\mathrm{rt}$ and stirred for an additional $20 \mathrm{~min}$ before the solution was extracted with EtOAc ( 3 x $40 \mathrm{~mL})$. The combined organic phases were washed $\mathrm{pH} 7$ buffer, dried over $\mathrm{MgSO}_{4}$, filtered and concentrated. The crude product was purified by flash column chromatography $\left(\mathrm{SiO}_{2}\right)$ using 2:1 $\mathrm{Et}_{2} \mathrm{O} /$ hexanes as the eluent to yield the primary alcohol $9(26 \mathrm{mg}, 81 \%)$ as a viscous bright yellow oil.

$\mathrm{R}_{f}=0.29\left(2: 1 \mathrm{Et}_{2} \mathrm{O} /\right.$ hexanes, $\mathrm{UV} /$ vanillin stain); $[\alpha]^{20}{ }_{\mathrm{D}}=2.0\left(c=1.095, \mathrm{CH}_{2} \mathrm{Cl}_{2}\right) ; \mathrm{IR}$ (thin film, $\mathrm{cm}^{-1}$ ) 3369, 2930, 1613, 1515, 1457, 1428, 1248, 1113, 1078, 823, 703; ${ }^{1} \mathrm{H}$ NMR (acetonitrile-d $\mathrm{d}_{3}$, $400 \mathrm{MHz}) \oint .7 .75-7.69$ (m, 4 H), 7.48-7.35 (m, $6 \mathrm{H})$, 7.31-7.27 (m, 2 H), 6.92-6.90 (m, 2 H), 4.52 (d, $1 \mathrm{H}, J=11.2 \mathrm{~Hz}), 4.34(\mathrm{~d}, 1 \mathrm{H}, J=11.3 \mathrm{~Hz}), 3.89-3.82(\mathrm{~m}, 1 \mathrm{H}), 3.78(\mathrm{~s}, 3 \mathrm{H}), 3.65(\mathrm{~m}, 2 \mathrm{H})$, 3.53 (br m, $2 \mathrm{H}), 2.61$ (s, $1 \mathrm{H}), 1.91-1.30(\mathrm{~m}, 10 \mathrm{H}), 1.04$ (s, $9 \mathrm{H}), \mathrm{ppm} ;{ }^{13} \mathrm{C}$ NMR (acetonitrile-d $\mathrm{d}_{3}$, $100 \mathrm{MHz}) \delta .159 .3,135.9,135.8,131.7,130.4,129.5,128.1,128.0,114.0,100.0,71.9,67.9,62.1$, 61.2, 55.2, 33.9, 32.7, 27.2, 27.0, 26.6, 19.2, 18.9 ppm. HRMS (ESI) calcd. for $\mathrm{C}_{33} \mathrm{H}_{44} \mathrm{O}_{5} \mathrm{NaSi}$ 571.2856 , found $571.2858, \Delta 0.3 \mathrm{ppm}$.

\section{Spiroketals 12a and 12b}

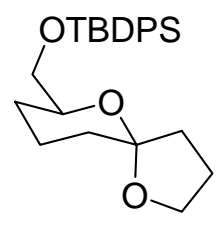

$12 \mathbf{a}$

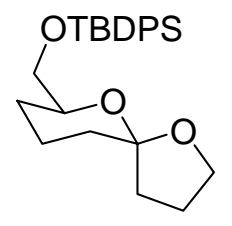

$12 b$

To a solution of the alcohol $8(14 \mathrm{mg}, 0.03 \mathrm{mmol})$ in the $\mathrm{DCM}(2 \mathrm{~mL})$ was added $\mathrm{ClCH}_{2} \mathrm{COOH}(80$ mol\%) at $\mathrm{rt}$. The resulting solution was stirred at $\mathrm{rt}$ until the reaction was completed as revealed by TLC. The reaction was quenched by addition of saturated aqueous $\mathrm{NaHCO}_{3}(2 \mathrm{~mL})$ and $\mathrm{H}_{2} \mathrm{O}(2$ 
$\mathrm{mL})$. The separated aqueous phase was extracted with EtOAc $(3 \times 5 \mathrm{~mL})$ and the combined organic phases were dried over $\mathrm{Na}_{2} \mathrm{SO}_{4}$, filtered and concentrated. The crude product was purified by flash column chromatography $\left(\mathrm{SiO}_{2}\right)$ using $1: 4 \mathrm{Et}_{2} \mathrm{O} /$ hexanes as the eluent to yield fraction $\mathrm{A}$ : spiroketal 12a (8.2 mg, 67\%), fraction B: spiroketal 12b (4 mg, 33\%).

\section{Anomeric spiroketal 12a}

$\mathrm{R}_{f}=0.72\left(2: 3 \mathrm{Et}_{2} \mathrm{O} /\right.$ hexanes, vanillin stain), $[\alpha]^{20}{ }_{\mathrm{D}}=+9.6\left(c=0.6, \mathrm{CH}_{2} \mathrm{Cl}_{2}\right) ; \mathrm{IR}$ (thin film, $\left.\mathrm{cm}^{-1}\right)$ 3054, 2987, 2305, 1421, 1264; ${ }^{1} \mathrm{H}$ NMR (acetonitrile-d $\mathrm{d}_{3}, 400 \mathrm{MHz}$ ) $\delta$ 7.76-7.72 (m, 4H), 7.48-7.43 (m, 6H), 3.88-3.83 (m, 3H), 3.63-3.61 (d, 2H, J = 5.3 Hz), 1.91-1.56 (m, 8H), 1.36-1.21 (m, 2H), 1.05 (s, 9H) ppm; ${ }^{13} \mathrm{C}$ NMR (acetonitrile-d $\left.\mathrm{d}_{3}, 400 \mathrm{MHz}\right) \delta 135.9,134.0,130.1,128.0,106.0,71.5$, 67.9, 66.6, 37.8, 33.0, 27.0, 26.5, 23.7, 20.2, 19.1 ppm. HRMS (ESI) calcd. For $\mathrm{C}_{25} \mathrm{H}_{34} \mathrm{O}_{3} \mathrm{NaSi}$ 433.2175, found 433.2193, $\Delta 4.1 \mathrm{ppm}$.

\section{Nonanomeric spiroketal 12b}

$\mathrm{R}_{f}=0.52\left(2: 3 \mathrm{Et}_{2} \mathrm{O} /\right.$ hexanes, vanillin stain), $[\alpha]^{20}{ }_{\mathrm{D}}=-5.1\left(c=0.3, \mathrm{CH}_{2} \mathrm{Cl}_{2}\right)$; IR (thin film, $\left.\mathrm{cm}^{-1}\right)$ 3054, 2987, 2305, 1421, 1264; ${ }^{1} \mathrm{H}$ NMR (acetonitrile-d $\mathrm{d}_{3}, 400 \mathrm{MHz}$ ) $\delta$ 7.74-7.71 (m, 4H), 7.48-7.42 (m, 6H), 3.91-3.88 (m, 1H), 3.85-3.80 (m, 1H), 3.70-3.63 (m, 3H), 2.22-2.20 (m, 1H), 1.88-1.79 (m, 2H), 1.64-1.52 (m, 5H), 1.33-1.27 (m, 2H), $1.06(\mathrm{~s}, 9 \mathrm{H}) \mathrm{ppm} ;{ }^{13} \mathrm{C}$ NMR (acetonitrile- $\mathrm{d}_{3}, 400 \mathrm{MHz}$ ) $\delta 135.8,131.6,130.1,128.1,107.7,75.1,67.5,67.3,34.3,32.9,27.0,26.6,24.1,20.9,19.2$ ppm. HRMS (ESI) calcd. For $\mathrm{C}_{25} \mathrm{H}_{34} \mathrm{O}_{3} \mathrm{NaSi} 433.2175$, found 433.2182, $\Delta 1.6 \mathrm{ppm}$.

\section{Synthesis of spiroketals 13a-c}
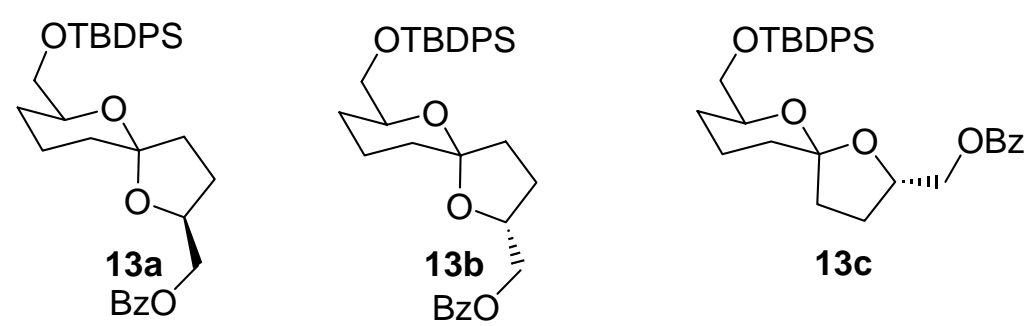

To a solution of alcohol $10(36 \mathrm{mg}, 0.06 \mathrm{mmol})$ in THF/water 4:1 (3 mL) was added $\mathrm{Cl}_{3} \mathrm{CCOOH}$ $(60 \mathrm{~mol} \%, 0.036 \mathrm{mmol})$ at $\mathrm{rt}$. The resulting solution was stirred at $\mathrm{rt}$ until the reaction was completed as revealed by TLC. The reaction was quenched by addition of saturated aqueous $\mathrm{NaHCO}_{3}(3 \mathrm{~mL})$ and $\mathrm{H}_{2} \mathrm{O}(3 \mathrm{~mL})$. The separated aqueous phase was extracted with EtOAc $(3 \times 5$ $\mathrm{mL}$ ) and the combined organic phases were dried over $\mathrm{Na}_{2} \mathrm{SO}_{4}$, filtered and concentrated. The crude product was purified by flash column chromatography $\left(\mathrm{SiO}_{2}\right)$ using 1:4 $\mathrm{Et}_{2} \mathrm{O} /$ hexane as the eluent to 
yield fraction A: spiroketal 13a (7.5 mg, 23\%), fraction B: spiroketal 13b (7.5 mg, 23\%), fraction C: spiroketal 13c (16 mg, 49\%).

\section{Anomeric spiroketal 13a}

$\mathrm{R}_{f}=0.88\left(1: 1 \mathrm{Et}_{2} \mathrm{O} /\right.$ hexanes, vanillin stain), $[\alpha]^{20}{ }_{\mathrm{D}}=+1.4\left(c=0.5, \mathrm{CH}_{2} \mathrm{Cl}_{2}\right) ; \mathrm{IR}$ (thin film, $\left.\mathrm{cm}^{-1}\right)$ 3054, 2987, 1718, 1424, 1266; ${ }^{1} \mathrm{H}$ NMR (acetonitrile-d $\left.{ }_{3}, 400 \mathrm{MHz}\right) \delta 8.06-8.03$ (d, 2H, J=7.8 Hz), 7.75-7.71 (m, 4H), 7.66-7.64 (m, 1H), 7.55-7.51 (m, 2H), 7.47-7.40 (m, 6H), 4.41-4.38 (m, 2H), 4.31-4.26 (dd, $1 \mathrm{H}, J=6.4 \mathrm{~Hz}, 12.4 \mathrm{~Hz}), 3.94-3.90(\mathrm{ddt}, 1 \mathrm{H}, J=2.2,5.1,11.7 \mathrm{~Hz}), 3.64-3.63$ (d, $2 \mathrm{H}, J=5.2 \mathrm{~Hz}), 2.17(\mathrm{~m}, 1 \mathrm{H}), 1.95-1.96(\mathrm{~m}, 7 \mathrm{H}), 1.31-1.22(\mathrm{~m}, 2 \mathrm{H}), 1.05(\mathrm{~s}, 9 \mathrm{H}) ;{ }^{13} \mathrm{C} \mathrm{NMR}$ (acetonitrile- $\left.\mathrm{d}_{3}, 400 \mathrm{MHz}\right) \delta 166.7,135.8,134.1,133.4,130.3,129.7,128.9,128.1,128.0,119.5$, 107.0, 75.9, 71.7, 67.9, 67.0, 37.4, 33.0, 27.1, 26.1, 20.0, 19.1 ppm. HRMS (ESI) calcd. For $\mathrm{C}_{33} \mathrm{H}_{40} \mathrm{O}_{5} \mathrm{NaSi}$ 567.2543, found 567.2535, $\Delta 1.4 \mathrm{ppm}$.

\section{Anomeric spiroketal 13b}

$\mathrm{R}_{f}=0.73\left(1: 1 \mathrm{Et}_{2} \mathrm{O} /\right.$ hexanes, vanillin stain), $[\alpha]^{20}{ }_{\mathrm{D}}=-5.8\left(c=0.8, \mathrm{CH}_{2} \mathrm{Cl}_{2}\right)$; IR (thin film, $\left.\mathrm{cm}^{-1}\right)$ 3054, 2987, 1712, 1421, 1265; ${ }^{1} \mathrm{H}$ NMR (acetonitrile-d $\left.{ }_{3}, 400 \mathrm{MHz}\right) \delta 8.04-8.01$ (d, 2H, J=7.8 Hz), 7.75-7.71 (m, 4H), 7.64-7.60 (m, 1H), 7.49-7.39 (m, 8H), 4.45-4.28 (m, 2H), $4.02(\mathrm{~m}, 1 \mathrm{H})$, 3.94$3.90(\mathrm{~m}, 1 \mathrm{H}), 3.64-3.56(\mathrm{~m}, 2 \mathrm{H}), 2.12(\mathrm{~m}, 1 \mathrm{H}), 1.84-1.58(\mathrm{~m}, 7 \mathrm{H}), 1.32-1.28(\mathrm{~m}, 2 \mathrm{H}), 1.03(\mathrm{~s}, 9 \mathrm{H})$; ${ }^{13} \mathrm{C}$ NMR (acetonitrile- $\left.\mathrm{d}_{3}, 400 \mathrm{MHz}\right) \delta 166.2,135.9,134.1,133.4,130.7,130.1,129.6,128.9$, 128.0, 117.7, 106.8, 78.0, 71.3, 68.8, 67.8, 38.4, 33.2, 27.0, 26.6, 20.2, 19.2 ppm. HRMS (ESI) calcd. For $\mathrm{C}_{33} \mathrm{H}_{40} \mathrm{O}_{5} \mathrm{NaSi} 567.2543$, found 567.2546, $\Delta 0.5 \mathrm{ppm}$.

\section{Nonanomeric spiroketal 13c}

$\mathrm{R}_{f}=0.63\left(1: 1 \mathrm{Et}_{2} \mathrm{O} /\right.$ hexanes, vanillin stain), $[\alpha]^{20}{ }_{\mathrm{D}}=+2.8\left(c=1.0, \mathrm{CH}_{2} \mathrm{Cl}_{2}\right) ; \mathrm{IR}$ (thin film, $\left.\mathrm{cm}^{-1}\right)$ 3054, 2987, 1712, 1420, 1265; ${ }^{1} \mathrm{H}$ NMR (acetonitrile-d $\left.3,400 \mathrm{MHz}\right) \delta 8.01-7.98$ (d, 2H, J=7.8 Hz), 7.72-7.69 (m, 4H), 7.64-7.57 (m, 3H), 7.47-7.40 (m, 6H), 4.36-4-32 (m, 2H), 4.27-4.22 (m, 1H), 3.68-3.63 (m, 3H), $2.38(\mathrm{ddd}, 1 \mathrm{H}, J=1.3,7.1,12.6 \mathrm{~Hz}), 2.12-2.02(\mathrm{~m}, 1 \mathrm{H}), 1.81-1.79(\mathrm{~m}, 2 \mathrm{H})$, 1.68-1.57 (m, 6H), $1.04(\mathrm{~s}, 9 \mathrm{H}) ;{ }^{13} \mathrm{C}$ NMR (acetonitrile-d $\left.\mathrm{d}_{3}, 400 \mathrm{MHz}\right) \delta 160.4,135.8,134.0,133.4$, 130.6, 130.1, 129.6, 128.9, 128.1, 117.7, 108.5, 77.8, 75.3, 68.6, 67.4, 34.4, 32.6, 27.1, 26.6, 21.0, 19.1 ppm. HRMS (ESI) calcd. For $\mathrm{C}_{33} \mathrm{H}_{40} \mathrm{O}_{5} \mathrm{NaSi} 567.2543$, found 567.2537, $\Delta 1.1 \mathrm{ppm}$. 


\section{Allyl alcohol 14a}

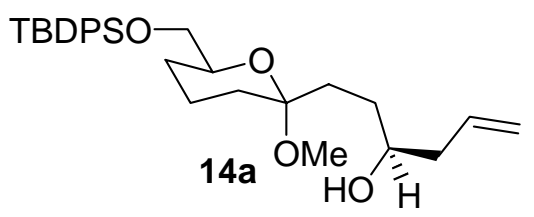

Brown's reagent $(+)$ - $B$-allyldiisopinocamphenylborane was prepared according to literature procedure. $^{3}$ A solution of $(+)$-Brown's reagent freshly prepared $(0.16 \mathrm{mmol})$ in $\operatorname{dry~}^{\mathrm{Et}} \mathrm{t}_{2} \mathrm{O}(1 \mathrm{~mL})$ was cooled at $-100{ }^{\circ} \mathrm{C}$. A solution of the aldehyde $6(74 \mathrm{mg}, 0.16 \mathrm{mmol})$ in $\operatorname{dry}^{\mathrm{Et}} \mathrm{t}_{2} \mathrm{O}(2 \mathrm{~mL})$ was added dropwise to the previous solution via syringe. The resulting mixture was further stirred at the same temperature for $5 \mathrm{~h}$. The reaction mixture was then quenched through addition of $\mathrm{MeOH}(3$ $\mathrm{mL}), 3 \mathrm{~N} \mathrm{NaOH}$ solution $(5 \mathrm{~mL})$ and $\mathrm{H}_{2} \mathrm{O}_{2} 30 \%$ (5 mL). After being stirred overnight, the mixture was poured into saturated aqueous $\mathrm{NaHCO}_{3}$ and worked up as usual $\left(\mathrm{Et}_{2} \mathrm{O}\right)$. The crude product was purified by flash column chromatography $\left(\mathrm{SiO}_{2}\right)$ using 1:5 $\mathrm{Et}_{2} \mathrm{O} /$ hexanes as the eluent to yield alcohol 14a $(82 \%, 66 \mathrm{mg})$ as a $6: 1$ mixture of diastereoisomers as revealed by ${ }^{1} \mathrm{H}$ NMR data. Spectroscopic data of major diastereoisomer are reported. Spectroscopic data of minor diastereoisomer are reported below (compound 14b).

$\mathrm{R}_{f}=0.26\left(1: 1 \mathrm{Et}_{2} \mathrm{O} /\right.$ hexanes, vanillin stain), $[\alpha]^{20}{ }_{\mathrm{D}}=+15.1\left(c=0.55, \mathrm{CH}_{2} \mathrm{Cl}_{2}\right)$; IR (thin film, $\left.\mathrm{cm}^{-1}\right)$ 3691, 3054, 2987, 2305, 1422, 1264; ${ }^{1} \mathrm{H}$ NMR (acetonitrile-d $\left.\mathrm{d}_{3}, 400 \mathrm{MHz}\right) \delta$ 7.77-7.73 (m, 4H), 7.48-7.43 (m, 6H), $5.87(\mathrm{~m}, 1 \mathrm{H}), 5.10(\mathrm{dd}, 1 \mathrm{H}, J=1.2 \mathrm{~Hz}, 17.2 \mathrm{~Hz}), 5.05(\mathrm{dd}, 1 \mathrm{H}, J=1.2 \mathrm{~Hz}, 9.2$ Hz), $3.72(\mathrm{~m}, 1 \mathrm{H}), 3.64(\mathrm{~m}, 2 \mathrm{H}), 3.56(\mathrm{~m}, 1 \mathrm{H}), 3.15(\mathrm{~s}, 3 \mathrm{H}), 2.68(\mathrm{~d}, 1 \mathrm{H}, J=5.2 \mathrm{~Hz}), 2.20$ (m, 2H), 1.76-1.23 (m, 10H), 1.06 (s, 9H); ${ }^{13} \mathrm{C}$ NMR (acetonitrile-d $\left.\mathrm{d}_{3}, 400 \mathrm{MHz}\right) \delta 136.2,135.9,134.1,130.1$, $128.1,116.5,99.6,71.4,70.9,67.8,46.8,42.2,32.7,32.5,30.9,27.0,26.6,19.2,18.8$ ppm. HRMS (ESI) calcd. For $\mathrm{C}_{29} \mathrm{H}_{42} \mathrm{O}_{4} \mathrm{NaSi} 505.2750$, found 505.2759, $\Delta 1.8 \mathrm{ppm}$. 


\section{Spiroketals 15a-b}
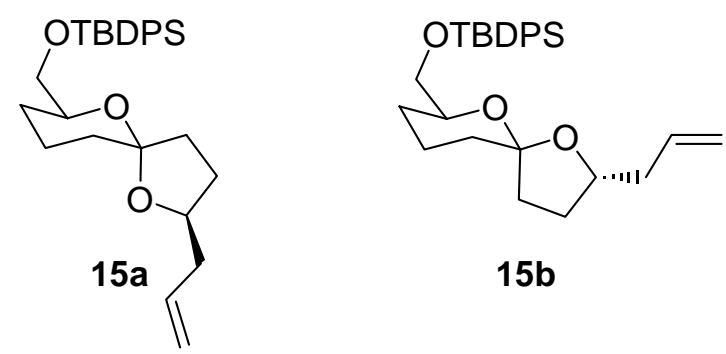

To a solution of alcohol 14a $(12.4 \mathrm{mg}, 0.025 \mathrm{mmol})$ in THF/water $(3 \mathrm{~mL})$ was added $\mathrm{Cl}_{3} \mathrm{CCOOH}$ at rt. The resulting solution was stirred at $\mathrm{rt}$ until the reaction was completed as revealed by TLC. The reaction was quenched by addition of saturated aqueous $\mathrm{NaHCO}_{3}(3 \mathrm{~mL})$ and $\mathrm{H}_{2} \mathrm{O}(3 \mathrm{~mL})$. The separated aqueous phase was extracted with EtOAc $(3 \times 5 \mathrm{~mL})$ and the combined organic phases were dried over $\mathrm{Na}_{2} \mathrm{SO}_{4}$, filtered and concentrated. The crude product was purified by flash column chromatography ( $\mathrm{SiO} 2)$ using 1:4 $\mathrm{Et}_{2} \mathrm{O} /$ hexanes as the eluent to yield fraction A: spiroketal 15a (4 $\mathrm{mg}, 35 \%)$, fraction B: spiroketal $\mathbf{1 5 b}(5.2 \mathrm{mg}, 46 \%)$.

\section{Anomeric spiroketal 15a}

$\mathrm{R}_{f}=0.82\left(1: 4 \mathrm{Et}_{2} \mathrm{O} /\right.$ hexanes, vanillin stain), $[\alpha]^{20}{ }_{\mathrm{D}}=+7.0\left(c=0.2, \mathrm{CH}_{2} \mathrm{Cl}_{2}\right) ; \mathrm{IR}$ (thin film, $\left.\mathrm{cm}^{-1}\right)$ 3054, 2987, 2305, 1551, 1422, 1269, 1251; ${ }^{1} \mathrm{H}$ NMR (acetonitrile-d $\left.\mathrm{d}_{3}, 400 \mathrm{MHz}\right) \delta$ 7.75-7.72 (m, 4H), 7.48-7.41 (m, 6H), $5.85(\mathrm{~m}, 1 \mathrm{H}), 5.13(\mathrm{dd}, 1 \mathrm{H}, J=2.0 \mathrm{~Hz}, 15.2 \mathrm{~Hz}), 5.06(\mathrm{dd}, 1 \mathrm{H}, J=2.4 \mathrm{~Hz}$, $10.4 \mathrm{~Hz}), 4.11(\mathrm{~m}, 1 \mathrm{H}), 3.88(\mathrm{~m}, 1 \mathrm{H}), 3.61(\mathrm{~d}, 2 \mathrm{H}, J=5.2 \mathrm{~Hz}), 2.32(\mathrm{ddd}, 1 \mathrm{H}, J=1.6,7.0,12.5$ $\mathrm{Hz}), 2.25(\mathrm{~m}, 2 \mathrm{H}), 1.85-1.56(\mathrm{~m}, 9 \mathrm{H}), 1.05(\mathrm{~s}, 9 \mathrm{H}) ;{ }^{13} \mathrm{C} \mathrm{NMR}$ (acetonitrile-d $\left.\mathrm{d}_{3}, 400 \mathrm{MHz}\right) \delta 135.9$, 135.7, 134.2, 130.1, 128.0, 116.4, 106.2, 77.2, 71.6, 67.9, 39.9, 37.5, 33.3, 30.0, 28.9, 27.0, 26.5, 20.2, 19.2 ppm. HRMS (ESI) calcd. For $\mathrm{C}_{28} \mathrm{H}_{38} \mathrm{O}_{3} \mathrm{NaSi}$ 473.2488, found, 473.2497 1.9 ppm.

\section{Nonanomeric spiroketal 15b}

$\mathrm{R}_{f}=0.58\left(1: 4 \mathrm{Et}_{2} \mathrm{O} /\right.$ hexanes, vanillin stain), $[\alpha]^{20}{ }_{\mathrm{D}}=-3.5\left(c=0.2, \mathrm{CH}_{2} \mathrm{Cl}_{2}\right)$; IR (thin film, $\left.\mathrm{cm}^{-1}\right)$ 3054, 2987, 2305, 1551, 1423, 1264; ${ }^{1} \mathrm{H}$ NMR (acetonitrile-d $\left.{ }_{3}, 400 \mathrm{MHz}\right) \delta$ 7.74-7.71 (m, 4H), 7.48-7.44 (m, 6H), $5.81(\mathrm{~m}, 1 \mathrm{H}), 5.04-4.95(\mathrm{~m}, 2 \mathrm{H}), 4.05-3.98(\mathrm{~m}, 1 \mathrm{H}), 3.67(\mathrm{~m}, 3 \mathrm{H}), 2.37(\mathrm{~m}, 1 \mathrm{H})$, $2.31(\mathrm{ddd}, 1 \mathrm{H}, J=1.6,7.0,12.5 \mathrm{~Hz}), 2.23(\mathrm{~m}, 1 \mathrm{H}), 1.81-1.52(\mathrm{~m}, 9 \mathrm{H}), 1.06(\mathrm{~s}, 9 \mathrm{H}) \mathrm{ppm} ;{ }^{13} \mathrm{C} \mathrm{NMR}$ (acetonitrile- $\left.\mathrm{d}_{3}, 400 \mathrm{MHz}\right) \delta 135.9,135.7,134.3,130.1,128.0,116.4,106.2,77.2,71.6,67.9,39.9$, 37.5, 33.3, 30.0, 28.9, 27.0, 26.5, 20.2, 19.2 ppm. HRMS (ESI) calcd. For $\mathrm{C}_{28} \mathrm{H}_{38} \mathrm{O}_{3} \mathrm{NaSi} 473.2497$, found $473.2492, \Delta 0.8 \mathrm{ppm}$. 


\section{Allylic alcohol 14b}

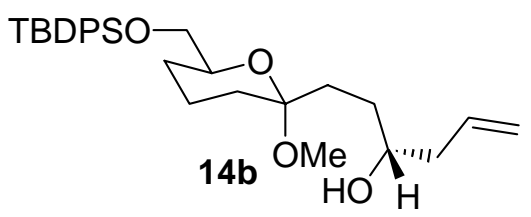

Brown's reagent (-)-B-allyldiisopinocamphenylborane was prepared according to literature procedure. ${ }^{3}$ A solution of (-)-Brown's reagent freshly prepared $(0.16 \mathrm{mmol})$ in $\operatorname{dry~}_{\mathrm{Et}} \mathrm{O}(1 \mathrm{~mL})$ was cooled at $-100{ }^{\circ} \mathrm{C}$. A solution of the aldehyde $6(74 \mathrm{mg}, 0.16 \mathrm{mmol})$ in dry $\mathrm{Et}_{2} \mathrm{O}(2 \mathrm{~mL})$ was added dropwise to the previous solution via syringe. The resulting mixture was further stirred at the same temperature for $5 \mathrm{~h}$. The reaction mixture was then quenched through addition of $\mathrm{MeOH}(3 \mathrm{~mL}), 3$ $\mathrm{N} \mathrm{NaOH}$ solution $(5 \mathrm{~mL})$ and $\mathrm{H}_{2} \mathrm{O}_{2} 30 \%(5 \mathrm{~mL})$. After being stirred overnight, the mixture was poured into saturated aqueous $\mathrm{NaHCO}_{3}$ and worked up as usual $\left(\mathrm{Et}_{2} \mathrm{O}\right)$. The crude product was purified by flash column chromatography ( $\mathrm{SiO} 2)$ using 1:5 $\mathrm{Et}_{2} \mathrm{O}$ :hexanes as the eluent to yield alcohol 14b $(78 \%, 56 \mathrm{mg})$ as a $5: 1$ mixture of diastereoisomers as revealed by ${ }^{1} \mathrm{H}$ NMR data. Spectroscopic data of major diastereoisomer are reported. Spectroscopic data of minor diastereoisomer are reported above (compound 14a).

$\mathrm{R}_{f}=0.26\left(1: 1 \mathrm{Et}_{2} \mathrm{O} /\right.$ hexanes, vanillin stain), $[\alpha]_{\mathrm{D}}^{20}=+18.8\left(c=0.6, \mathrm{CH}_{2} \mathrm{Cl}_{2}\right) ; \mathrm{IR}$ (thin film, $\left.\mathrm{cm}^{-1}\right)$ 3690, 3054, 2987, 2305, 1422, 1264; ${ }^{1} \mathrm{H}$ NMR (acetonitrile-d $\left.\mathrm{d}_{3}, 400 \mathrm{MHz}\right) \delta 7.77-7.73$ (m, 4H), 7.48-7.41 (m, 6H), $5.87(\mathrm{~m}, 1 \mathrm{H}), 5.12-5.03(\mathrm{~m}, 2 \mathrm{H}), 3.73-3.67(\mathrm{~m}, 1 \mathrm{H}), 3.63(\mathrm{~m}, 2 \mathrm{H}), 3.60-3.56(\mathrm{~m}$, $1 \mathrm{H}), 3.14(\mathrm{~s}, 3 \mathrm{H}), 2.67(\mathrm{~d}, 1 \mathrm{H}, J=4.8 \mathrm{~Hz}), 2.20(\mathrm{~m}, 2 \mathrm{H}), 1.79-1.20(\mathrm{~m}, 10 \mathrm{H}), 1.05(\mathrm{~s}, 9 \mathrm{H}) ;{ }^{13} \mathrm{C}$ NMR (acetonitrile- $\left.\mathrm{d}_{3}, 400 \mathrm{MHz}\right) \delta 136.2,135.9,134.1,130.1,128.1,116.5,99.7,71.4,70.9,67.8$, 46.8, 42.1, 32.6, 32.5, 30.8, 27.0, 26.6, 19.2, 18.8 ppm. HRMS (ESI) calcd. For $\mathrm{C}_{29} \mathrm{H}_{42} \mathrm{O}_{4} \mathrm{NaSi}$ 505.2750 , found $505.2769, \Delta 3.8 \mathrm{ppm}$. 


\section{Spiroketals 16a-b}
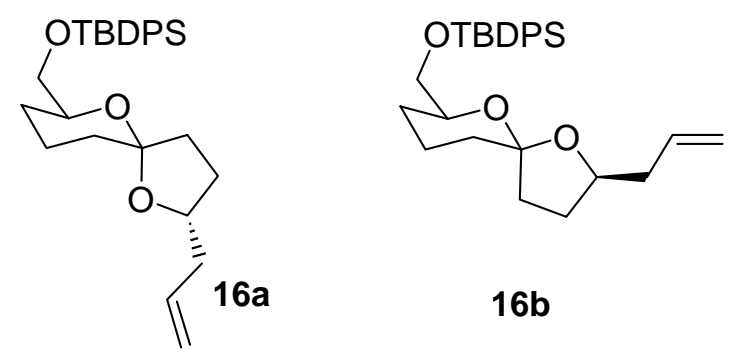

$16 b$

To a solution of alcohol 14b $(21.6 \mathrm{mg}, 0.044 \mathrm{mmol})$ in THF/water 4:1 (5 mL) was added $\mathrm{Cl}_{3} \mathrm{CCOOH}(60 \mathrm{~mol} \%)$ at $\mathrm{rt}$. The resulting solution was stirred at $\mathrm{rt}$ until the reaction was completed as revealed by TLC. The reaction was quenched by addition of saturated aqueous $\mathrm{NaHCO}_{3}(5 \mathrm{~mL})$ and $\mathrm{H}_{2} \mathrm{O}(5 \mathrm{~mL})$. The separated aqueous phase was extracted with EtOAc $(3 \times 10 \mathrm{~mL})$ and the combined organic phases were dried over $\mathrm{Na}_{2} \mathrm{SO}_{4}$, filtered and concentrated. The crude product was purified by flash column chromatography ( $\mathrm{SiO} 2)$ using 1:5 $\mathrm{Et}_{2} \mathrm{O}$ :hexanes as the eluent to yield fraction A: spiroketal 16a (8.5 mg, 43 \%), fraction B: spiroketal 16b (8 mg, 40\%).

\section{Anomeric spiroketal 16a}

$\mathrm{R}_{f}=0.71\left(1: 4 \mathrm{Et}_{2} \mathrm{O} /\right.$ hexanes, vanillin stain), $[\alpha]^{20}{ }_{\mathrm{D}}=+6.5\left(c=0.7, \mathrm{CH}_{2} \mathrm{Cl}_{2}\right) ; \mathrm{IR}$ (thin film, $\left.\mathrm{cm}^{-1}\right)$ 3054, 2987, 1604, 1421, 1264; ${ }^{1} \mathrm{H}$ NMR (acetonitrile-d $\mathrm{d}_{3}, 400 \mathrm{MHz}$ ) $\delta$ 7.77-7.73 (m, 4H), 7.47-7.41 (m, 6H), 5.85 (m, 1H), $5.05(\mathrm{dd}, 1 \mathrm{H}, J=1.0 \mathrm{~Hz}, 17.2 \mathrm{~Hz}), 5.06$ (dd, 1H, $J=1.0 \mathrm{~Hz}, 10.0 \mathrm{~Hz}), 4.11$ (qn, 1H, $J=7.0 \mathrm{~Hz}), 4.00(\mathrm{~m}, 1 \mathrm{H}), 3.60$ (d, 2H, $J=5.2 \mathrm{~Hz}), 2.49-2.45$ (m, 1H), 2.24 (m, 1H), 1.99$1.59(\mathrm{~m}, 10 \mathrm{H}), 1.05(\mathrm{~s}, 9 \mathrm{H}) ;{ }^{13} \mathrm{C} \mathrm{NMR}$ (acetonitrile-d $\left.\mathrm{d}_{3}, 400 \mathrm{MHz}\right) \delta 136.5,135.9,134.1,130.1$, 128.1, 116.0, 106.1, 80.2, 71.3, 68.1, 42.6, 38.9, 33.5, 29.8, 27.2, 26.6, 20.2, 19.2 ppm. HRMS (ESI) calcd. For $\mathrm{C}_{28} \mathrm{H}_{38} \mathrm{O}_{3} \mathrm{NaSi} 473.2488$, found 473.2478, $\Delta 2.1 \mathrm{ppm}$.

\section{Nonanomeric spiroketal 16b}

$\mathrm{R}_{f}=0.66\left(1: 4 \mathrm{Et}_{2} \mathrm{O} /\right.$ hexanes, vanillin stain), $[\alpha]^{20}{ }_{\mathrm{D}}=-4.1\left(c=0.7, \mathrm{CH}_{2} \mathrm{Cl}_{2}\right)$; IR (thin film, $\left.\mathrm{cm}^{-1}\right)$ 3054, 2987, 1551, 1421, 1263; ${ }^{1} \mathrm{H}$ NMR (acetonitrile-d $\mathrm{d}_{3}, 400 \mathrm{MHz}$ ) $\delta$ 7.73-7.71 (m, 4H), 7.48-7.41 (m, 6H), $5.80(\mathrm{~m}, 1 \mathrm{H}), 5.11-4.99(\mathrm{~m}, 2 \mathrm{H}), 4.27-4.12(\mathrm{~m}, 1 \mathrm{H}), 3.74-3.63(\mathrm{~m}, 3 \mathrm{H}), 2.26$ (obs m, 1H), $2.16(\mathrm{~m}, 2 \mathrm{H}), 1.80-1.54(\mathrm{~m}, 9 \mathrm{H}), 1.05(\mathrm{~s}, 9 \mathrm{H}) ;{ }^{13} \mathrm{C} \mathrm{NMR}$ (acetonitrile-d $\left.\mathrm{d}_{3}, 400 \mathrm{MHz}\right) \delta 135.8,135.7$, 134.2, 130.1, 128.10, 116.4, 107.7, 78.0, 74.9, 67.4, 40.0, 34.6, 33.0, 30.5, 29.0, 26.9, 26.6, 20.6, 19.2 ppm. HRMS (ESI) calcd. For $\mathrm{C}_{28} \mathrm{H}_{38} \mathrm{O}_{3} \mathrm{NaSi}$ 473.2488, found 473.2466, $\Delta 4.6 \mathrm{ppm}$. 


\section{Procedure for the equilibration studies}

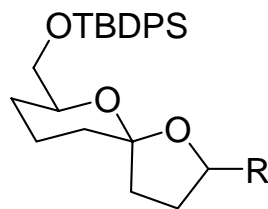

12b: $\mathrm{R}=\mathrm{H}$

13c: $\mathrm{R}=\mathrm{CH}_{2} \mathrm{OBz}$

15b: $\mathrm{R}=\mathrm{CH}_{2} \mathrm{CH}=\mathrm{CH}_{2}$

16b: $\mathrm{R}=\mathrm{CH}_{2} \mathrm{CH}=\mathrm{CH}_{2}$

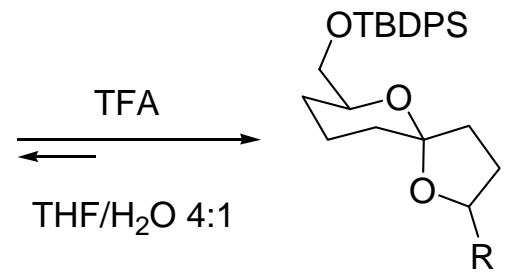

12a: $\mathrm{R}=\mathrm{H}$

13a: $\mathrm{R}=\mathrm{CH}_{2} \mathrm{OBz}$

15a: $\mathrm{R}=\mathrm{CH}_{2} \mathrm{CH}=\mathrm{CH}_{2}$

16a: $\mathrm{R}=\mathrm{CH}_{2} \mathrm{CH}=\mathrm{CH}_{2}$

To a solution of the appropriate nonanomeric spiroketal $\mathbf{1 2 b} / \mathbf{1 3 c} / \mathbf{1 5 b} / \mathbf{1 6} \mathbf{b}(0.006 \mathrm{mmol})$ in $4: 1$ THF/water $(2.5 \mathrm{~mL})$ was added TFA $(0.0072 \mathrm{mmol}, 1.2$ equiv) at $\mathrm{rt}$. The resulting solution was stirred at rt untill the conversion was completed as revealed by TLC. The reaction was quenched by addition of saturated aqueous $\mathrm{NaHCO}_{3}(2 \mathrm{~mL})$ and $\mathrm{H}_{2} \mathrm{O}(2 \mathrm{~mL})$. The separated aqueous phase was extracted with EtOAc $(3 \times 5 \mathrm{~mL})$ and the combined organic phases were dried over $\mathrm{Na}_{2} \mathrm{SO}_{4}$, filtered and concentrated, to afford the anomeric spiroketal 12a/13a/15a/16a as the only isomer. The identity was confirmed by HPTLC and ${ }^{1} \mathrm{H}$ NMR studies.

\section{Ester 18}

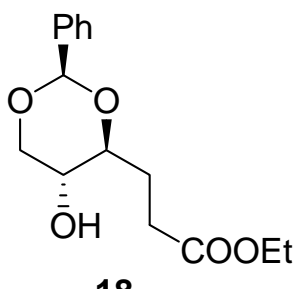

18

Alkene $17^{4}$ (900 mg, $3.25 \mathrm{mmol}$ ) was dissolved in EtOAc $(10 \mathrm{~mL})$, flushed with argon, and 10\% $\mathrm{Pd} / \mathrm{C}$ was added to the solution. The mixture was flushed with argon and then with hydrogen ( $1 \mathrm{~atm})$ and stirred at room temperature for 30 minutes. The mixture was filtered through a pad of Celite and washed with ethyl acetate. The filtrate was washed with brine $(20 \mathrm{~mL})$, dried over $\mathrm{Na}_{2} \mathrm{SO}_{4}$, filtered and concentrated, affording crude ester 18 (900 mg, 99\%) which was used in the next step without further purification.

$\mathrm{R}_{f}=0.44$ (1:1 EtOAc/hexanes, vanillin stain), $[\alpha]^{20}{ }_{\mathrm{D}}=-23.2\left(c=3.6, \mathrm{CH}_{2} \mathrm{Cl}_{2}\right)$; IR (thin film, $\left.\mathrm{cm}^{-1}\right)$ 3430, 1725, 1442; ${ }^{1} \mathrm{H}$ NMR $\left(\mathrm{CDCl}_{3}, 400 \mathrm{MHz}\right) \delta$ 7.50-7.46 (m, 2H), 7.44-7.33 (m, 3H), 5.49 (s, 1H), 4.33-4.27 (m, 1H), 4.16 (q, 2H, $J=7.1 \mathrm{~Hz}), 3.65-3.54(\mathrm{~m}, 3 \mathrm{H}), 2.97$ (br s, $1 \mathrm{H}), 2.65$ (dt, 1H, $J$ $=7.0,17.0 \mathrm{~Hz}), 2.54-2.46(\mathrm{dt}, 1 \mathrm{H}, J=7.0,17.0 \mathrm{~Hz}), 2.28-2.20(\mathrm{~m}, 1 \mathrm{H}), 2.06-1.92(\operatorname{app}$ sextet, $1 \mathrm{H}$, $J=7.0 \mathrm{~Hz}), 1.27(\mathrm{t}, 3 \mathrm{H}, \mathrm{J}=7.1 \mathrm{~Hz}) \mathrm{ppm} ;{ }^{13} \mathrm{C} \mathrm{NMR}\left(\mathrm{CDCl}_{3}, 400 \mathrm{MHz}\right) \delta 175.0,138.1,129.3$, 
128.6, 126.5, 101.3, 81.3, 71.4, 65.4, 61.1, 29.6, 26.7, 14.5 ppm. HRMS (ESI) calcd. For $\mathrm{C}_{15} \mathrm{H}_{20} \mathrm{O}_{5} \mathrm{Na} 303.1208$, found 303.1200, $\Delta 2.9 \mathrm{ppm}$.

\section{Lactone 19}<smiles>O=C1CCC2OC(c3ccccc3)OCC2O1</smiles>

A solution of ester $18(700 \mathrm{mg}, 2.5 \mathrm{mmol})$ in a mixture of THF $(10 \mathrm{~mL})$ and $1 \mathrm{M}$ aqueous $\mathrm{NaOH}$ $(15 \mathrm{~mL})$ was stirred for $1 \mathrm{~h}$. The solution was acidified to $\mathrm{pH} 2$ by addition of $1 \mathrm{M}$ aqueous $\mathrm{HCl}$, diluted with $\mathrm{H}_{2} \mathrm{O}(10 \mathrm{~mL})$, and extracted with EtOAc $(20 \mathrm{~mL}$ x 3). The combined organic phases were dried $\left(\mathrm{Na}_{2} \mathrm{SO}_{4}\right)$ and concentrated to afford a crude carboxylic acid that was used immediately in the next step.

A solution of the carboxylic acid (obtained above) in pyridine $(10 \mathrm{~mL})$ was stirred in the presence of DCC (642 mg, $3.12 \mathrm{mmol})$ and a catalytic amount of DMAP for $12 \mathrm{~h}$ and then concentrated in vacuo. The crude product was purified by flash column chromatography $\left(\mathrm{SiO}_{2}\right)$ using 1:4 EtOAc/hexanes as the eluent to yield lactone $19(73 \%, 427 \mathrm{mg})$.

$\mathrm{R}_{f}=0.41(2: 3 \mathrm{EtOAc} /$ hexanes, vanillin stain $),[\alpha]^{20}{ }_{\mathrm{D}}=+30.6\left(c=2.2, \mathrm{CH}_{2} \mathrm{Cl}_{2}\right) ; \mathrm{IR}$ (thin film, $\left.\mathrm{cm}^{-1}\right)$ 3690, 3054, 2980, 2868, 2306, 1422, 1265; ${ }^{1} \mathrm{H}$ NMR $\left(\mathrm{CDCl}_{3}, 400 \mathrm{MHz}\right) \delta$ 7.52-7.49 (m, 2H), 7.43$7.39(\mathrm{~m}, 3 \mathrm{H}), 5.59(\mathrm{~s}, 1 \mathrm{H}), 4.45-4.41(\mathrm{dd}, 1 \mathrm{H}, J=5.0,10.6 \mathrm{~Hz}), 4.26-4.20(\mathrm{~m}, 1 \mathrm{H}), 3.89-3.79(\mathrm{~m}$, 2H), 2.91-2.83 (ddd, 1H, $J=4.2,9.3,13.6 \mathrm{~Hz}), 2.74-2.66(\mathrm{~m}, 1 \mathrm{H}), 2.31-2.21(\mathrm{~m}, 1 \mathrm{H}), 2.09-2.01(\mathrm{~m}$, 1H) ppm; ${ }^{13} \mathrm{C} \mathrm{NMR}\left(\mathrm{CDCl}_{3}, 400 \mathrm{MHz}\right) \delta 169.8,137.1,129.7,128.8,126.5,102.2,75.0,71.8,68.9$, 28.2, 24.7 ppm. HRMS (ESI) calcd. For $\mathrm{C}_{13} \mathrm{H}_{14} \mathrm{O}_{4} \mathrm{Na} 257.0790$, found 257.0793, $\Delta 1.2 \mathrm{ppm}$.

\section{Ketoalcohol 20}<smiles>C=CCCC(=O)CC[C@H]1O[C@@H](c2ccccc2)OC[C@H]1O</smiles> 
To a stirred solution of Mg powder (248 mg, $10.3 \mathrm{mmol}$ ) in THF (15 mL) was added 4-bromo-1butene $(1 \mathrm{~mL}, 10.3 \mathrm{mmol})$. Heat was evolved and the formation of the Grignard reagent was evident from the darkening of the reaction mixture. After $1 \mathrm{~h}$, the solution of the Grignard reagent prepared above was added dropwise to a $-78^{\circ} \mathrm{C}$ solution of the lactone 19 (440 $\left.\mathrm{mg}, 1.88 \mathrm{mmol}\right)$ in THF (15 $\mathrm{mL}$ ). The resulting solution was stirred at $-78{ }^{\circ} \mathrm{C}$ for additional $1 \mathrm{~h}$ and $15 \mathrm{~min}$. Then, saturated aqueous $\mathrm{NH}_{4} \mathrm{Cl}(20 \mathrm{~mL})$ and $\mathrm{H}_{2} \mathrm{O}(15 \mathrm{~mL})$ were added. The mixture was warmed to $\mathrm{rt}$ and then extracted with $\mathrm{Et}_{2} \mathrm{O}(3 \times 50 \mathrm{~mL})$. The combined organic phases were dried over $\mathrm{MgSO}_{4}$, filtered and concentrated. The crude product was purified by flash column chromatography $\left(\mathrm{SiO}_{2}\right)$ using $1: 2$ EtOAc/hexanes as the eluent to yield ketoalcohol $20(354 \mathrm{mg}, 65 \%)$ as a pale yellow oil.

$\mathrm{R}_{f}=0.43\left(1: 1 \mathrm{Et}_{2} \mathrm{O} /\right.$ hexanes, vanillin stain), $[\alpha]^{20}=-4.4\left(c=3.2, \mathrm{CH}_{2} \mathrm{Cl}_{2}\right)$; IR (thin film, $\left.\mathrm{cm}^{-1}\right)$ 3430, 3054, 2986, 2305, 1732, 1421, 1264; ${ }^{1} \mathrm{H} \mathrm{NMR}\left(\mathrm{CDCl}_{3}, 400 \mathrm{MHz}\right) \delta$ 7.49-7.47 (m, 2H), 7.39$7.28(\mathrm{~m}, 3 \mathrm{H}), 5.91-5.74(\mathrm{~m}, 1 \mathrm{H}), 5.47(\mathrm{~s}, 1 \mathrm{H}), 5.10-4.99(\mathrm{~m}, 2 \mathrm{H}), 4.29-4.26(\mathrm{dd}, 1 \mathrm{H}, J=5.0,10.6$ Hz), 3.71-3.58 (m, 2H), 3.51-3.47 (m, 1H), 3.19 (br s, 1H), 2.82-2.74 (m, 1H), 2.69-2.56 (m, 3H), 2.41-2.31 (m, 2H), 2.28-2.11 (m, 1H), 2.04-1.93 (m, 1H) ppm; ${ }^{13} \mathrm{C} \mathrm{NMR}\left(\mathrm{CDCl}_{3}, 400 \mathrm{MHz}\right) \delta$ 212.0, 138.2, 137.2, 129.3, 128.6, 126.5, 115.8, 101.4, 81.4, 71.4, 65.3, 42.2, 38.0, 28.1, 25.1 ppm. HRMS (ESI) calcd. For $\mathrm{C}_{17} \mathrm{H}_{22} \mathrm{O}_{4} \mathrm{Na} 313.1416$, found 313.1426, $\Delta 3.3 \mathrm{ppm}$.

\section{Ketal 21}

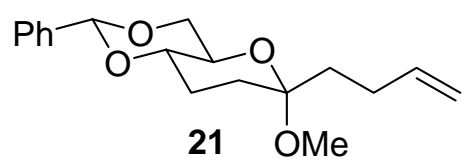

To a stirred solution of ketoalcohol $20(250 \mathrm{mg}, 0.86 \mathrm{mmol})$ in methanol $(20 \mathrm{~mL})$ at $\mathrm{rt}$ was added pyridinium $p$-toluenesulfonate $(46 \mathrm{mg}, 0.17 \mathrm{mmol})$. The resulting solution was stirred for $3 \mathrm{~h}$ and then saturated aqueous $\mathrm{NaHCO}_{3}(20 \mathrm{~mL})$ and $\mathrm{H}_{2} \mathrm{O}(10 \mathrm{~mL})$ were added. The separated aqueous phase was further extracted with EtOAc $(3 \times 50 \mathrm{~mL})$ and the combined organic phases were dried over $\mathrm{MgSO}_{4}$, filtered and concentrated. The crude product was purified by flash column chromatography $\left(\mathrm{SiO}_{2}\right)$ using 1:3 EtOAc/hexanes as the eluent to yield the ketal 21 (57.5 mg, $22 \%)^{*}$ as a $\tan$ oil.

$\mathrm{R}_{f}=0.92(1: 1 \mathrm{EtOAc} /$ hexanes, vanillin stain $),[\alpha]^{20}{ }_{\mathrm{D}}=+30.0\left(c=2.4, \mathrm{CH}_{2} \mathrm{Cl}_{2}\right) ; \mathrm{IR}$ (thin film, $\left.\mathrm{cm}^{-1}\right)$ 3050, 2859, 1424, 1110; ${ }^{1} \mathrm{H}$ NMR $\left(\mathrm{CDCl}_{3}, 400 \mathrm{MHz}\right) \delta 7.53-7.51(\mathrm{~m}, 2 \mathrm{H}), 7.40-7.35$ (m, 3H), 5.91-

\footnotetext{
* The low yield in the preparation of $\mathbf{2 1}$ is likely a result of considerable acetal hydrolysis that accompanies the ketal formation. Attempts at improving the yield by introducing benzaldehyde dimethyl acetal to the reaction mixture or the use of trimethyl orthoformate as the ketalization reagent failed to improve the yield.
} 
$5.81(\mathrm{~m}, 1 \mathrm{H}), 5.58(\mathrm{~s}, 1 \mathrm{H}), 5.07(\mathrm{dd}, 1 \mathrm{H}, J=1.5,17.2 \mathrm{~Hz}), 5.00(\mathrm{dd}, 1 \mathrm{H}, J=1.4,10.2 \mathrm{~Hz}), 4.27-$ $4.21(\mathrm{~m}, 1 \mathrm{H}), 3.77-3.69(\mathrm{~m}, 2 \mathrm{H}), 3.59-3.53(\mathrm{~m}, 1 \mathrm{H}), 3.23(\mathrm{~s}, 3 \mathrm{H}), 2.12-1.98(\mathrm{~m}, 4 \mathrm{H}), 1.94-1.83(\mathrm{~m}$, 2H), $1.67(\mathrm{dd}, 1 \mathrm{H}, J=4.6,14.5 \mathrm{~Hz}), 1.58(\mathrm{ddd}, 1 \mathrm{H}, J=3.8,10.4,14.5 \mathrm{~Hz}) ;{ }^{13} \mathrm{C} \mathrm{NMR}\left(\mathrm{CDCl}_{3}, 400\right.$ MHz) $\delta 138.3,138.1,129.4,128.7,126.5,114.9,102.2,100.0,78.8,70.0,66.4,47.8,34.9,32.8$, 28.1, 24.9 ppm. HRMS (ESI) calcd. For $\mathrm{C}_{18} \mathrm{H}_{24} \mathrm{O}_{4} \mathrm{Na} 327.1572$, found 327.1572, $\Delta 0.1 \mathrm{ppm}$.

\section{Diol S3 via AD}

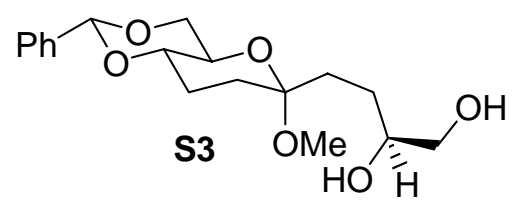

Ketal 21 (35 mg, $0.11 \mathrm{mmol}$ ) was dissolved in 1:1 tert-butyl alcohol/water $(4: 4 \mathrm{~mL})$ and the solution was cooled at $0{ }^{\circ} \mathrm{C}$. AD-mix $\alpha(165 \mathrm{mg})$ and $\mathrm{CH}_{3} \mathrm{SO}_{2} \mathrm{NH}_{2}(11.4 \mathrm{mg}, 0.11 \mathrm{mmol})$ were slowly added and the mixture was stirred at the same temperature for $2 \mathrm{~h}$. Then the mixture was allowed to warm to $\mathrm{rt}$ and stirring was continued for $15 \mathrm{~h}$ before $\mathrm{Na}_{2} \mathrm{SO}_{3}$ was added. The resulting mixture was stirred vigorously for additional $30 \mathrm{~min}$ and then diluted with EtOAc $(10 \mathrm{~mL})$. Separated aqueous phases were washed with $\mathrm{H}_{2} \mathrm{O}(10 \mathrm{~mL})$, dried over $\mathrm{MgSO}_{4}$, filtered and concentrated. The crude product S3 was immediately used in the next step without further purification.

$\mathrm{R}_{f}=0.13$ (1:1 EtOAc/hexanes, vanillin stain), ${ }^{1} \mathrm{H}$ NMR (acetonitrile- $\left.\mathrm{d}_{3}, 400 \mathrm{MHz}\right) \delta 7.48-7.44(\mathrm{~m}$, 2H), 7.41-7.38 (m, 3H), $5.60(\mathrm{~s}, 1 \mathrm{H}), 4.17-4.07(\mathrm{~m}, 1 \mathrm{H}), 3.71-3.68(\mathrm{~m}, 1 \mathrm{H}), 3.66-3.48(\mathrm{~m}, 3 \mathrm{H})$, 3.36-3.34 (m, 2H), 3.19 (s, 3H), 2.91 (br s, 1H), 2.77 (br s, 1H), 1.93-1.58 (m, 5H), 1.49-1.24 (m, $3 \mathrm{H}) \mathrm{ppm} ;{ }^{13} \mathrm{C}$ NMR (acetonitrile-d $\left.\mathrm{d}_{3}, 400 \mathrm{MHz}\right) \delta 160.4,138.7,129.2,128.8,128.7,128.5,126.9$, 126.6, 101.8, 100.2, 100.1, 78.4, 72.0, 69.5, 66.5, 66.4, 66.4, 47.2, 47.1, 32.4, 31.7, 27.5, 27.5, 24.8 ppm.

\section{Benzoate 22}

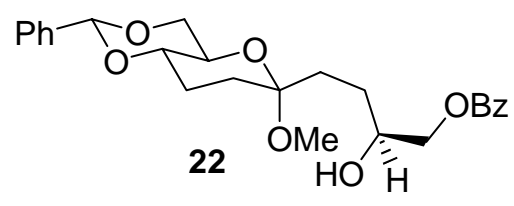


To a stirred solution of crude dihydroxyketal S3 $(0.11 \mathrm{mmol})$ in pyridine $(3.0 \mathrm{~mL})$ at $0{ }^{\circ} \mathrm{C}$ was added benzoyl chloride $(12.3 \mu \mathrm{L}, 0.11 \mathrm{mmol})$. The resulting solution was stirred at $0{ }^{\circ} \mathrm{C}$ for additional $1 \mathrm{~h}$. Aqueous saturated $\mathrm{NaHCO}_{3}(3 \mathrm{~mL})$ and $\mathrm{H}_{2} \mathrm{O}(5 \mathrm{~mL})$ were added and the phases were separated. The aqueous phase was extracted with EtOAc $(3 \times 10 \mathrm{~mL})$ and the combined organic phases were washed with $\mathrm{H}_{2} \mathrm{O}(5 \mathrm{~mL})$, dried over $\mathrm{MgSO}_{4}$, filtered and concentrated. The crude product was purified by flash column chromatography $\left(\mathrm{SiO}_{2}\right)$ using 1:3 EtOAc/hexanes as the eluent to yield benzoate 22 ( $25 \mathrm{mg}, 52 \%$ over 2 steps) as a tan, viscous oil.

$\mathrm{R}_{f}=0.60$ (1:1 EtOAc/hexanes, vanillin stain), $d r 1: 2.5 ;[\alpha]^{20}{ }_{\mathrm{D}}=+20.8\left(c=1.0, \mathrm{CH}_{2} \mathrm{Cl}_{2}\right)$; IR (thin film, $\mathrm{cm}^{-1}$ ) 3691, 3054, 2986, 2305, 1720, 1602, 1421, 1263; ${ }^{1} \mathrm{H}$ NMR (acetonitrile-d $\left.\mathrm{d}_{3}, 400 \mathrm{MHz}\right) \delta$ 8.09-8.07 (m, 2H), 7.68-7.62 (m, 1H), 7.55-7.52 (m, 2H), 7.48-7.43 (m, 2H), 7.42-7.34 (m, $3 \mathrm{H})$, 5.59 (s, 1H), 4.31-4.27 (m, $1 \mathrm{H}), 4.23-4.19(\mathrm{~m}, 1 \mathrm{H}), 4.18-4.13(\mathrm{~m}, 1 \mathrm{H}), 3.88$ (br s, $1 \mathrm{H}), 3.71-3.64$ $(\mathrm{m}, 1 \mathrm{H}), 3.63-3.53(\mathrm{~m}, 2 \mathrm{H}), 3.26-3.23(\mathrm{~m}, 1 \mathrm{H}), 3.21(\mathrm{~s}, 3 \mathrm{H}), 1.93-1.91(\mathrm{~m}, 1 \mathrm{H}), 1.88-1.68(\mathrm{~m}$, $2 \mathrm{H}), 1.67-1.41(\mathrm{~m}, 5 \mathrm{H}) \mathrm{ppm}$; in addition, the following signals due to the minor isomer 22b were observed: 7.78-7.74 (m, 2H), $5.60(\mathrm{~s}, 1 \mathrm{H}), 3.19$ (s, 3H) ppm; ${ }^{13} \mathrm{C}$ NMR (acetonitrile-d $\left.\mathrm{d}_{3}, 100 \mathrm{MHz}\right) \delta$ .160.3, 138.7, 133.5, 130.7, 129.7, 129.1, 128.9, 128.5, 126.6, 101.8, 100.0, 78.4, 69.5, 69.3, 69.0, $66.5,47.1,32.4,31.6,27.7,24.8 \mathrm{ppm}$; in addition, the following signals due to the minor isomer 22b were observed: 127.0, 100.1, 69.2, 69.0, 47.2 ppm. HRMS (ESI) calcd. for $\mathrm{C}_{25} \mathrm{H}_{30} \mathrm{O}_{7} \mathrm{Na}$ 465.1889, found $465.1886, \Delta 0.8 \mathrm{ppm}$.

\section{Synthesis of spiroketals 23}
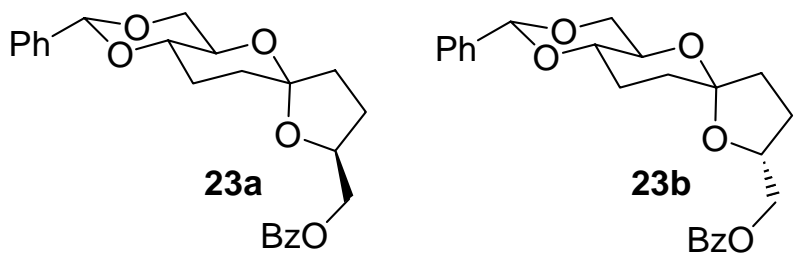

To a solution of alcohol $22(15 \mathrm{mg}, 0.033 \mathrm{mmol})$ in $\mathrm{CH}_{3} \mathrm{CN} /$ water $4: 1(3 \mathrm{~mL})$ was added $\mathrm{Cl}_{3} \mathrm{CCOOH}(60 \mathrm{~mol} \%, 0.02 \mathrm{mmol})$ at $\mathrm{rt}$. The resulting solution was stirred at $\mathrm{rt}$ until the reaction was completed as revealed by TLC. The reaction was quenched by addition of saturated aqueous $\mathrm{NaHCO}_{3}(3 \mathrm{~mL})$ and $\mathrm{H}_{2} \mathrm{O}(3 \mathrm{~mL})$. The separated aqueous phase was extracted with EtOAc $(3 \times 5$ $\mathrm{mL}$ ) and the combined organic phases were dried over $\mathrm{Na}_{2} \mathrm{SO}_{4}$, filtered and concentrated. The crude product was purified by flash column chromatography $\left(\mathrm{SiO}_{2}\right)$ using 1:4 $\mathrm{Et}_{2} \mathrm{O} /$ hexanes as the eluent to yield fraction A: spiroketal 23a (7.3 mg, 54\%), fraction B: spiroketal 23b (3mg, 22\%). 


\section{Anomeric spiroketal 23a}

$\mathrm{R}_{f}=0.55\left(2: 3 \mathrm{Et}_{2} \mathrm{O} /\right.$ hexanes, vanillin stain), $[\alpha]^{20}{ }_{\mathrm{D}}=+30.9\left(c=0.4, \mathrm{CH}_{2} \mathrm{Cl}_{2}\right) ; \mathrm{IR}$ (thin film, $\left.\mathrm{cm}^{-1}\right)$ 3691, 3054, 29867, 2305, 1719, 1551, 1421, 1264; ${ }^{1} \mathrm{H}$ NMR (acetonitrile-d $\mathrm{d}_{3}, 400 \mathrm{MHz}$ ) $\delta 8.09-8.03$ $(\mathrm{d}, 2 \mathrm{H}, J=8.0 \mathrm{~Hz}), 7.68-7.62(\mathrm{~m}, 1 \mathrm{H}), 7.56-7.50(\mathrm{~m}, 2 \mathrm{H}), 7.48-7.44(\mathrm{~m}, 2 \mathrm{H}), 7.40-7.37$ (m, 3H), $5.60(\mathrm{~s}, 1 \mathrm{H}), 4.51-4.46(\mathrm{~m}, 1 \mathrm{H}), 4.44-4.40(\mathrm{dd}, 1 \mathrm{H}, J=3.6,11.5 \mathrm{~Hz}), 4.34-4.29(\mathrm{dd}, 1 \mathrm{H}, J=5.3$, $11.4 \mathrm{~Hz}$ ), 4.14-4.10 (dd, 1H, $J=4.7,10.0 \mathrm{~Hz}$ ), 3.83-3.77 (ddd, 1H, J = 4.8, 9.4, $10.0 \mathrm{~Hz}$ ), 3.69-3.64 $(\mathrm{dd}, 1 \mathrm{H}, J=10.0,10.0 \mathrm{~Hz}), 3.62-3.56(\mathrm{~m}, 1 \mathrm{H}), 2.22-2.13(\mathrm{~m}, 2 \mathrm{H}), 2.03-1.84(\mathrm{~m}, 6 \mathrm{H}) \mathrm{ppm} ;{ }^{13} \mathrm{C}$ NMR (acetonitrile- $\left.\mathrm{d}_{3}, 400 \mathrm{MHz}\right) \delta 166.5,138.7,135.9,133.5,129.7,129.1,129.0,128.5,126.6$, 107.0, 101.8, 78.3, 76.6, 69.6, 66.9, 66.7, 36.9, 32.8, 26.2, 26.0 ppm. HRMS (ESI) calcd. For $\mathrm{C}_{24} \mathrm{H}_{26} \mathrm{O}_{6} \mathrm{Na} 433.1627$, found 433.1635, $\Delta 1.8 \mathrm{ppm}$.

\section{Anomeric spiroketal 23b}

$\mathrm{R}_{f}=0.48\left(2: 3 \mathrm{Et}_{2} \mathrm{O} /\right.$ hexanes, vanillin stain), $[\alpha]^{20}{ }_{\mathrm{D}}=+31.2\left(c=0.2 \mathrm{CH}_{2} \mathrm{Cl}_{2}\right)$; IR (thin film, $\left.\mathrm{cm}^{-1}\right)$ 3692, 3054, 2987, 2686, 2305, 1717, 1551, 1422, 1265; ${ }^{1} \mathrm{H}$ NMR (acetonitrile-d $\mathrm{d}_{3}, 400 \mathrm{MHz}$ ) $\delta 8.09$ $8.07(\mathrm{~d}, 2 \mathrm{H}, J=9.1 \mathrm{~Hz}), 7.68-7.64(\mathrm{~m}, 1 \mathrm{H}), 7.56-7.50(\mathrm{~m}, 2 \mathrm{H}), 7.41-7.36(\mathrm{~m}, 5 \mathrm{H}), 5.56(\mathrm{~s}, 1 \mathrm{H})$, 4.54-4.48 (m, 1H), 4.45-4.41 (dd, 1H, $J=3.8,11.5 \mathrm{~Hz}), 4.34-4.30$ (dd, 1H, J=4.1, $11.6 \mathrm{~Hz}), 3.93-$ 3.89 (dd, 1H, $J=4.8,9.9$ Hz), 3.81-3.75 (m, 1H), 3.60-3.53 (m, 2H), 2.13-2.07 (m, 2H), 2.01-1.83 $(\mathrm{m}, 6 \mathrm{H}) \mathrm{ppm} ;{ }^{13} \mathrm{C}$ NMR (acetonitrile-d $\left.\mathrm{d}_{3}, 400 \mathrm{MHz}\right) \delta 166.6,138.8,133.6,130.7,129.7,129.1$, $129.0,128.4,126.5,106.6,101.6,78.8,78.3,69.4,68.0,66.7,37.7,33.0,26.3,26.2$ ppm. HRMS (ESI) calcd. For $\mathrm{C}_{24} \mathrm{H}_{26} \mathrm{O}_{6} \mathrm{Na} 433.1627$, found 433.1608, $\Delta 4.3 \mathrm{ppm}$.

\section{Diagnostic 2D-NOESY cross-peaks observed for the spiroketalization products}

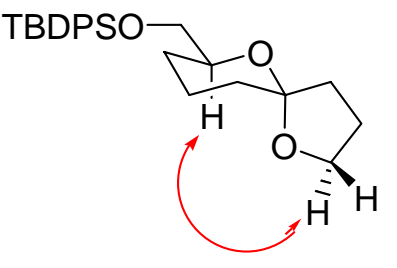

$12 a$

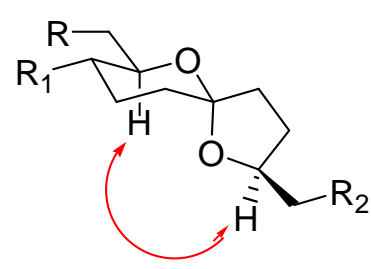

13a, 15a, 23a

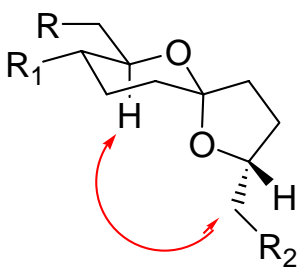

13b, 16a, 23b

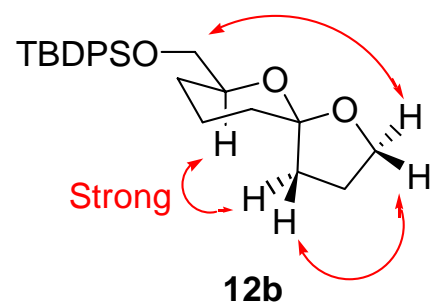

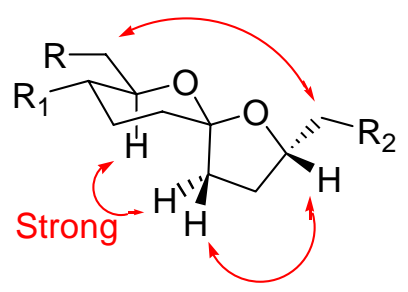

13c, 15b

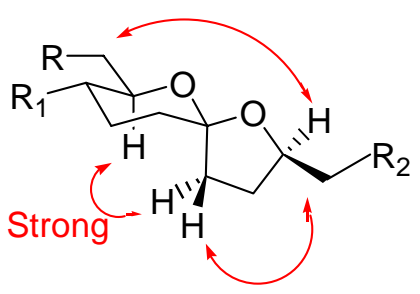

16b 


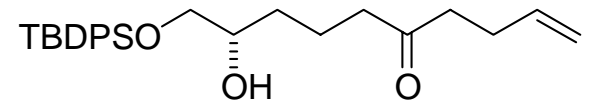

3

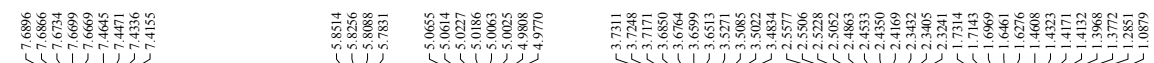
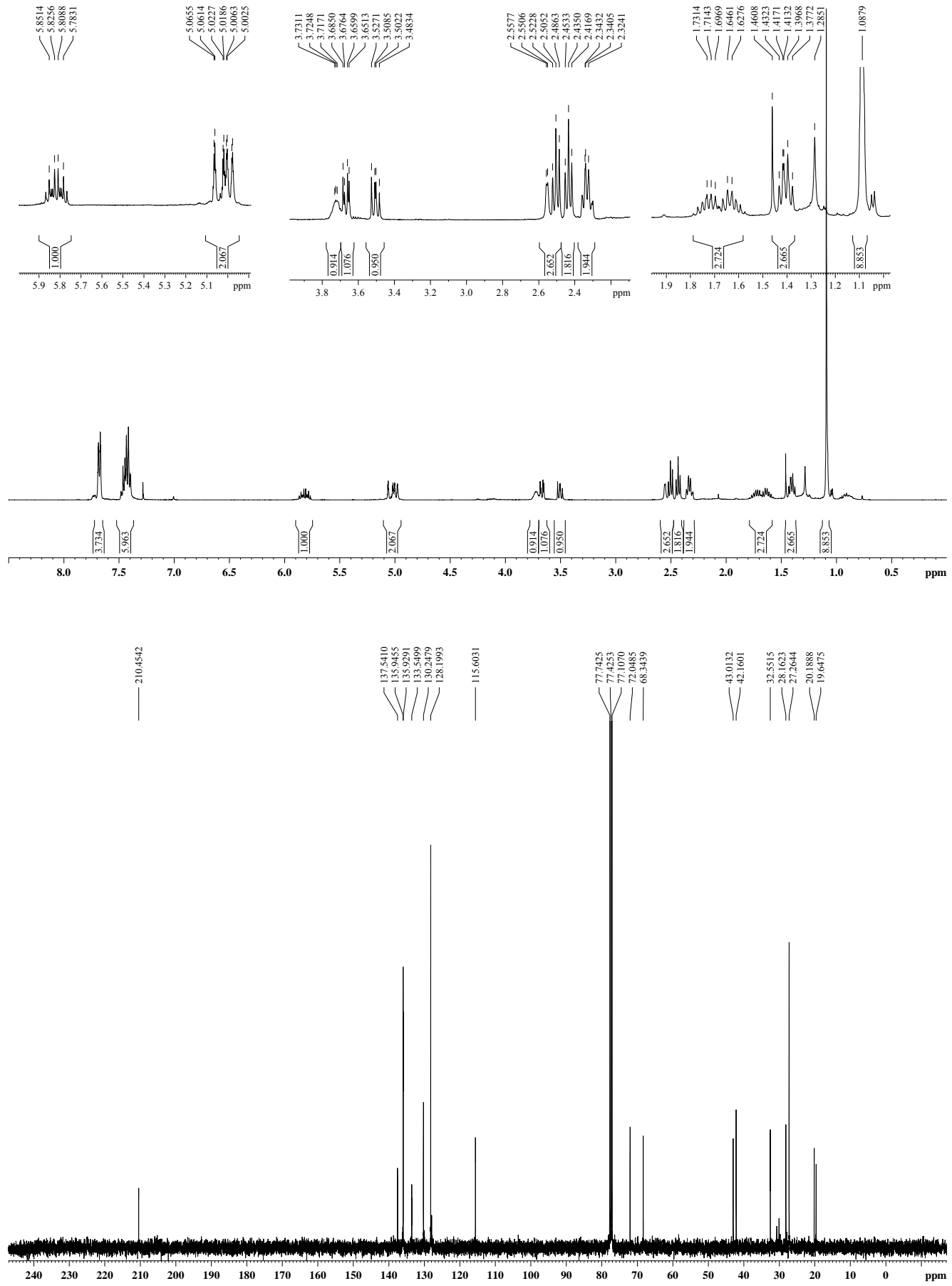


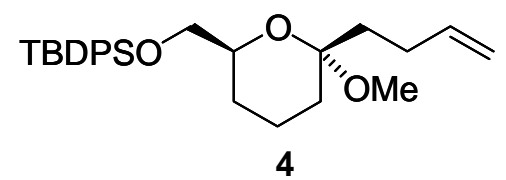

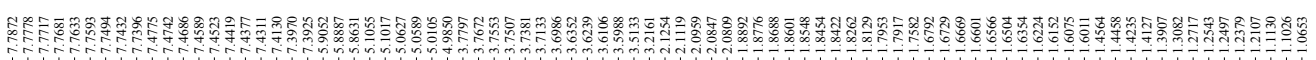

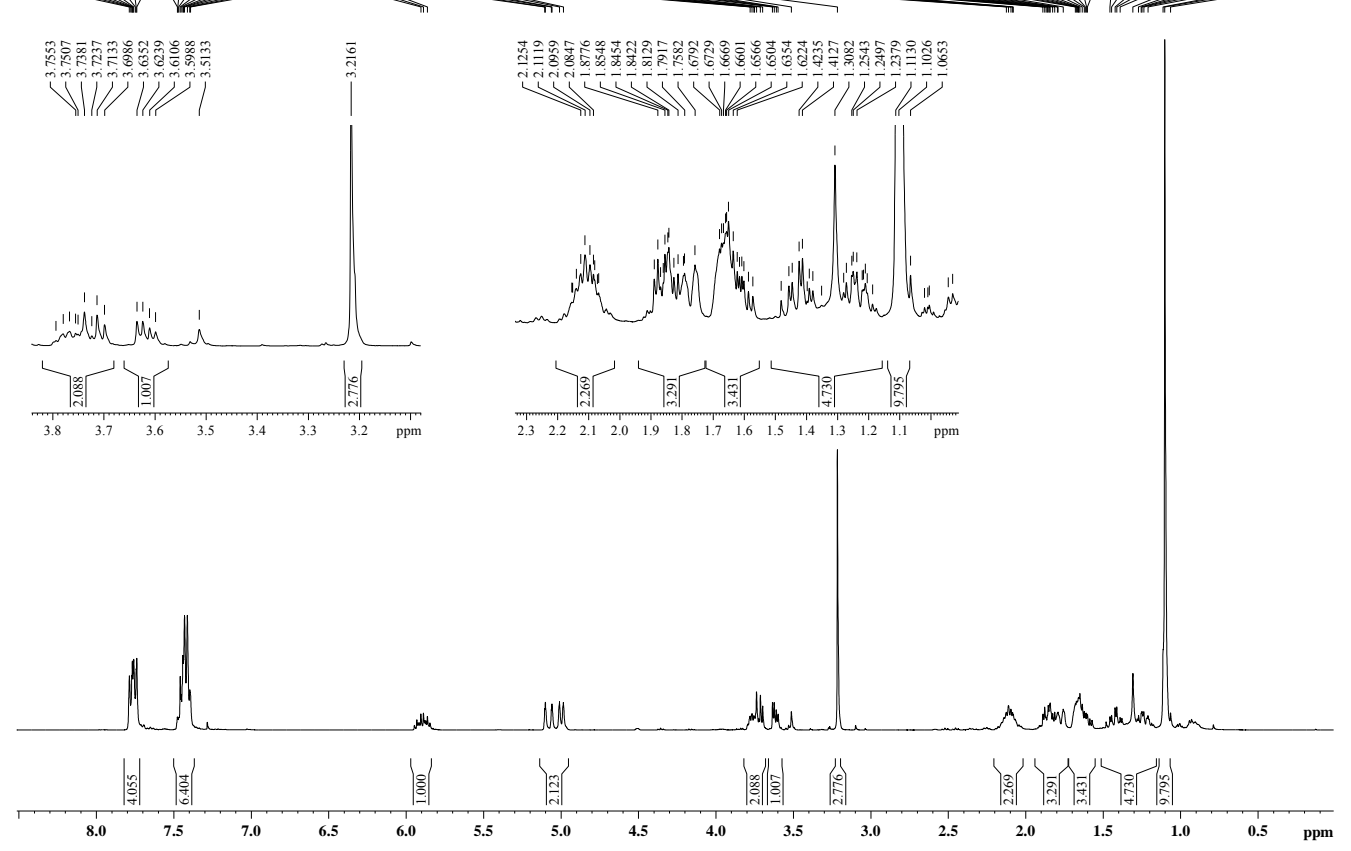

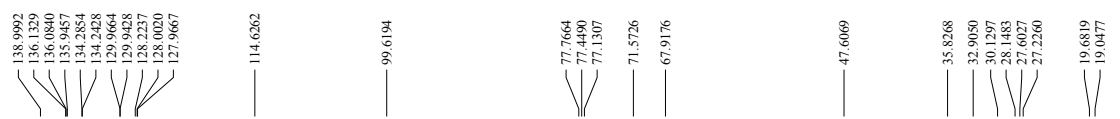

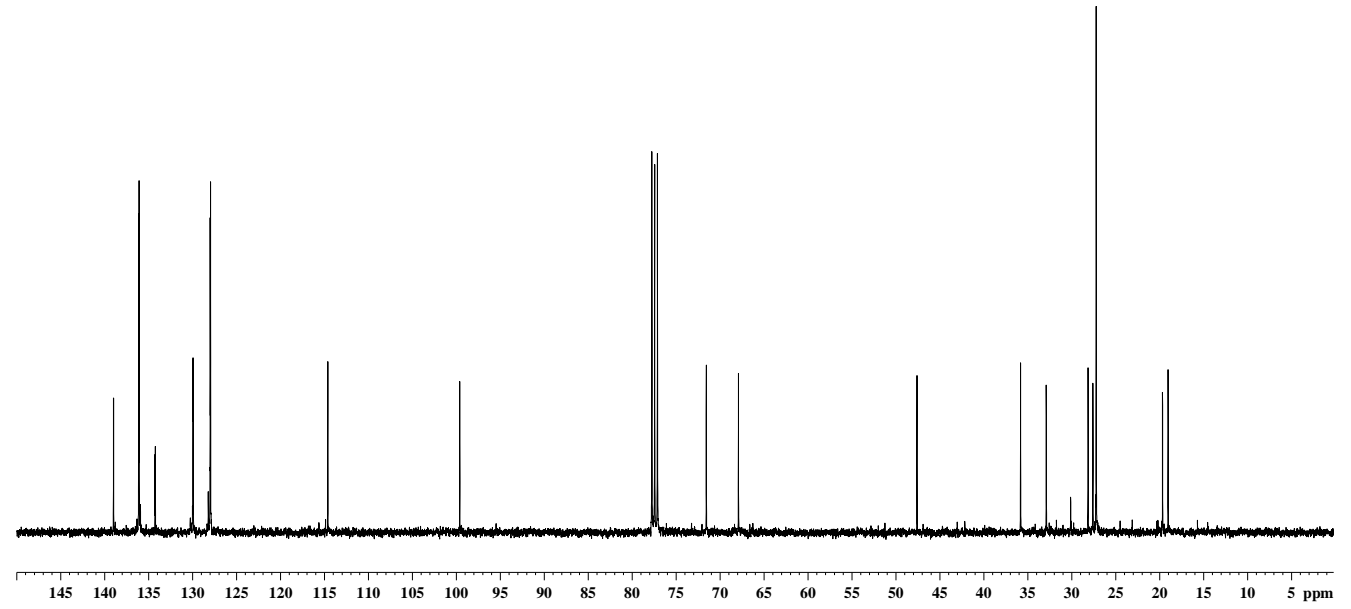




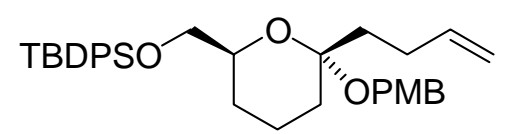

5

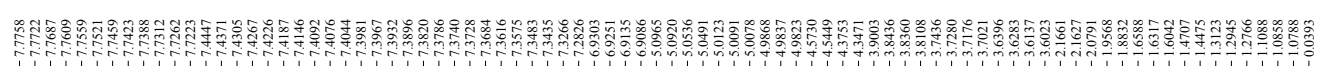

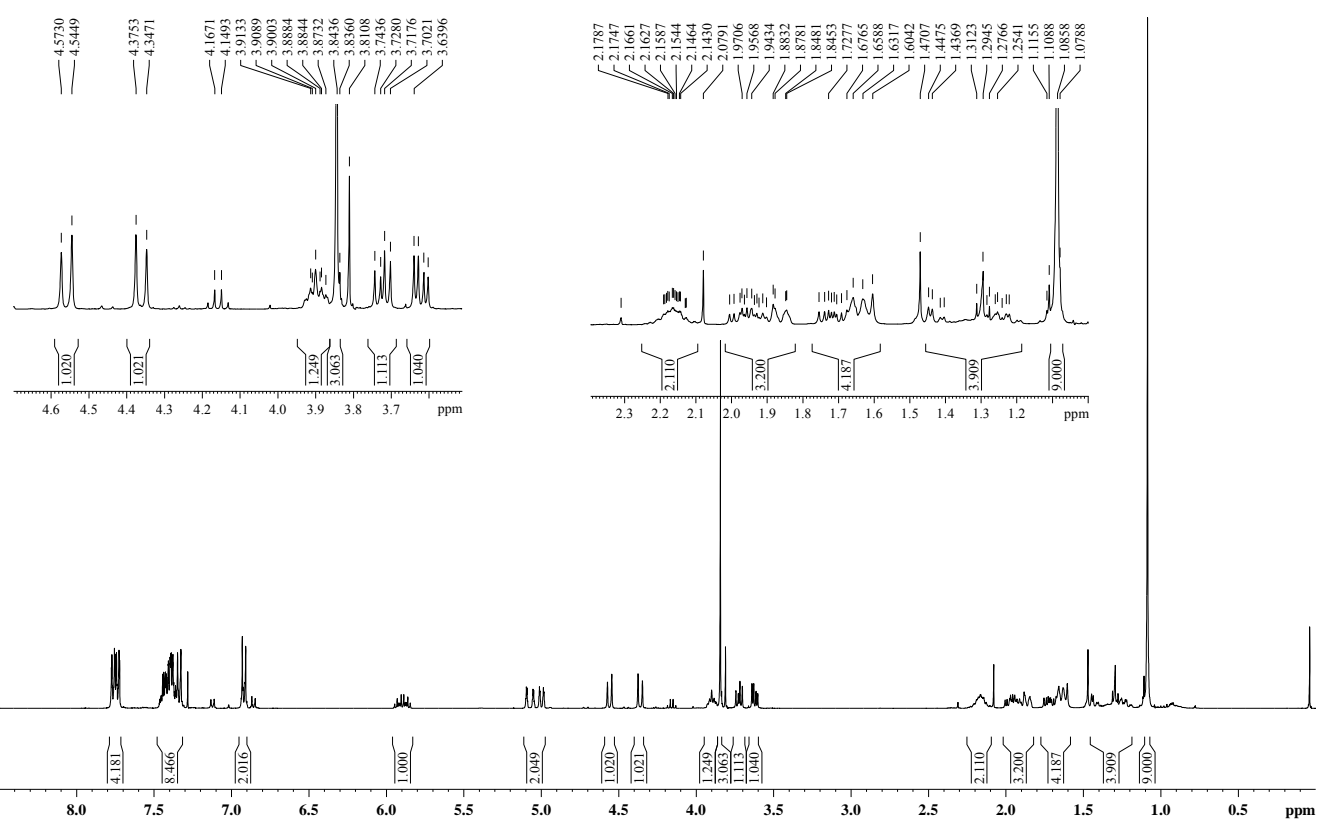

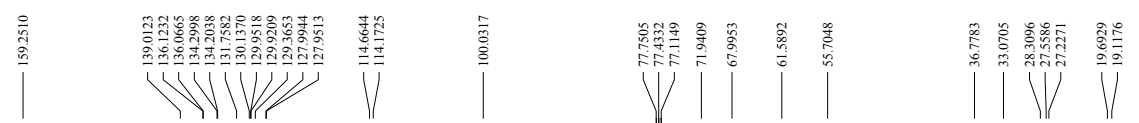

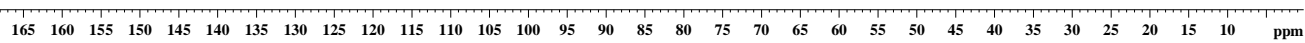




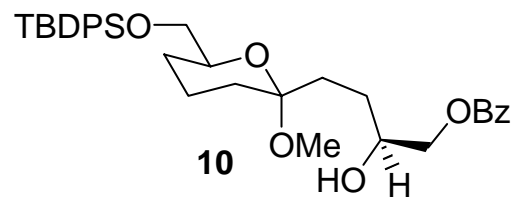

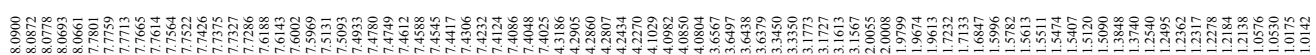
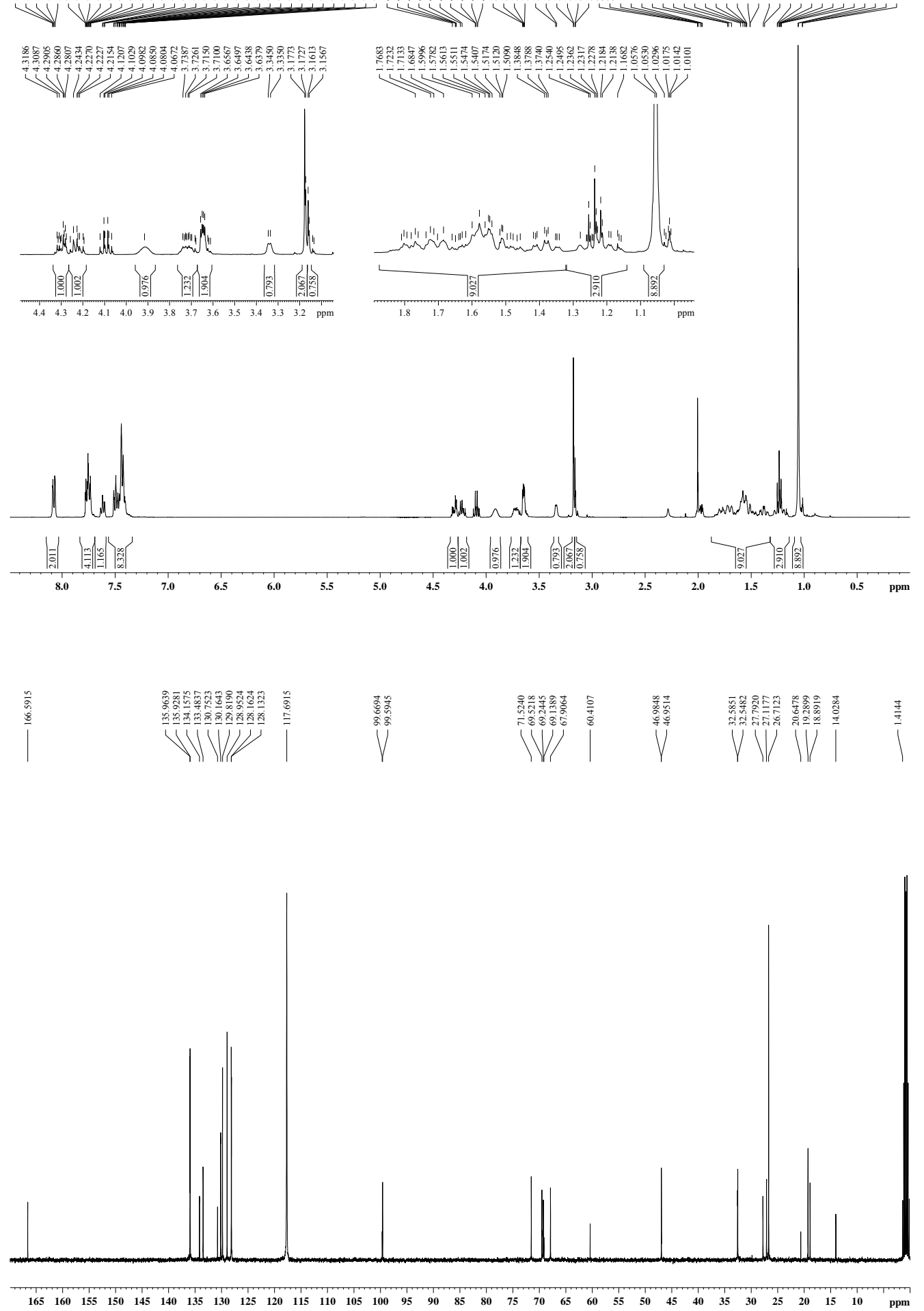


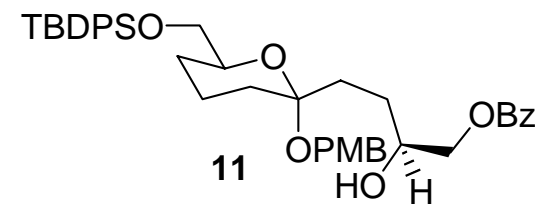

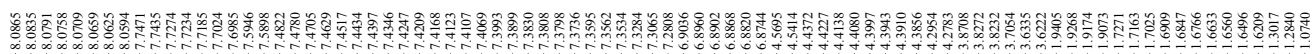
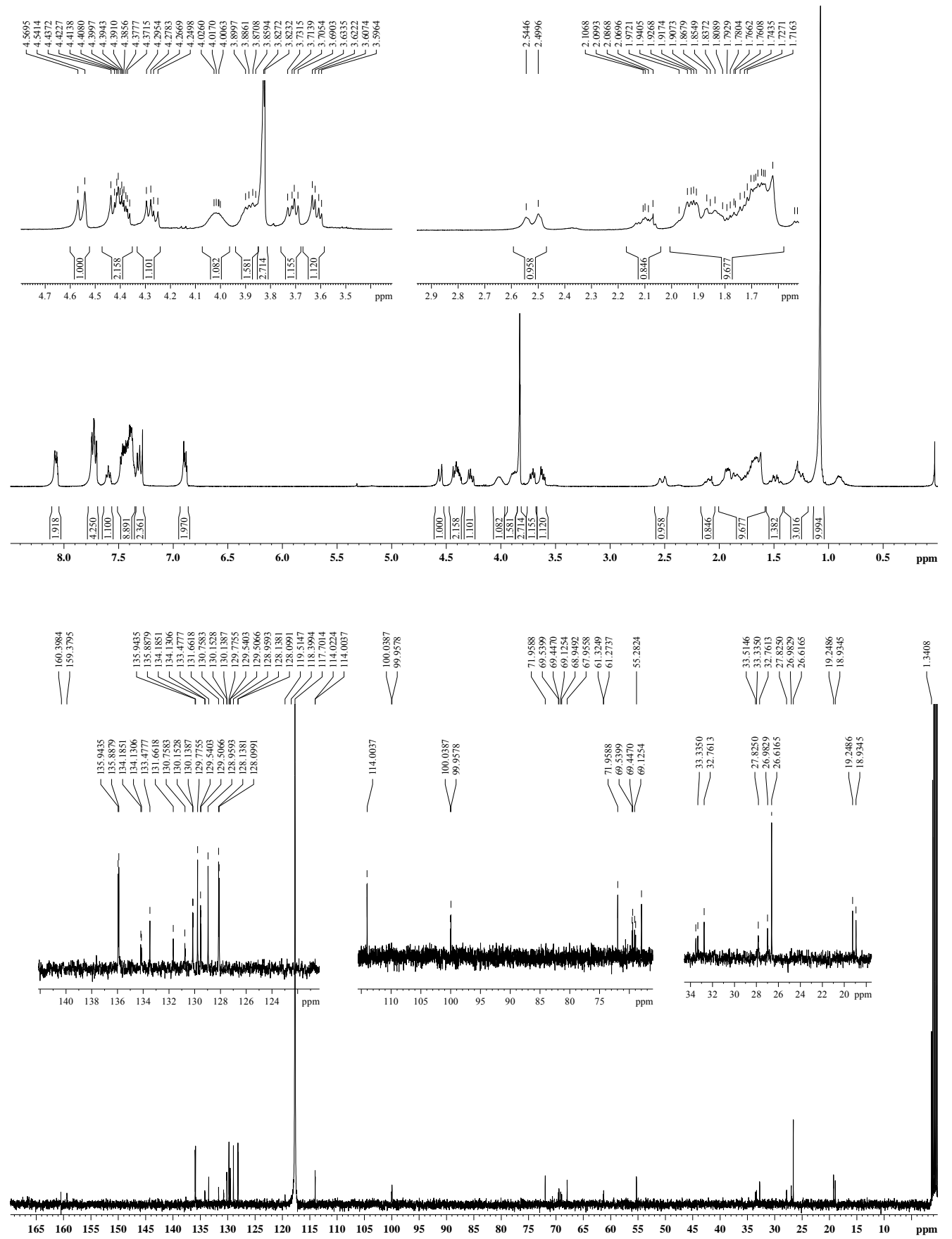

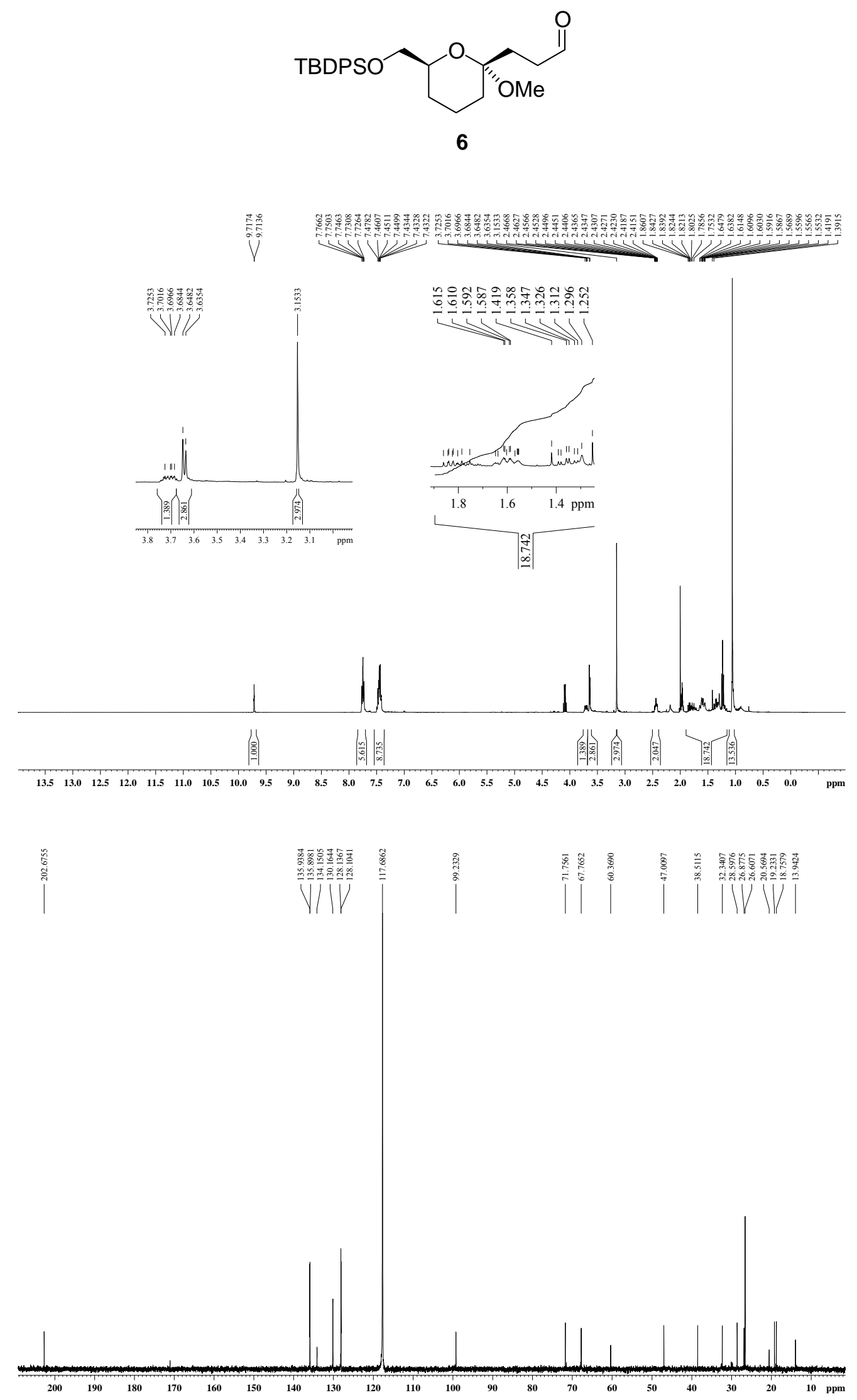


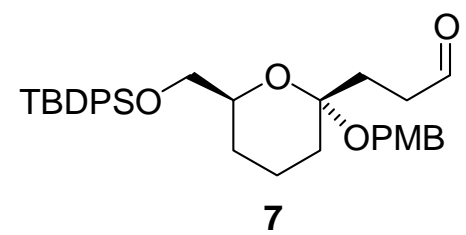

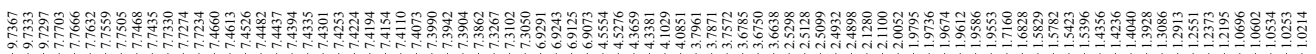

$\left.\right|^{\substack{1 \\ 0.0}}$

$\underbrace{(1 / 2}$

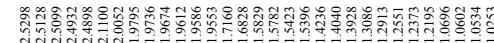

$W$ W

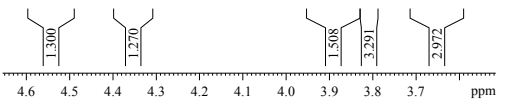

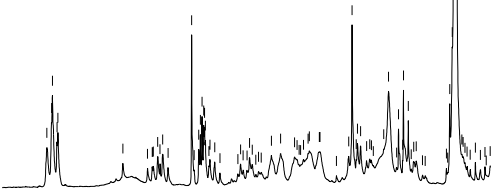
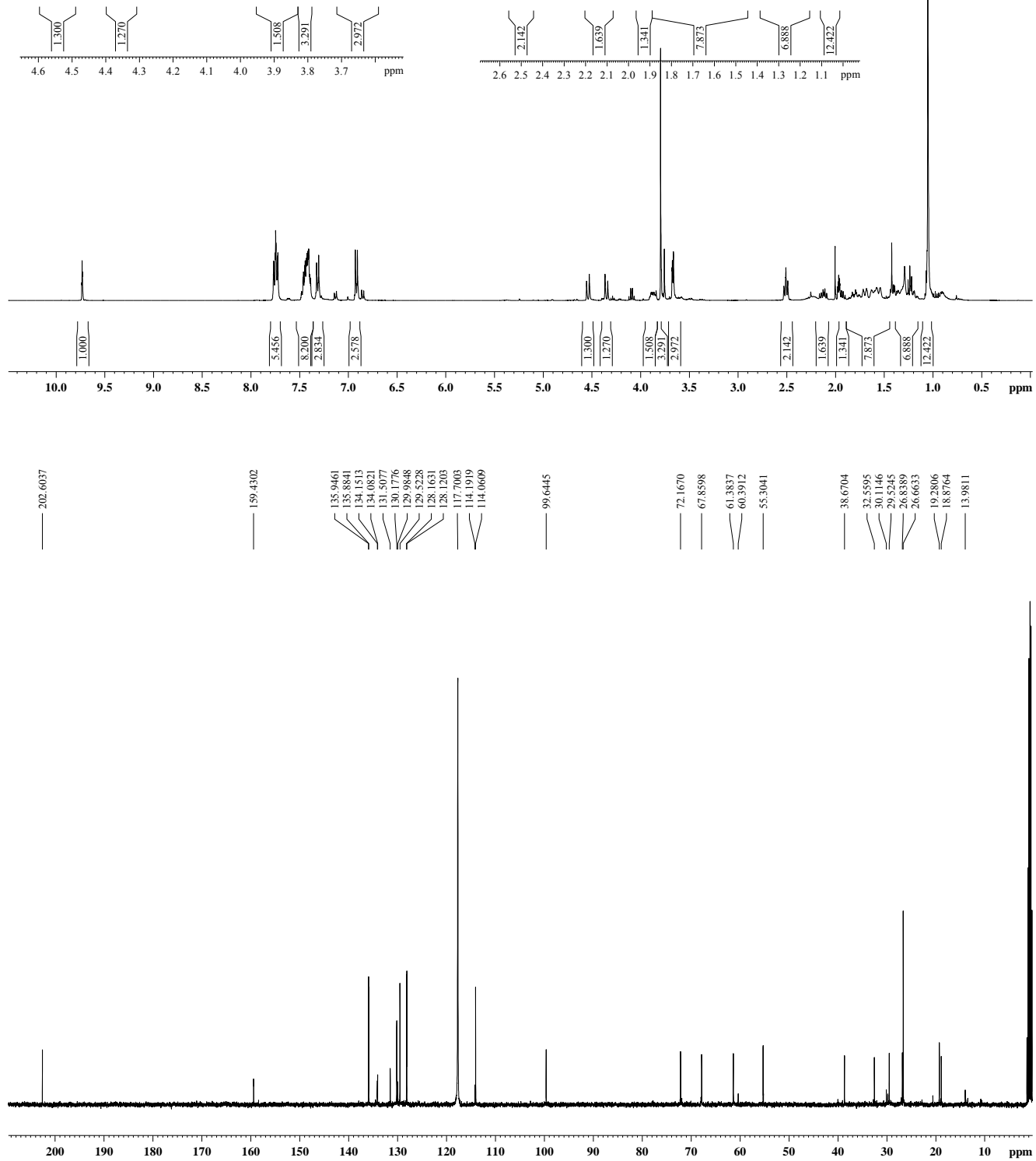


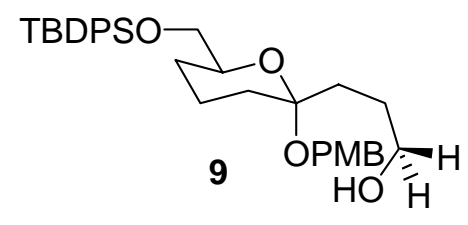

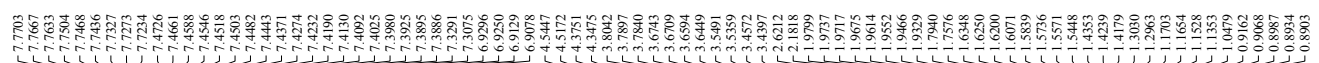
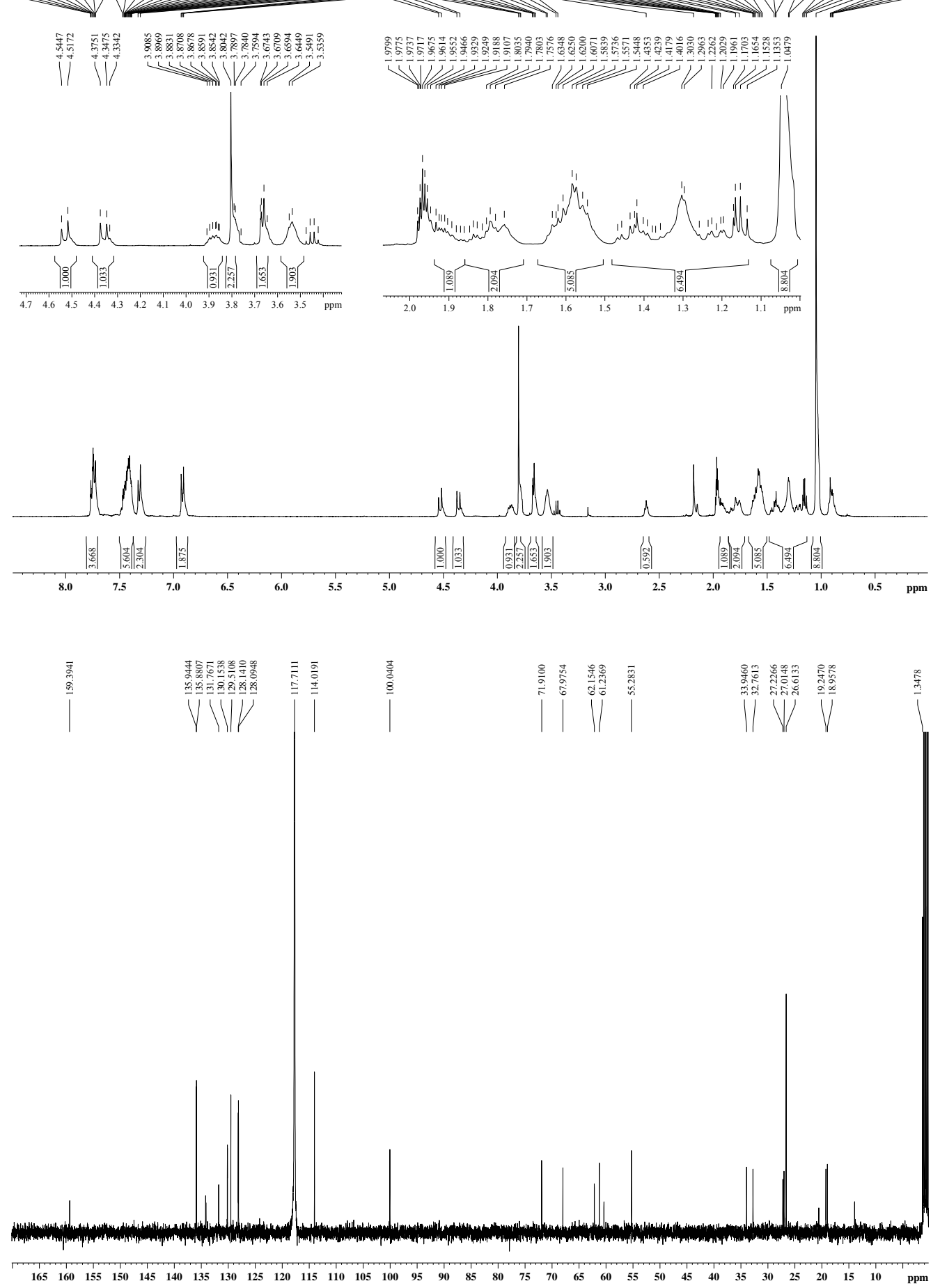

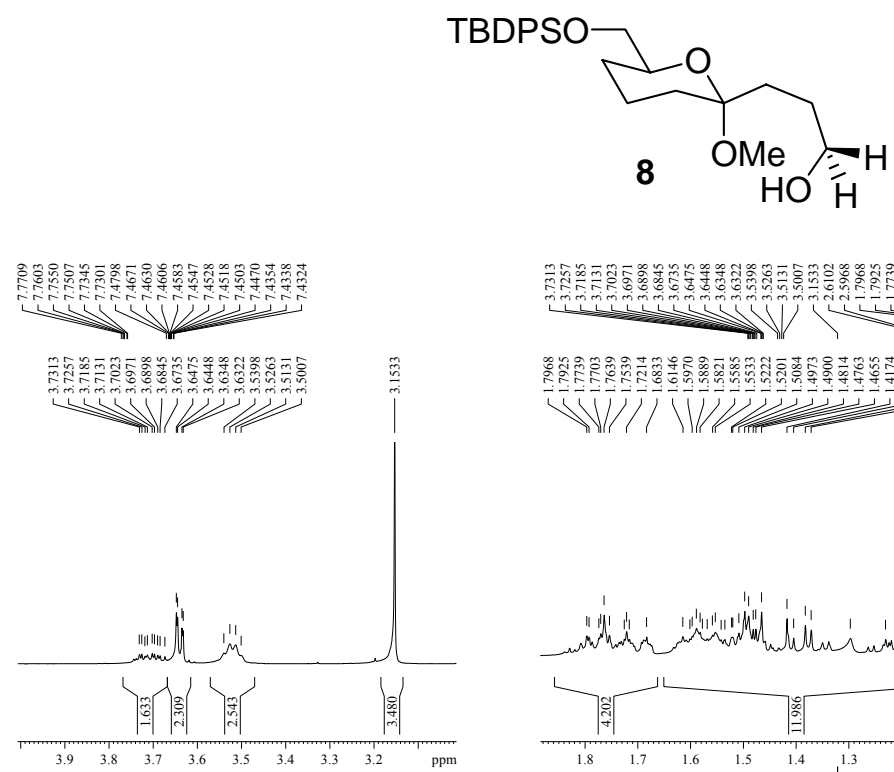

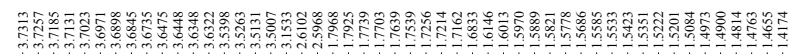

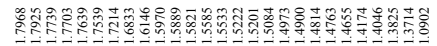

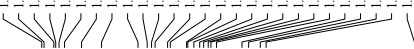
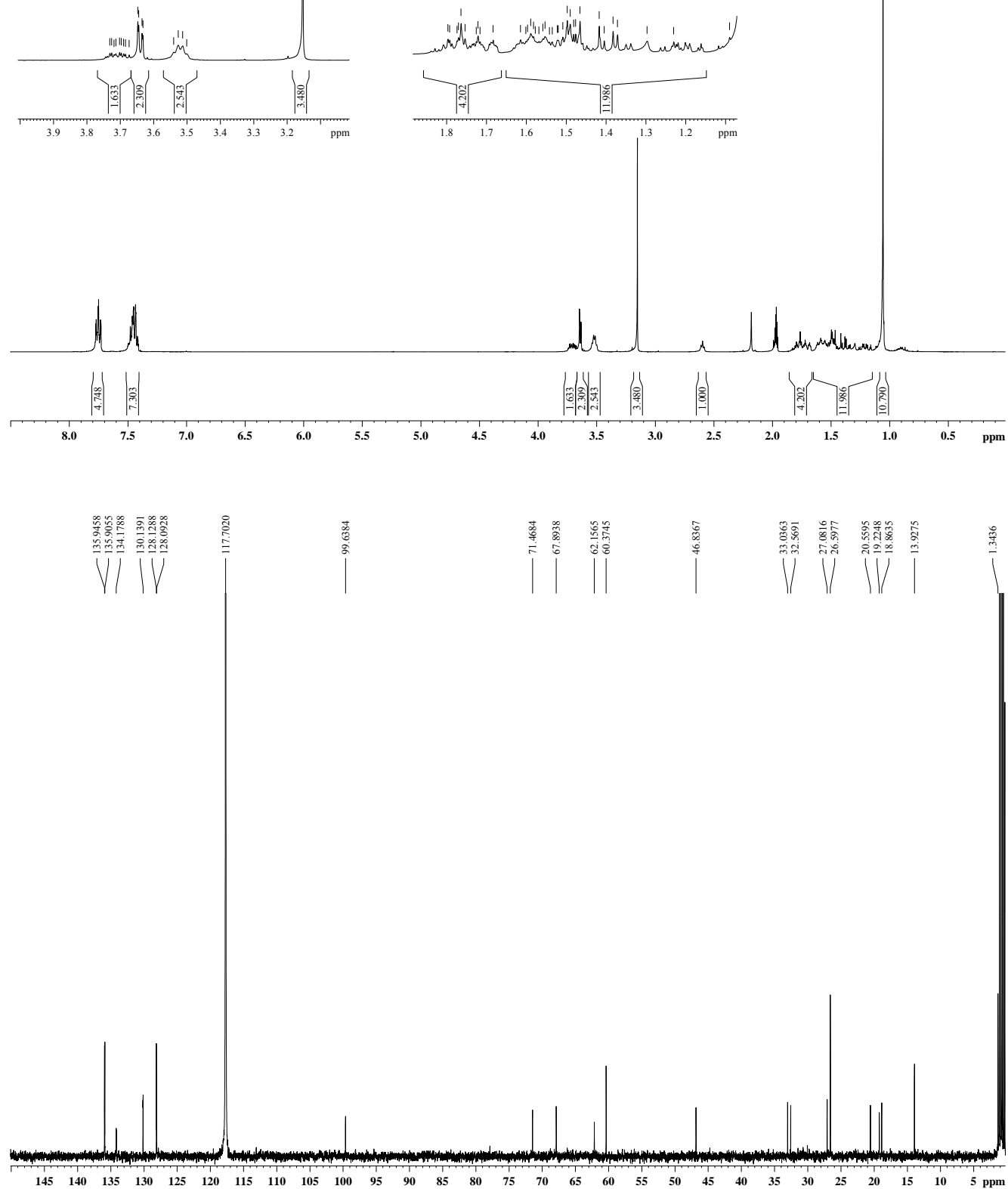


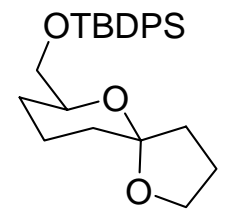

$12 a$

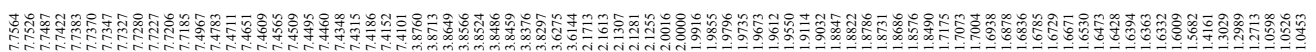
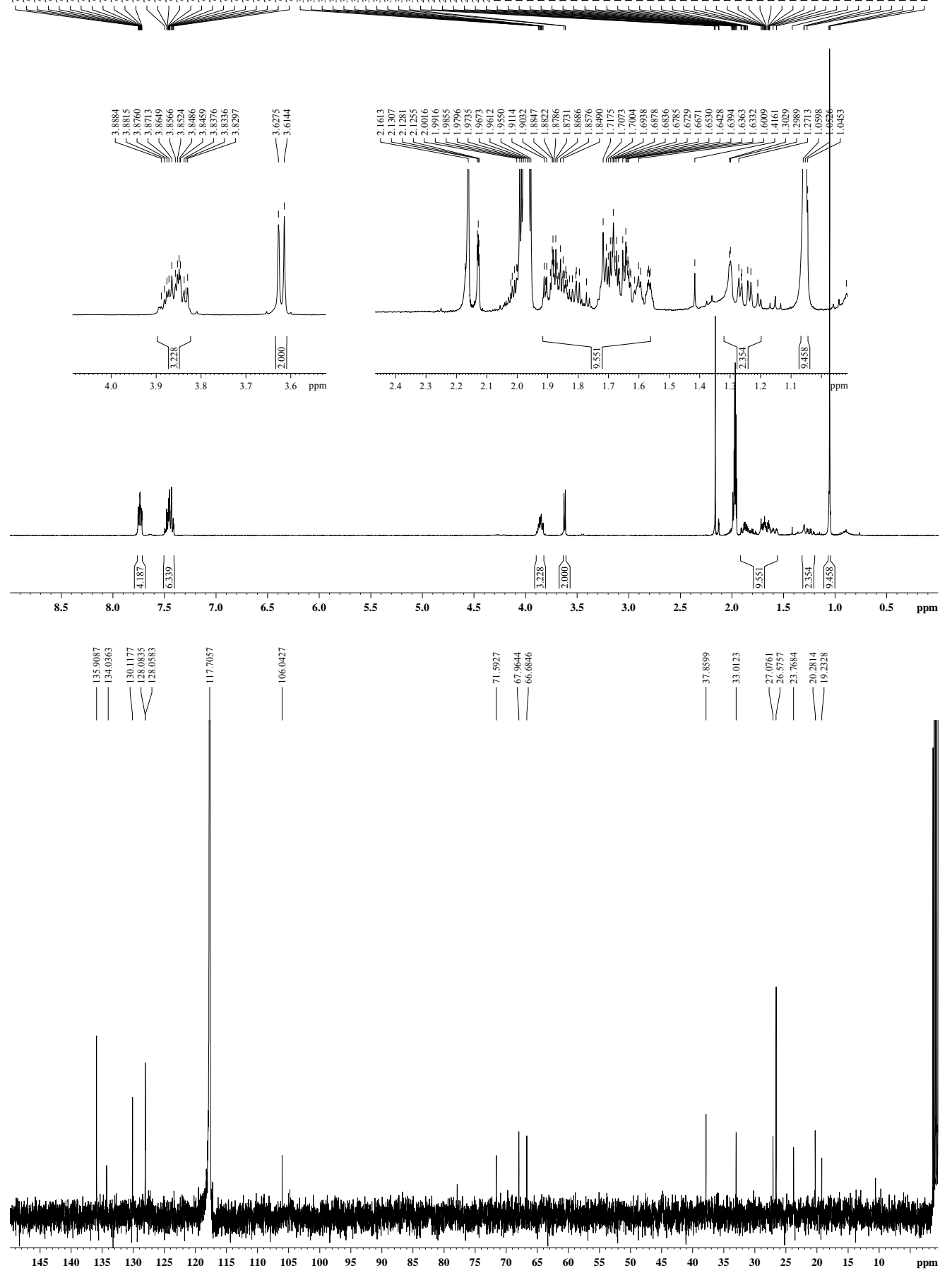


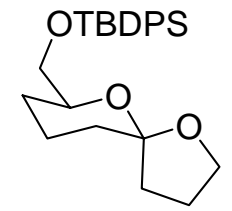

12b

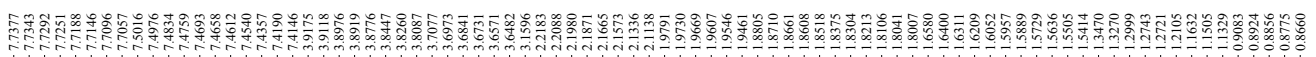

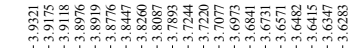

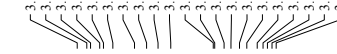
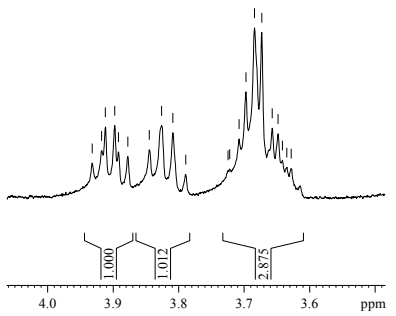

W

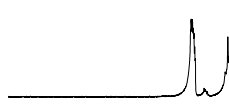

Wh

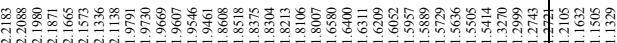

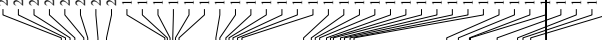
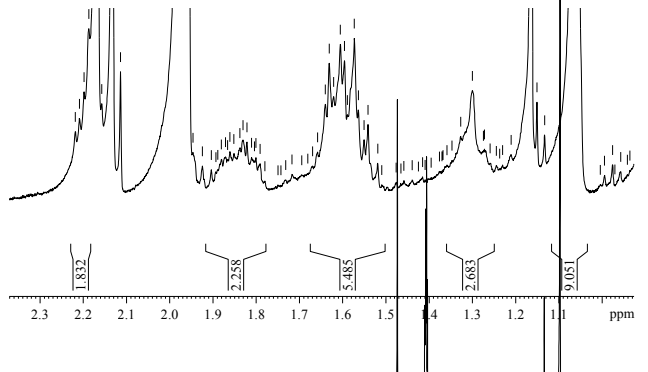
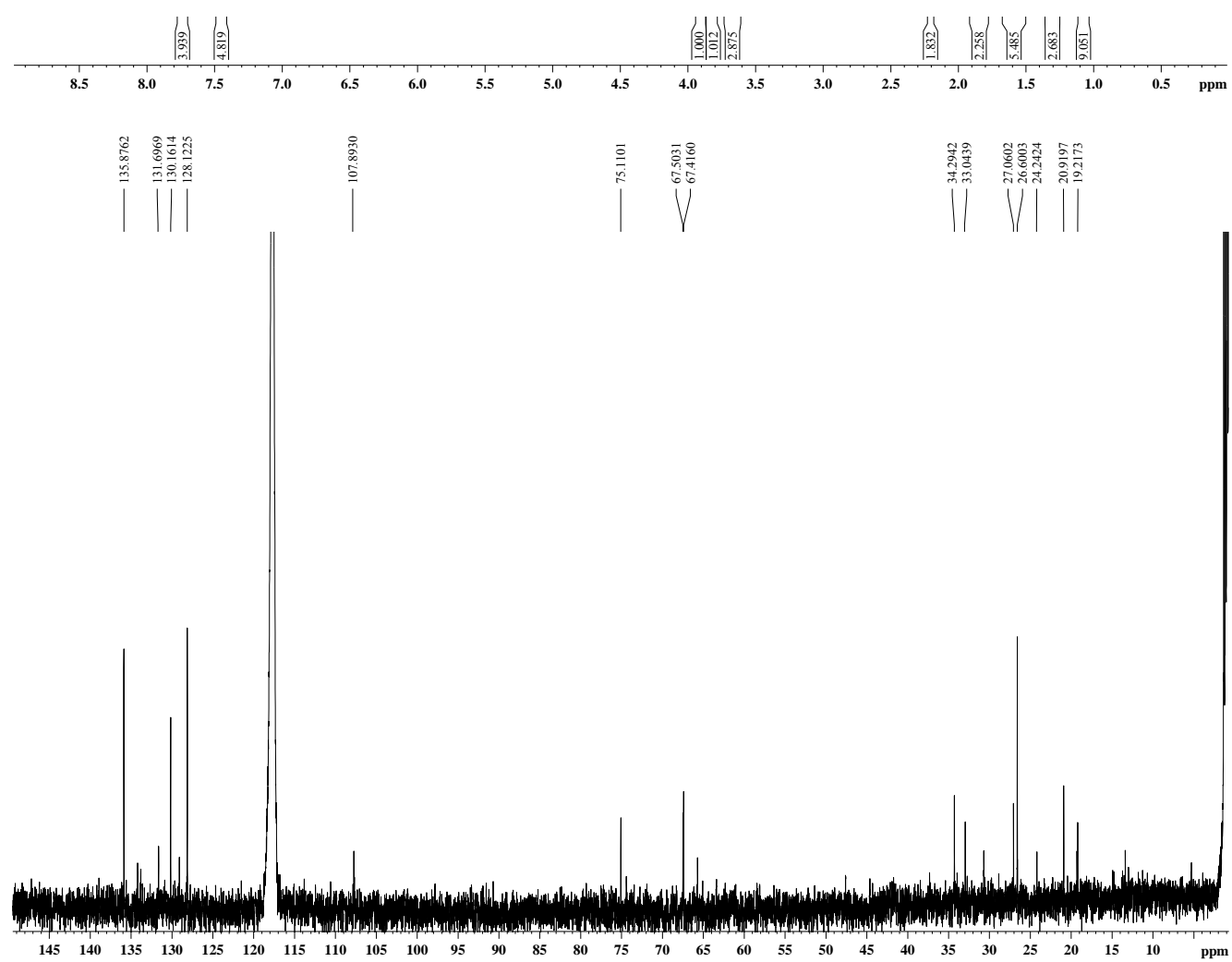


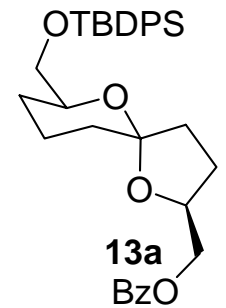

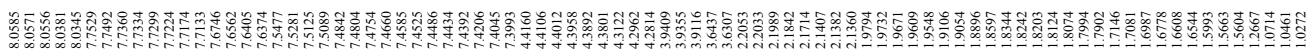
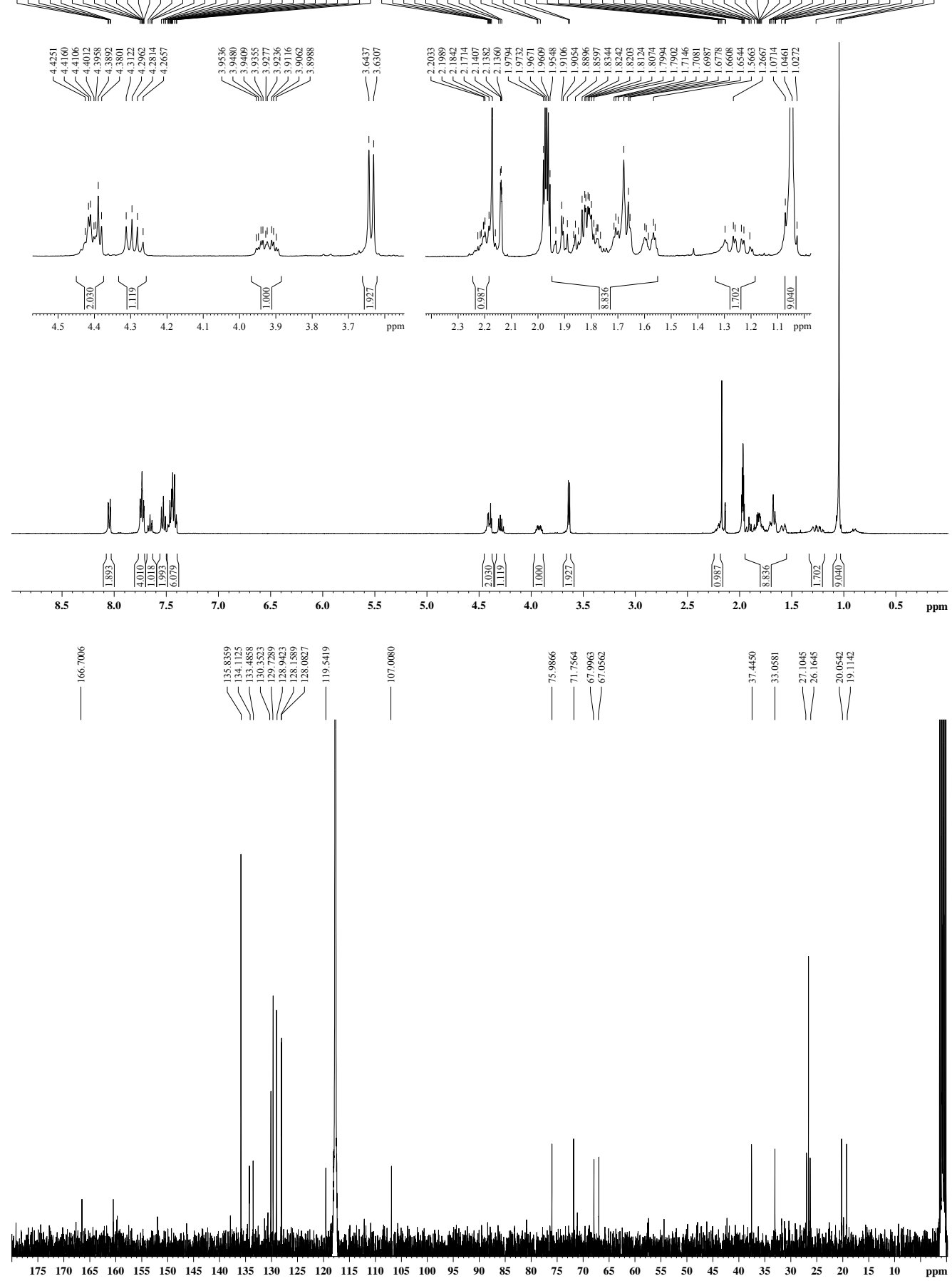


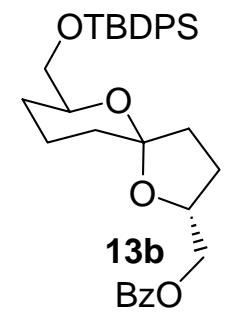

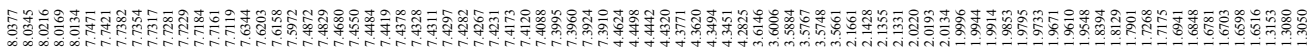
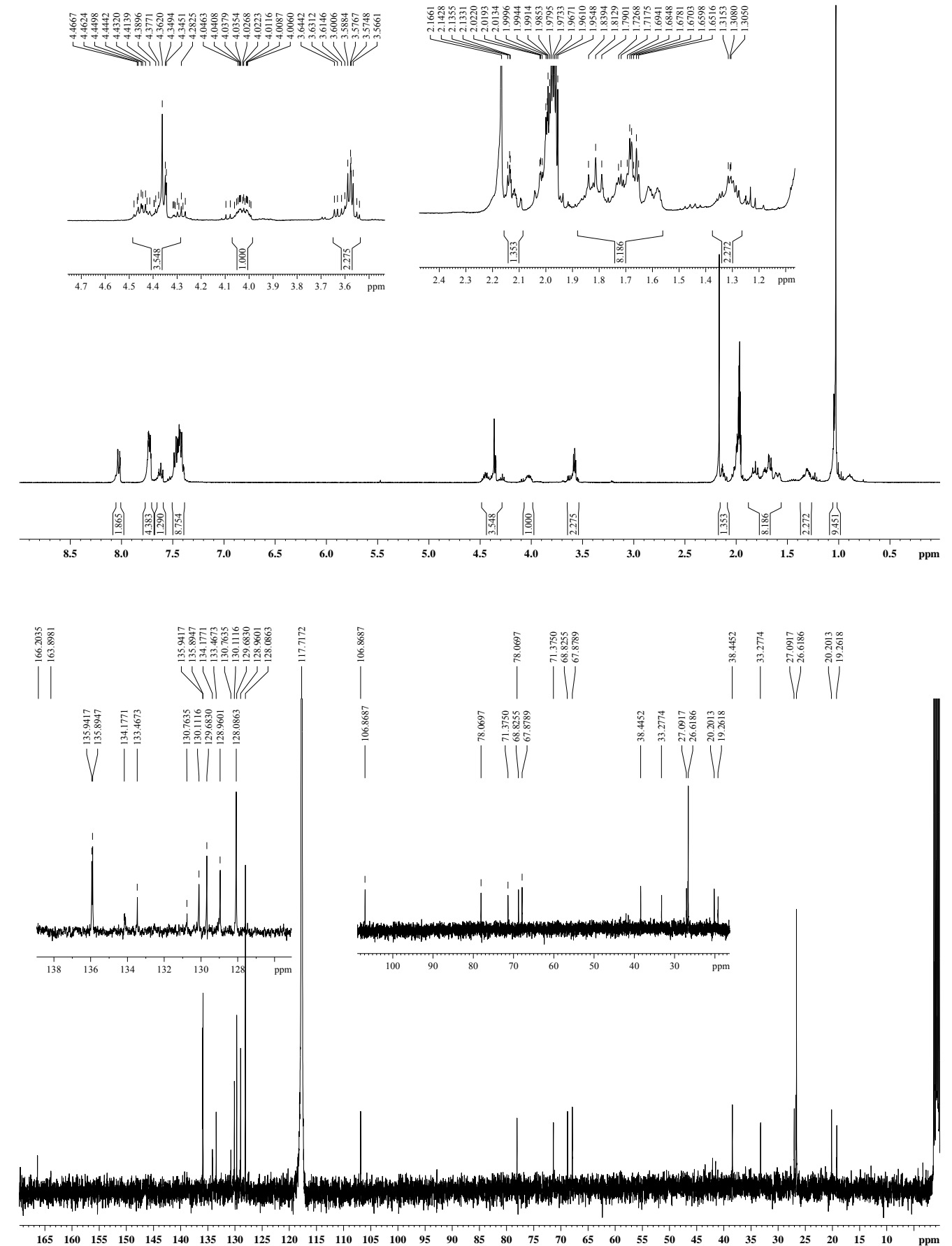


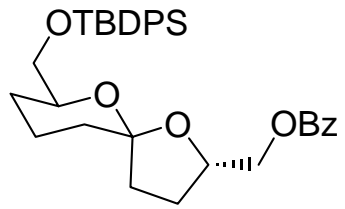

$13 c$

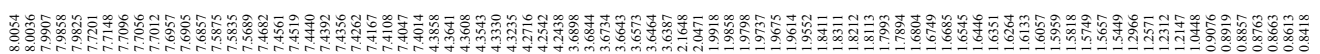

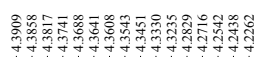

WWII
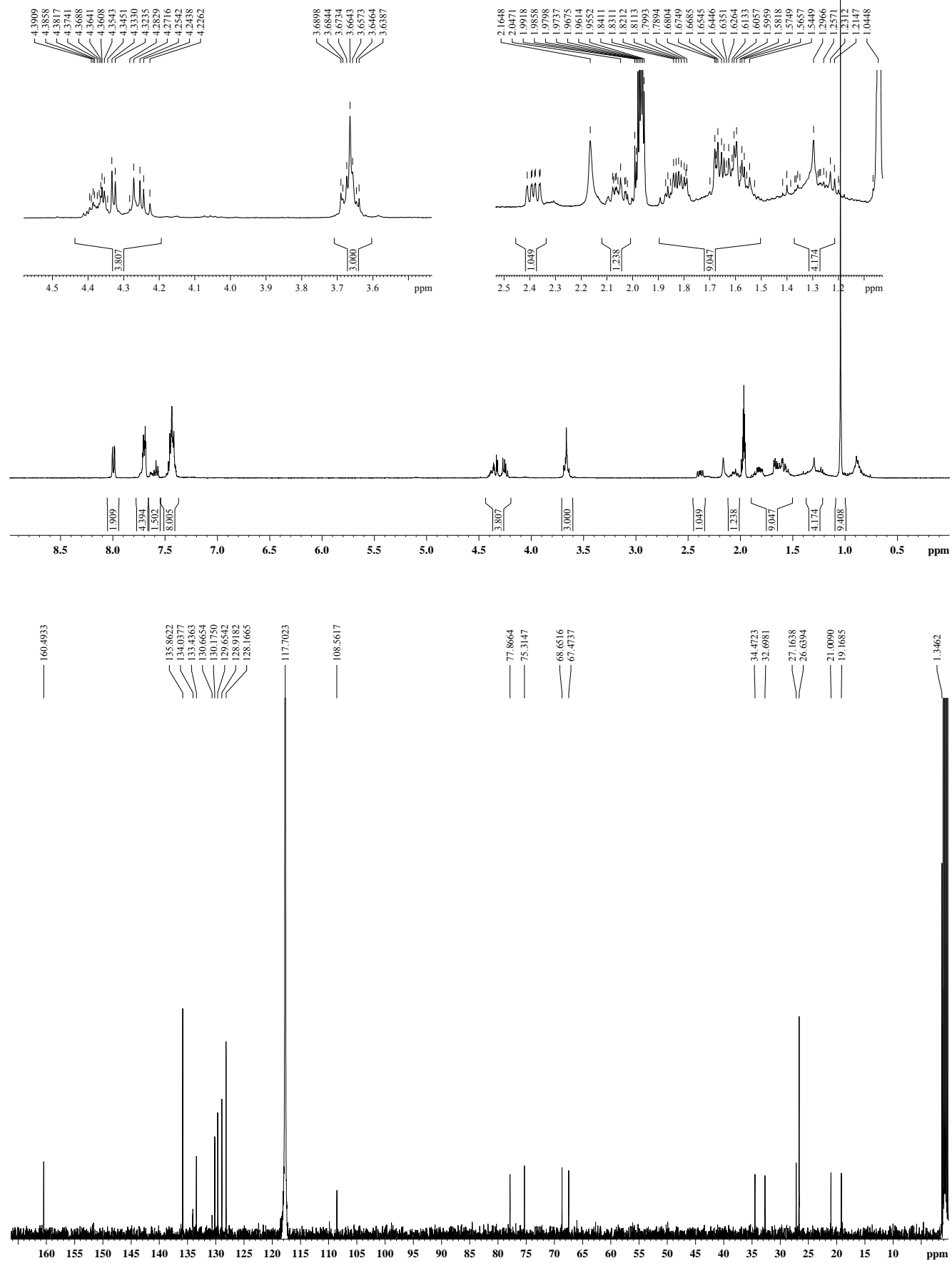


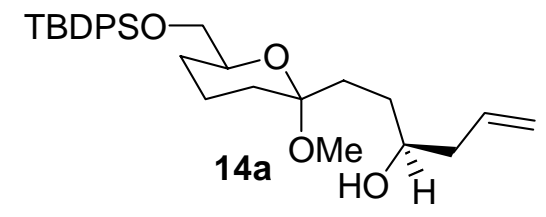

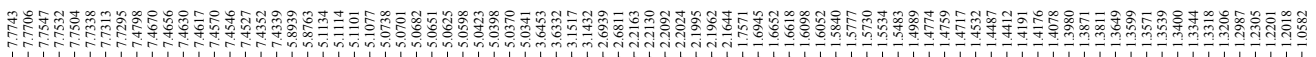
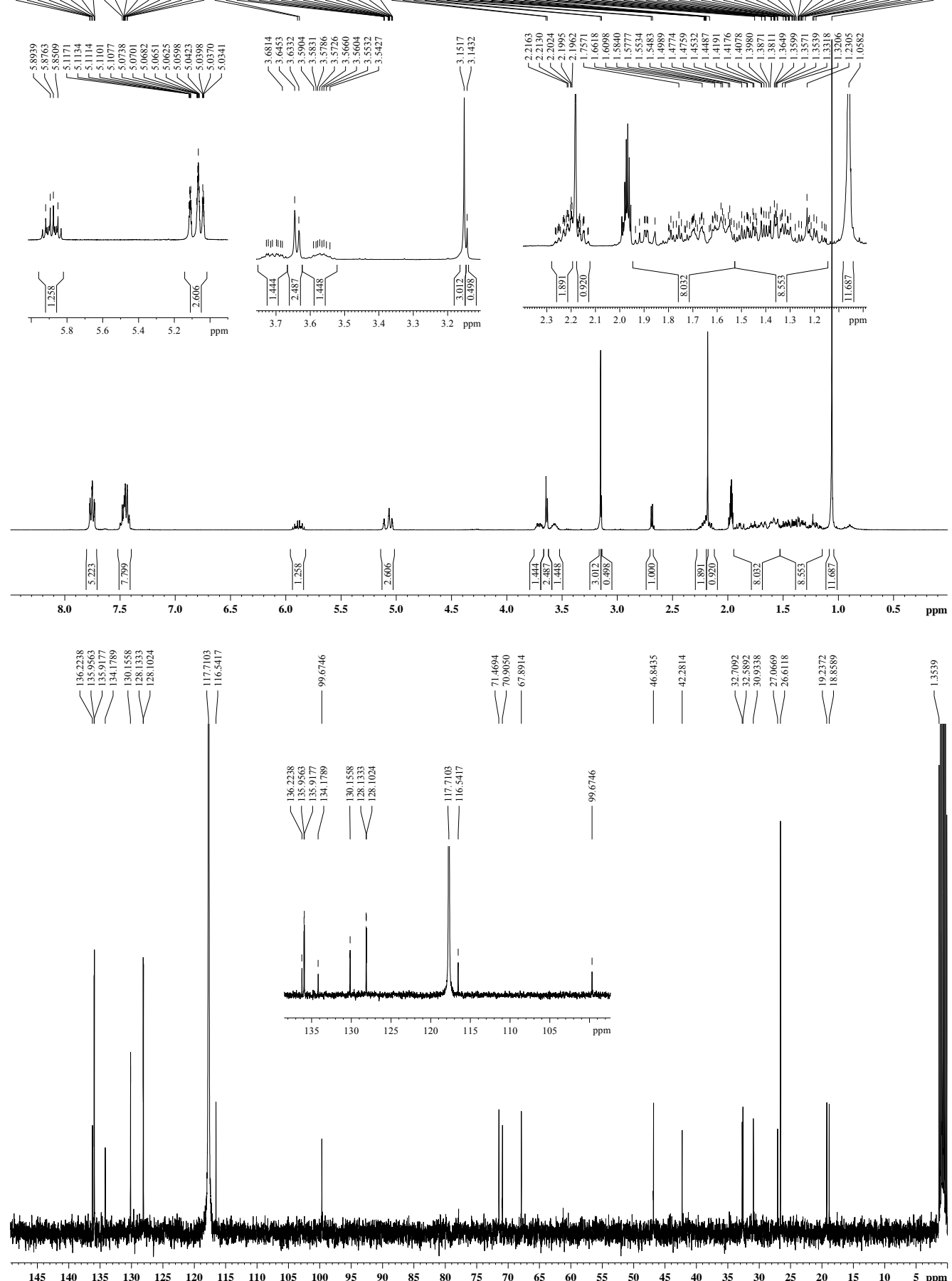


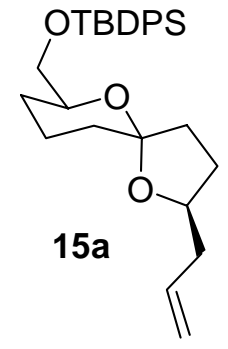

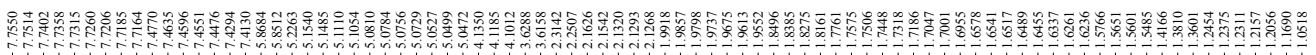
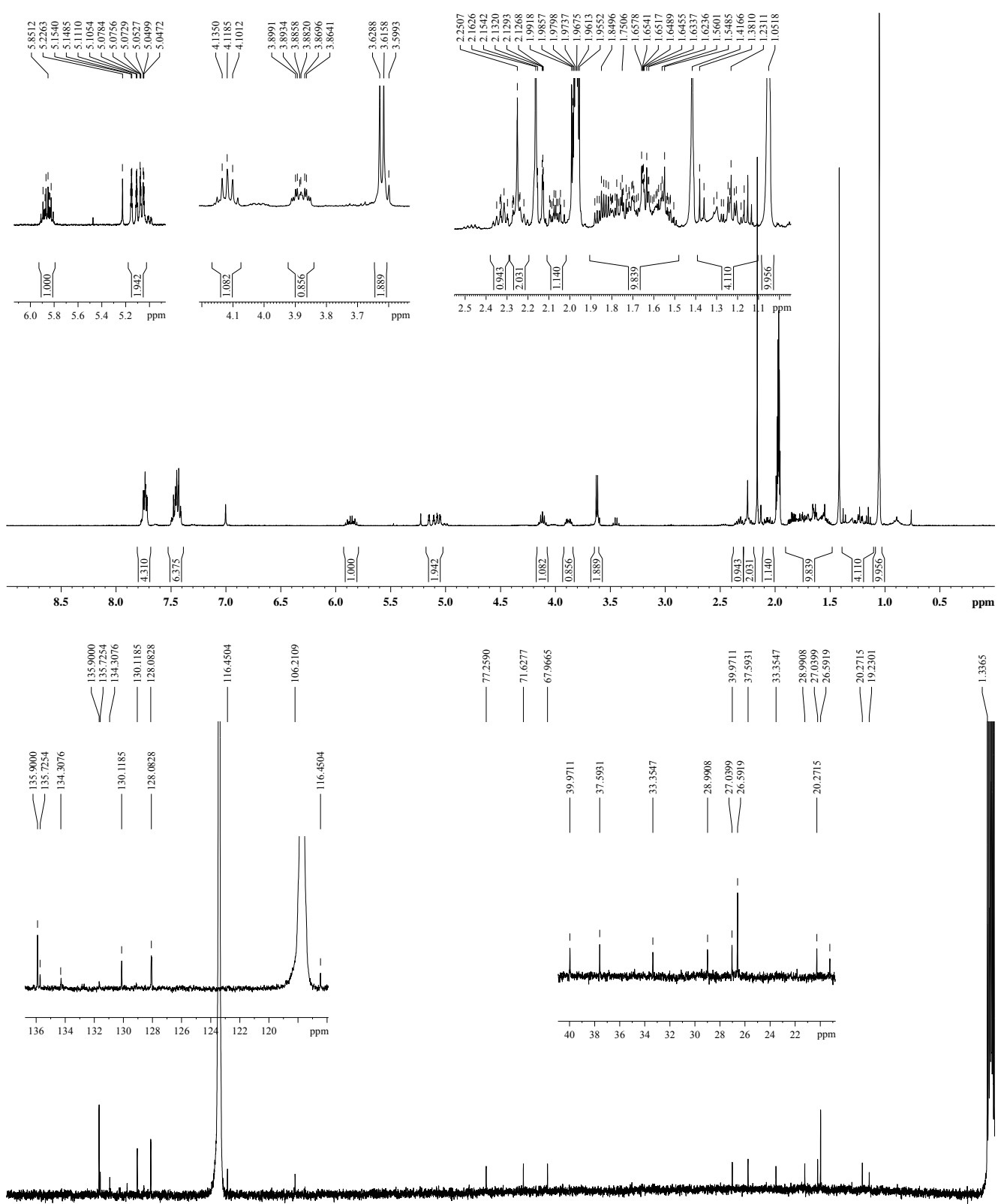

$\begin{array}{llllllllllllllllllllllllllllll}145 & 140 & 135 & 130 & 125 & 120 & 115 & 110 & 105 & 100 & 95 & 90 & 85 & 80 & 75 & 70 & 65 & 60 & 55 & 50 & 45 & 40 & 35 & 30 & 25 & 20 & 15 & 10 & 5 \mathrm{ppm}\end{array}$ 

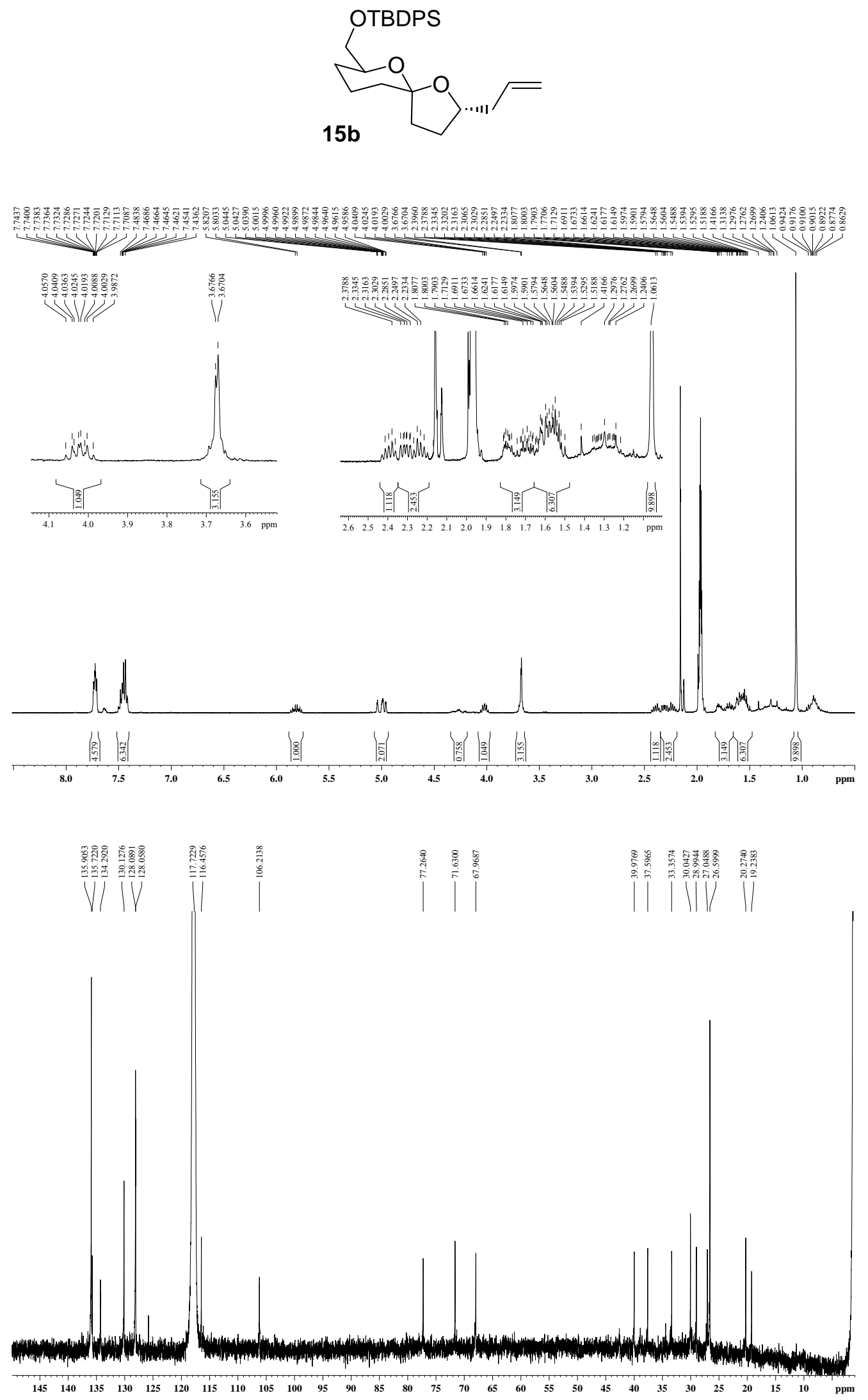


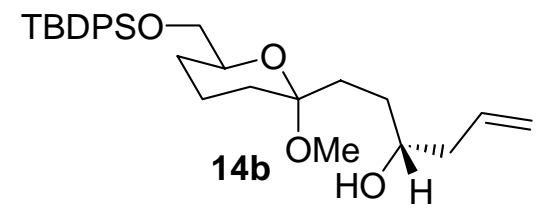

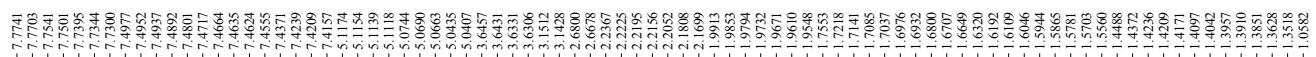
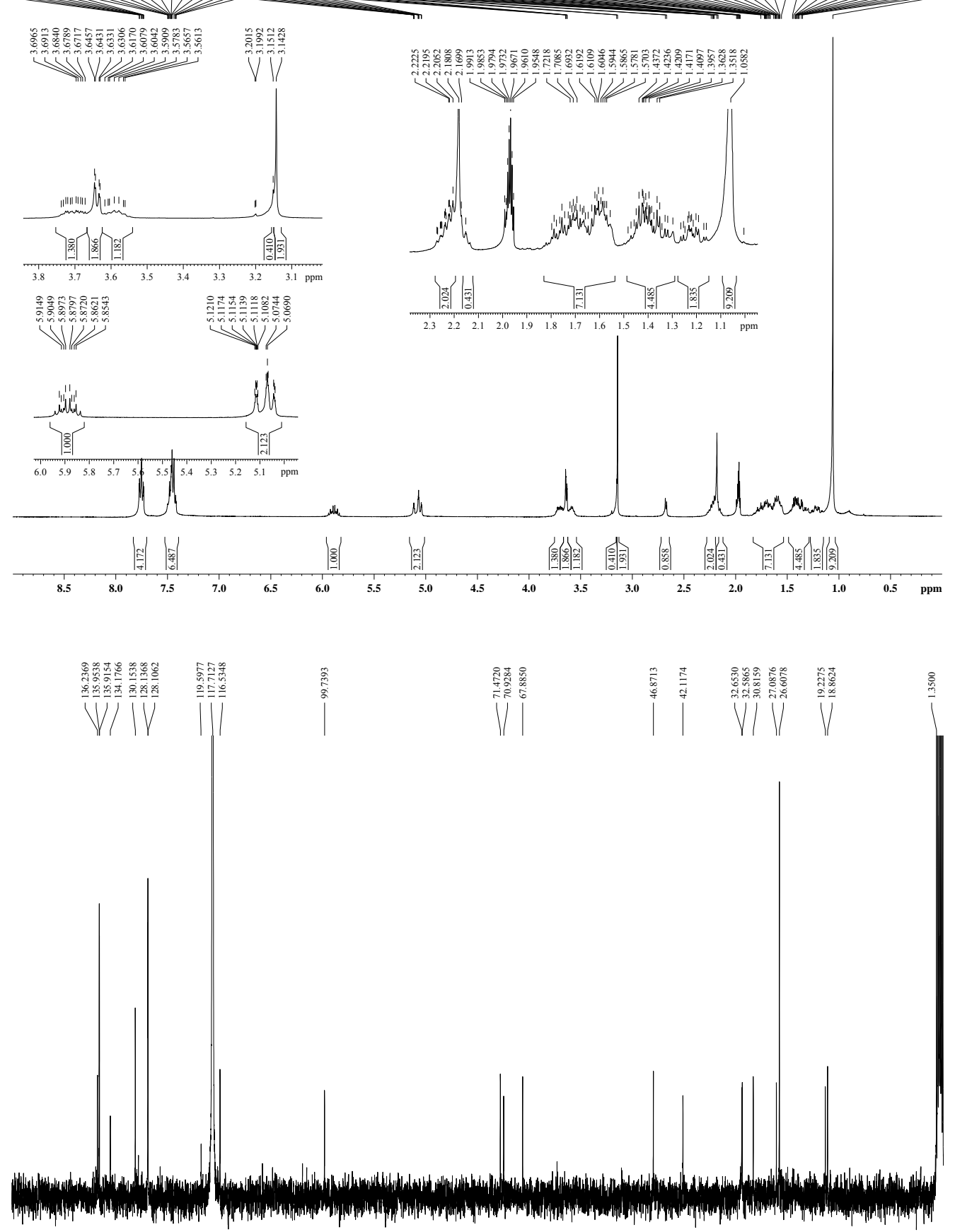

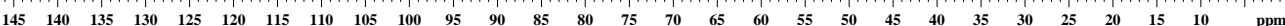




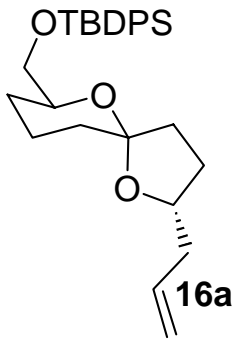

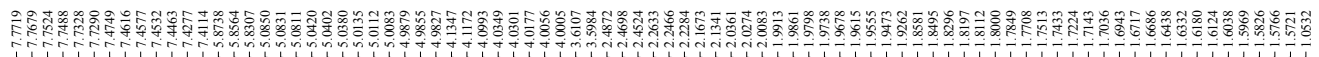
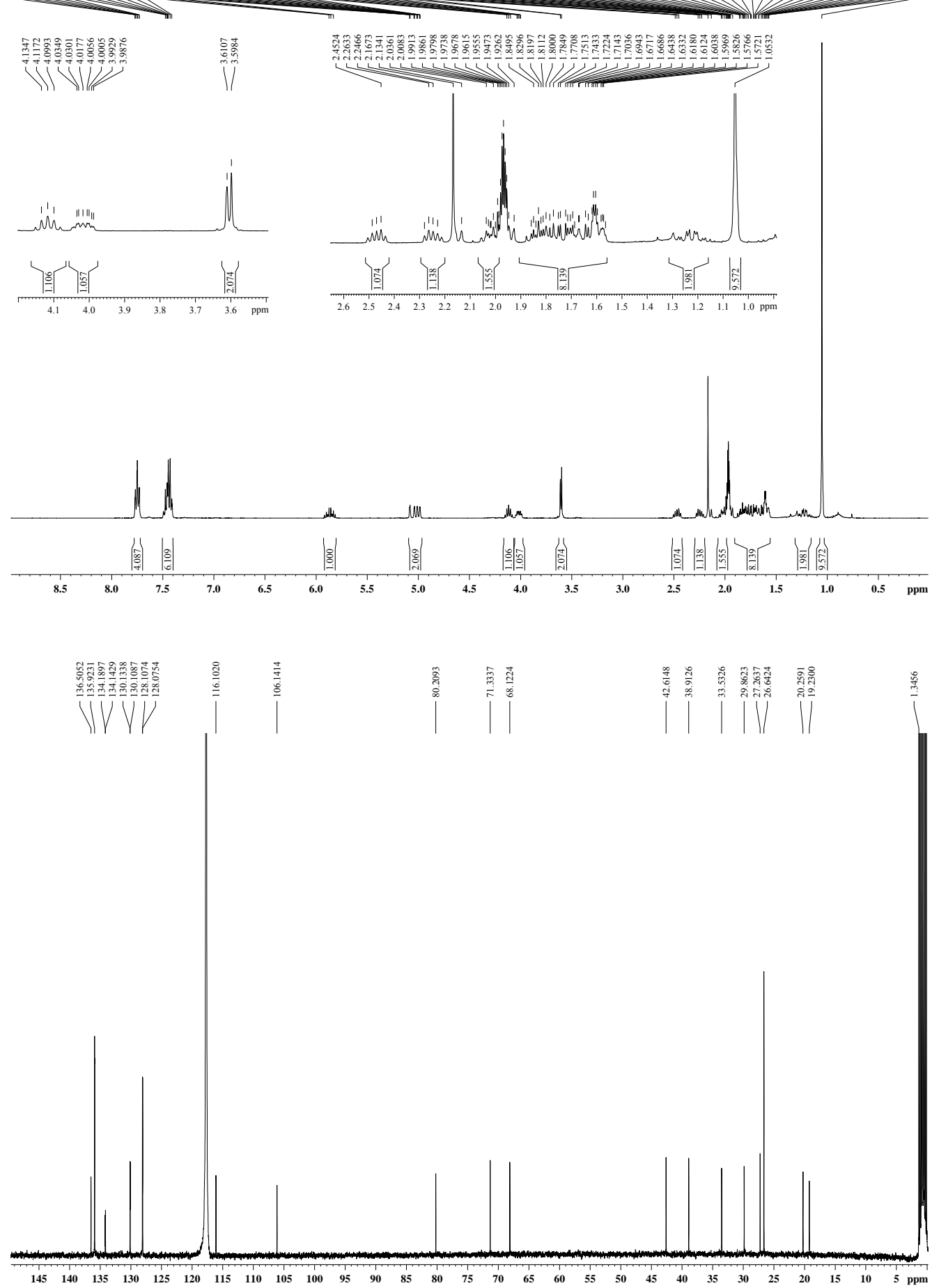


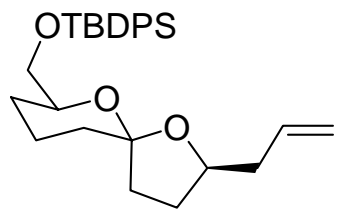

$16 b$
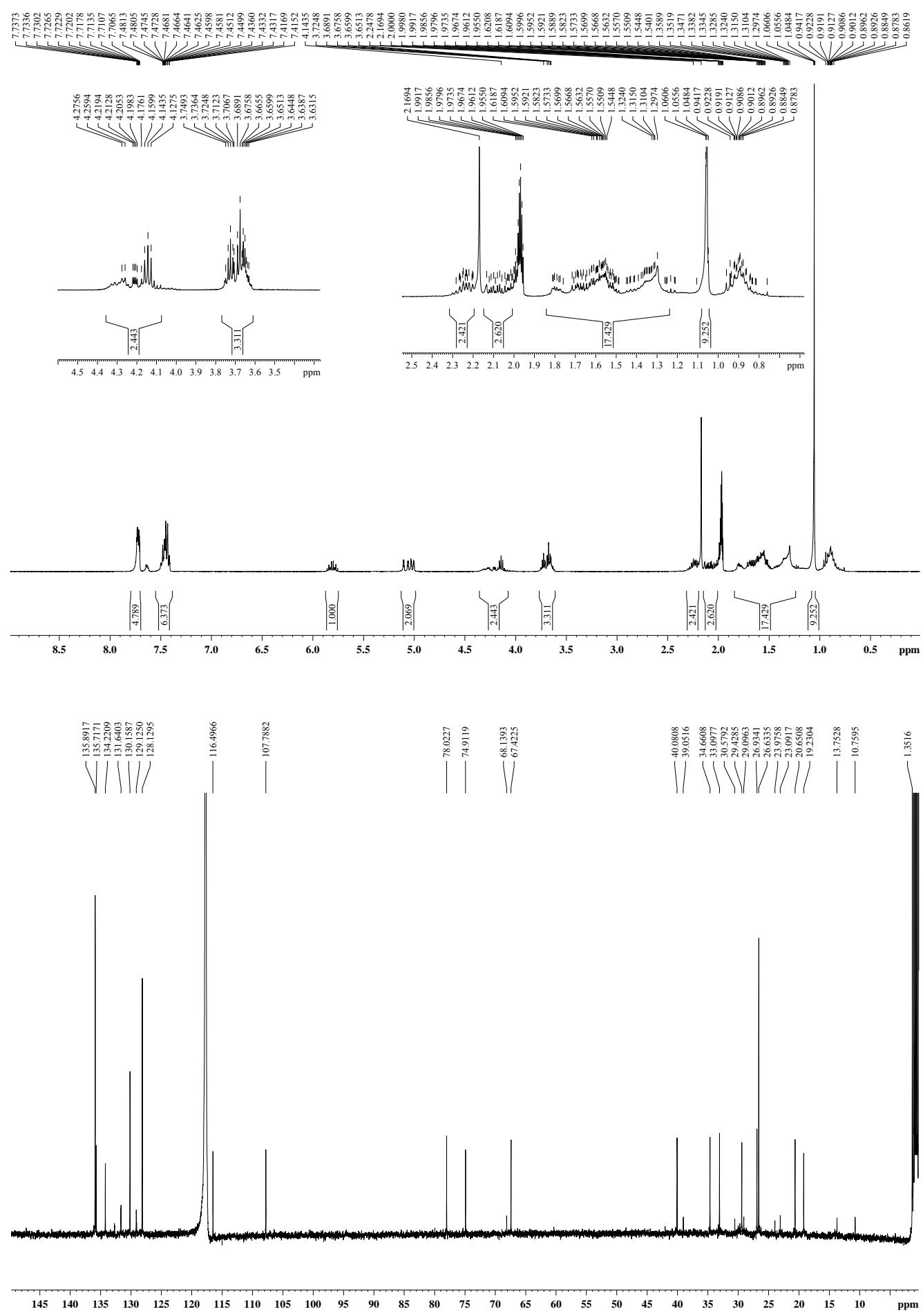


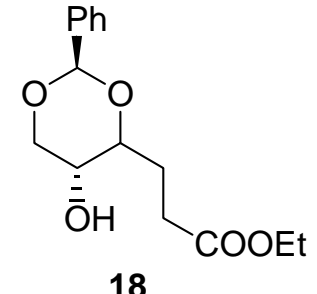

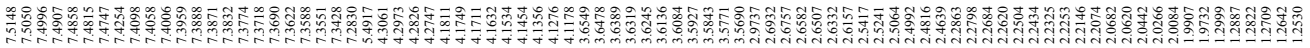
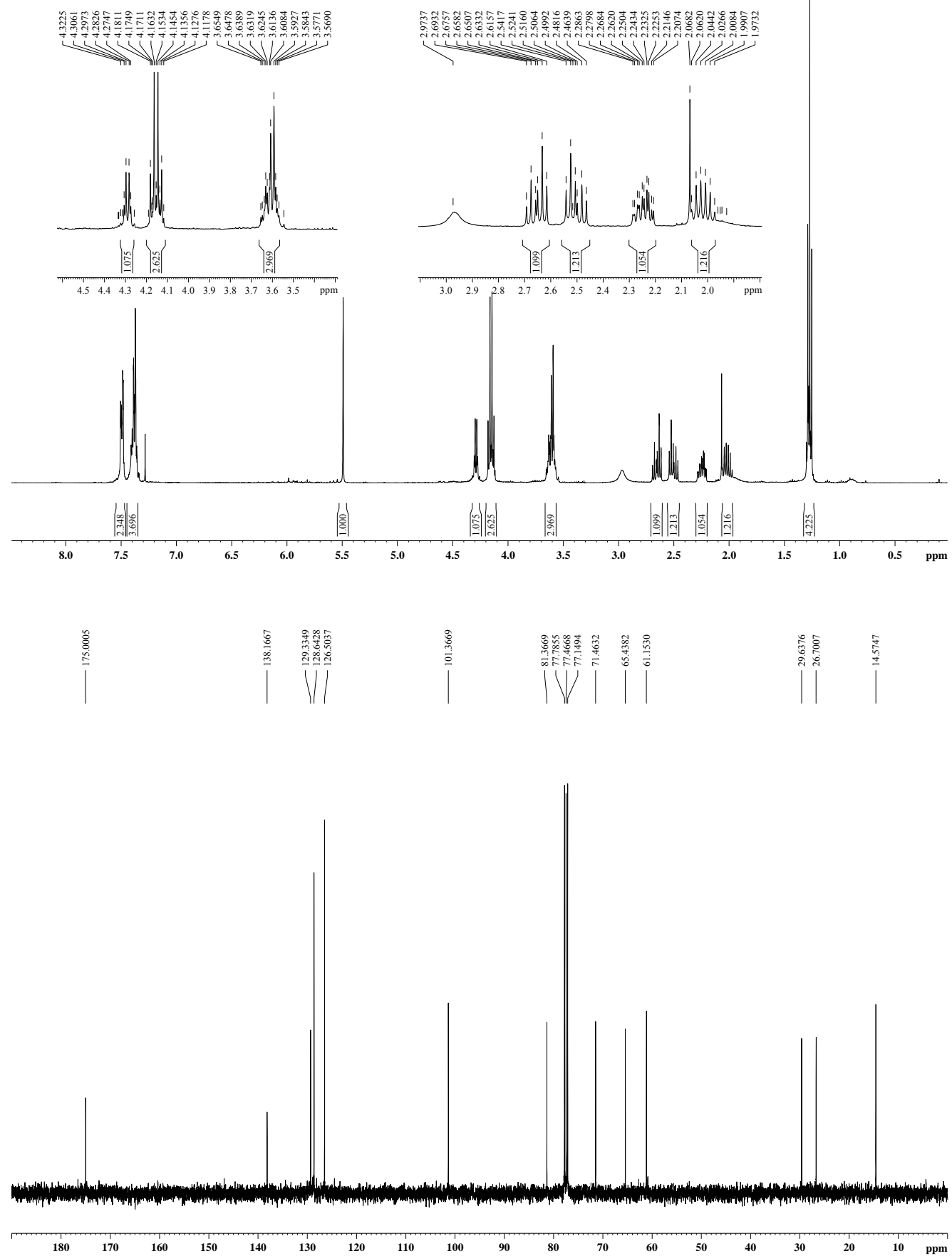
<smiles>O=C1OCC2OC(c3ccccc3)C(=O)CCC2O1</smiles>

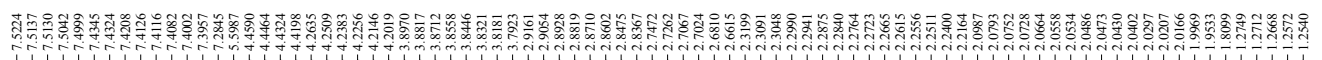
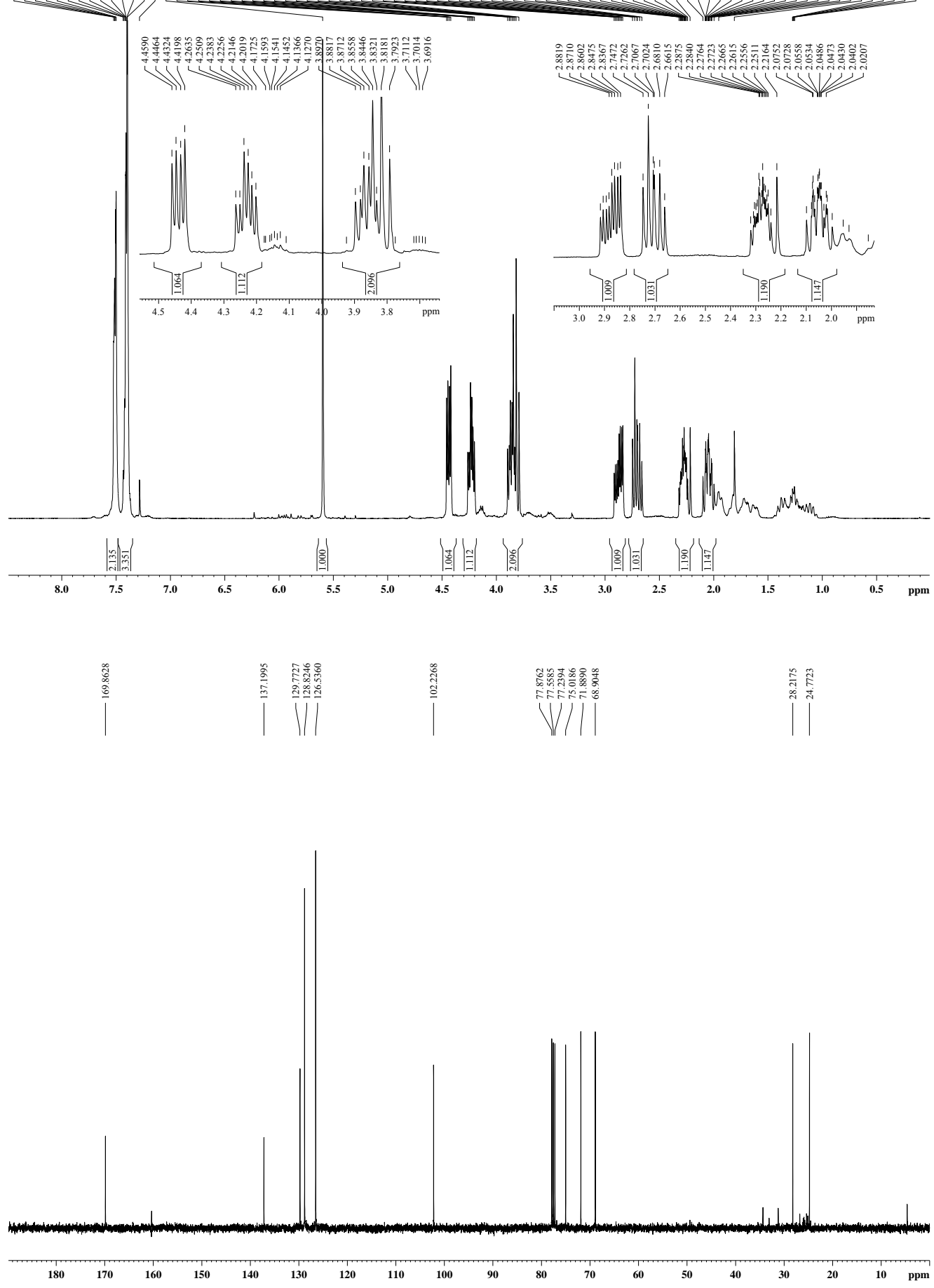
<smiles>C=CCCC(=O)CC[C@H]1O[C@@H](c2ccccc2)OC[C@H]1O</smiles>

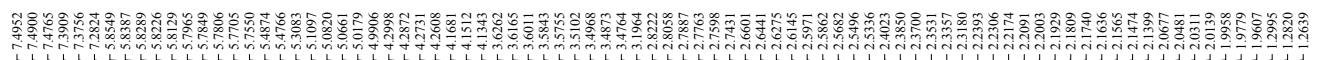
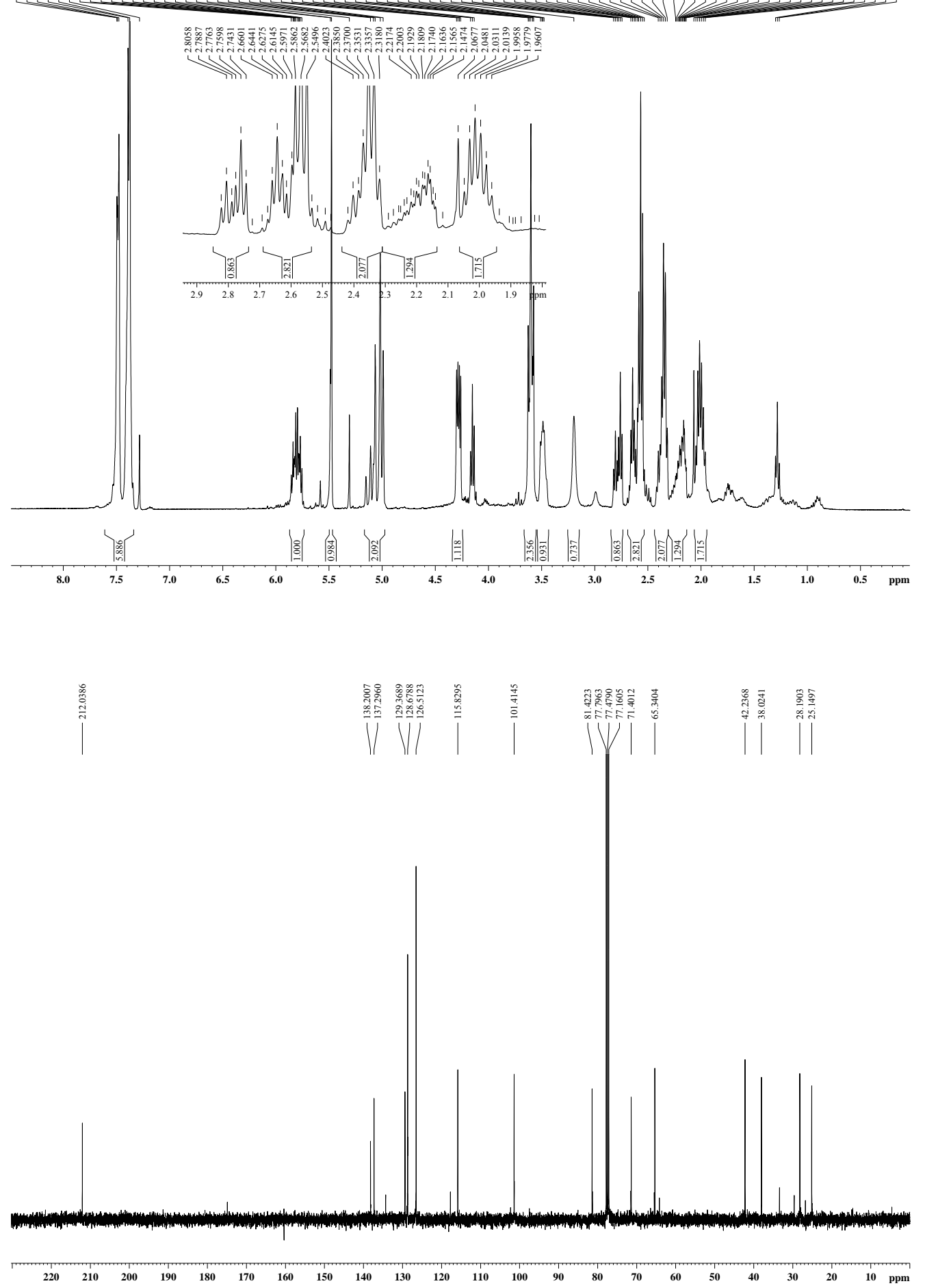


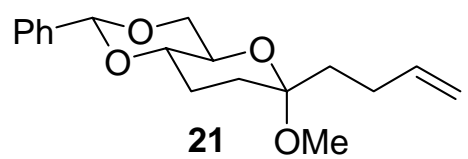

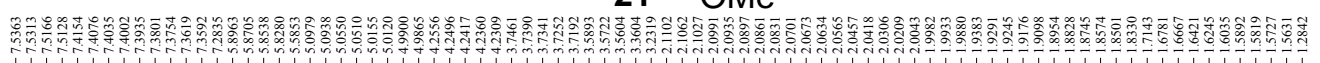
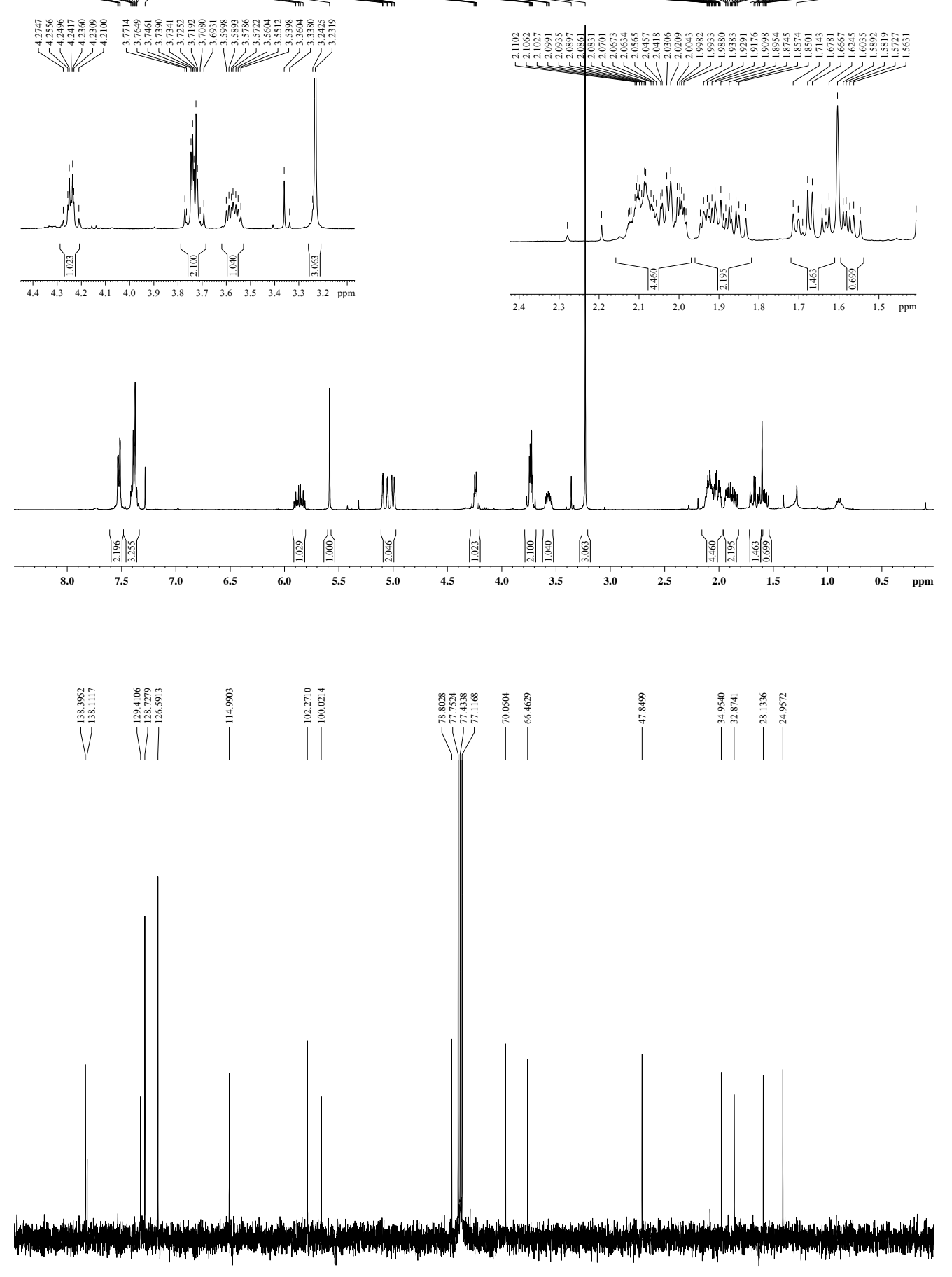

$\begin{array}{lllllllllllllllllllllllllllll}145 & 140 & 135 & 130 & 125 & 120 & 115 & 110 & 105 & 100 & 95 & 90 & 85 & 80 & 75 & 70 & 65 & 60 & 55 & 50 & 45 & 40 & 35 & 30 & 25 & 20 & 15 & 10 & \mathrm{ppm}\end{array}$ 


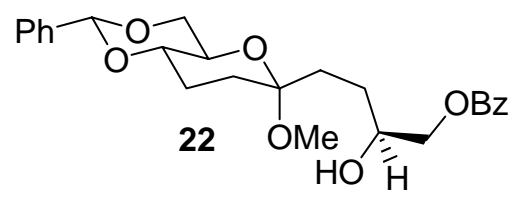

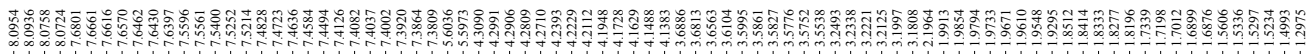
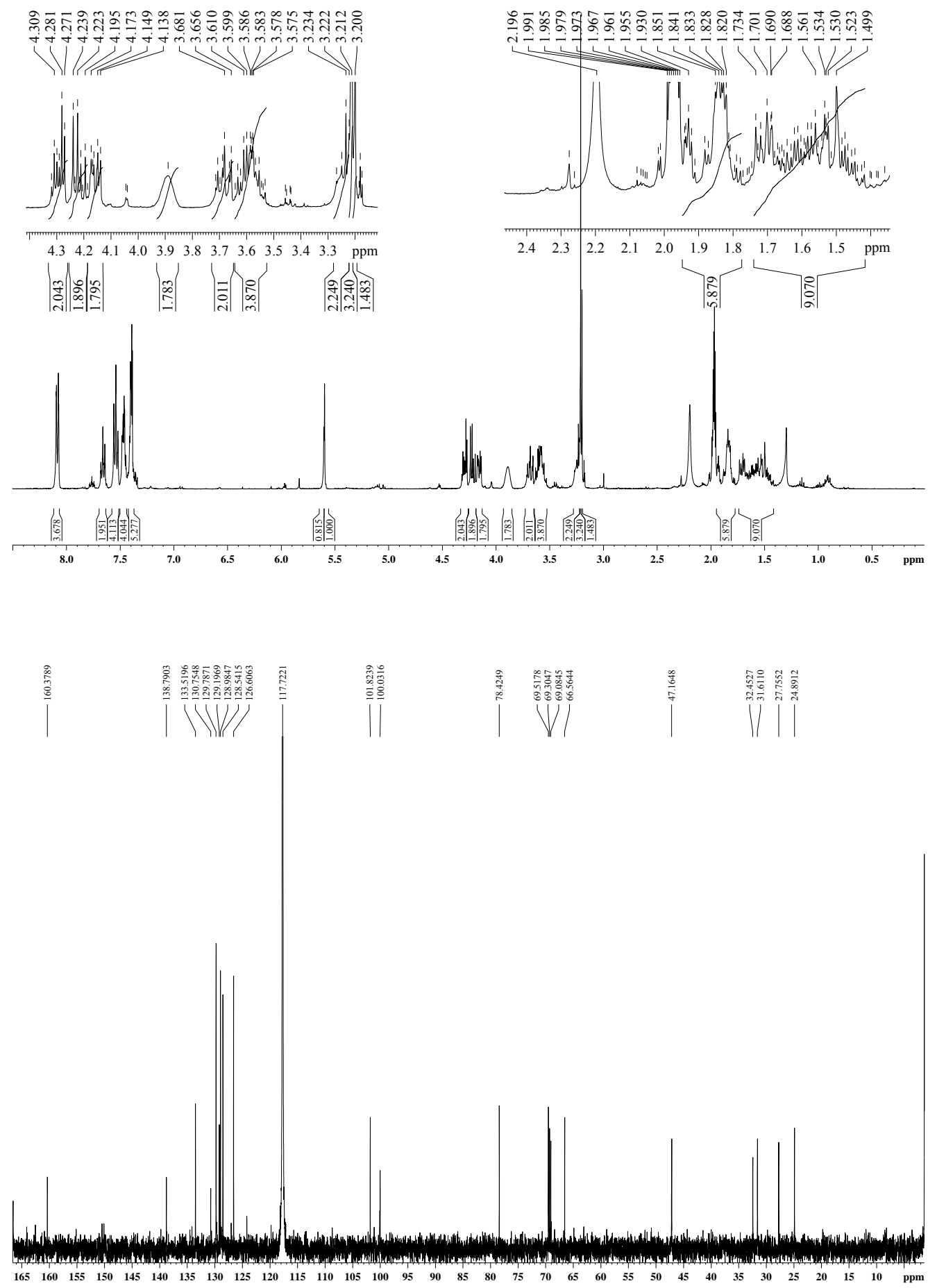


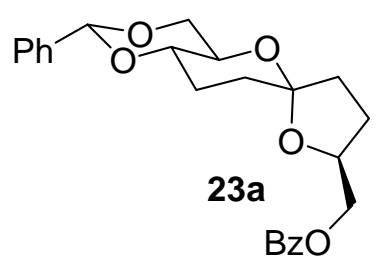

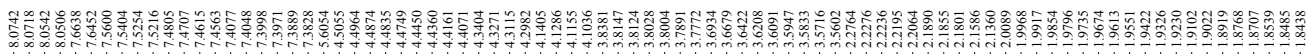
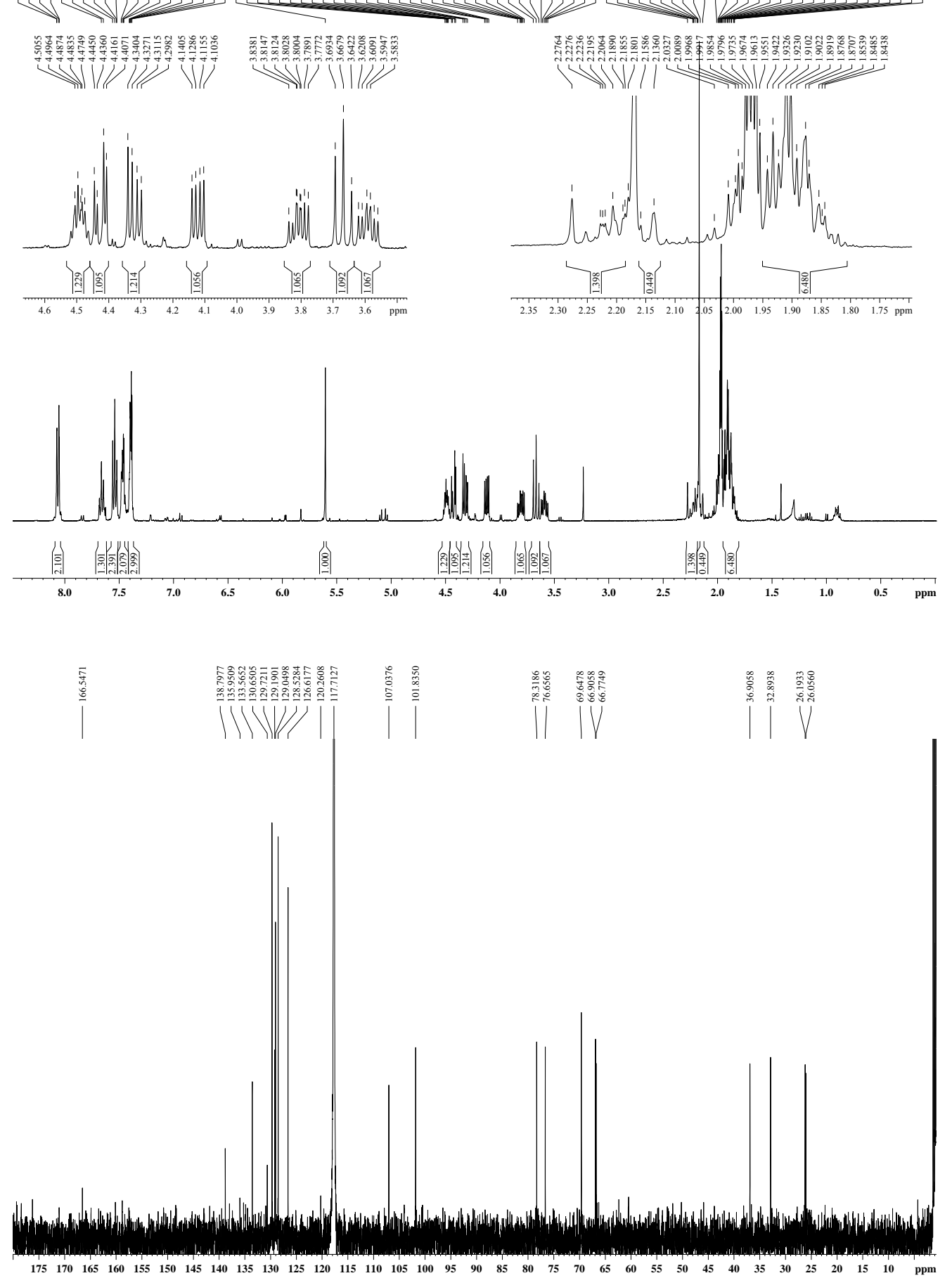


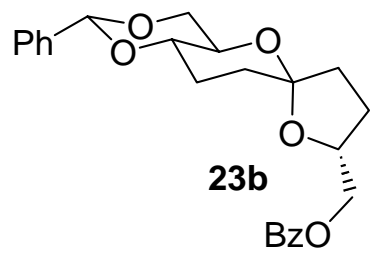

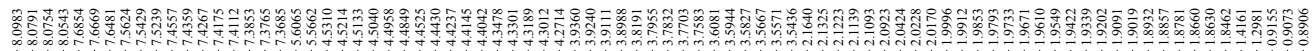
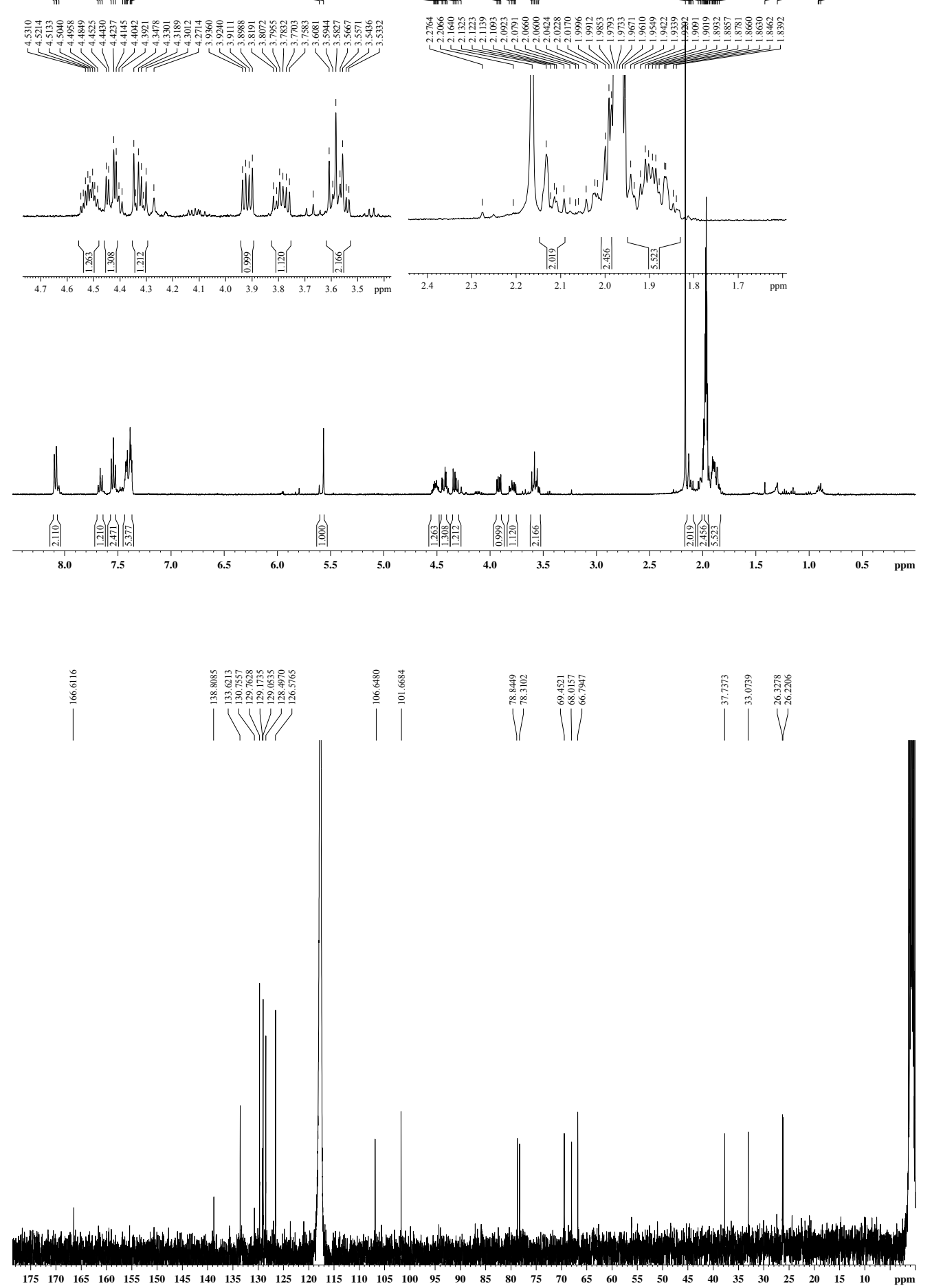


\section{Spiroketalization experiments in the presence of inorganic salts}

The purpose of these experiments was to probe the effect of mild Lewis acids on the reaction outcome. Lewis acids alone failed to promote the reaction (entries 1-3), and the effect of added Lewis acids on selectivity was minimal (entries 4-6).

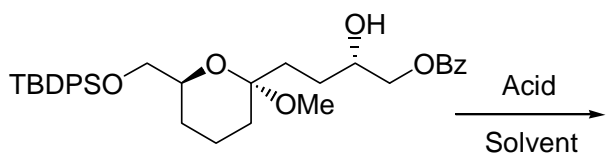

10

dr 2.5:1 (from ${ }^{1} \mathrm{H}-\mathrm{NMR}$ )
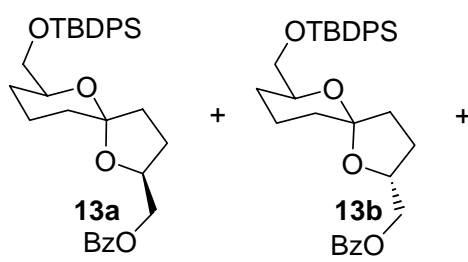

\begin{tabular}{cccccc}
\hline Entry & Catalyst & $\begin{array}{c}\text { Salt } \\
\mathbf{1 0 0 m o l} \%\end{array}$ & Solvent & Time & 13a/13b/13c \\
\hline 1 & & $\mathrm{MgCl} \cdot 6 \mathrm{H}_{2} \mathrm{O}$ & $\mathrm{THF} / \mathrm{H}_{2} \mathrm{O} 4 / 1$ & $24 \mathrm{~h}$ & Only SM \\
\hline 2 & & $\mathrm{LiCl}$ & $\mathrm{THF} / \mathrm{H}_{2} \mathrm{O} 4 / 1$ & $24 \mathrm{~h}$ & $\mathrm{Only} \mathrm{SM}$ \\
\hline 3 & & $\mathrm{MgBr} \cdot 6 \mathrm{H}_{2} \mathrm{O}$ & $\mathrm{THF} / \mathrm{H}_{2} \mathrm{O} 4 / 1$ & $24 \mathrm{~h}$ & $\mathrm{Only} \mathrm{SM}$ \\
\hline 4 & $\mathrm{Cl}_{3} \mathrm{CCOOH} 60 \mathrm{~mol} \%$ & $\mathrm{MgCl} \cdot 6 \mathrm{H}_{2} \mathrm{O}$ & $\mathrm{THF} / \mathrm{H}_{2} \mathrm{O} 4 / 1$ & $3 \mathrm{~h}$ & $45 \% / 19 \% / 42 \%$ \\
\hline 5 & $\mathrm{Cl}_{3} \mathrm{CCOOH} 60 \mathrm{~mol} \%$ & $\mathrm{LiCl}$ & $\mathrm{THF} / \mathrm{H}_{2} \mathrm{O} 4 / 1$ & $2,5 \mathrm{~h}$ & $30 \% / 21 \% / 47 \%$ \\
\hline 6 & $\mathrm{Cl}_{3} \mathrm{CCOOH} 60 \mathrm{~mol} \%$ & $\mathrm{MgBr} \cdot 6 \mathrm{H}_{2} \mathrm{O}$ & $\mathrm{THF} / \mathrm{H}_{2} \mathrm{O} 4 / 1$ & $3 \mathrm{~h}$ & $31 \% / 20 \% / 48 \%$ \\
\hline
\end{tabular}

\section{References}

1. Prepared according to the method of Forsyth and co-workers, starting from $(R)-(+)$-glycidol of 98\% ee: Dounay, A. B.; Urbanek, R. A.; Frydrychowski, V. A.; Forsyth, C. J. J. Org. Chem. 2001, 66, 925-938. See also: b) Anelli, P. L.; Banfi, S.; Montanari, F.; Quici, S. J. Org. Chem. 1989, 54, 2970-2972.

2. This procedure is adapted from: Rissa, T. Diploma thesis 2001, Helsinki University of Technology

3. Racherla, U. S.; Brown, H. C. J. Org. Chem. 1991, 56, 401-404

4. Rhee, J. U.; Bliss, B. I.; RajanBabu, T. V. J. Am. Chem. Soc. 2003, 125, 1492-1493. 